\title{
Radicals and Carbohydrates
}

\author{
Ine's Pe'rez-Mart'in and Ernesto Sua'rez
}

Instituto de Productos Naturales y Agrobiolog '́a del C.S.I.C., La Laguna, Tenerife, Spain

\section{INTRODUCTION}

Radical reactions in carbohydrate chemistry have been a matter of intense research activity dur- ing the last years. These synthetic and mechanis- tic studies have not only decisively contributed to a better understanding of radical reactions but have also played a major role in the transference of these methodologies to the synthetic chemistry community. Of particular note is the contribu- tion of carbohydrate chemistry in evaluating the importance of steric, stereoelectronic, and conformational effects on the reactivity and stereoselectivity of radical reactions. One important aspect of free-radical chemistry at the anomeric center is the predictable stereoselectivity of hexopyranosyl radicals, which makes them valuable intermediates for the stereoselective synthesis of $C$-glycosides and $C$ disqigeharigpslication of radical methods in carbohydrate chemistry has been thoroughly reviewed covering the literature up to $1999 .{ }^{1}$ Since then, a number of reviews, dealing with specific areas, have been published. ${ }^{2-7}$ Although some earlier work is mentioned, this article reviews progress in the area with special attention to new developments published during the past decade. Because of the great number of publications in this field, an exhaustive review of the literature is not possible. However, an attempt has been made to highlight the most synthetically valu- able processes. The major focus is on inter- and intramolecular carbon-carbon bond-forming radical reactions, with emphasis placed on the preparation of $C$-glycosides, $C$-ketosides, $C$-disaccharides, and branched-chain sugars, as well as on the synthe- sis of polyfunctionalized carbocycles by radical cyclization of acyclic carbohydrate derivatives. The next two sections describe methods for the formation of carbon-hydrogen bonds and synthesis in which a heteroatom-centered radical plays a clear role in the carbon-heteroatom bond forma- tion. Finally, a few selected examples of alkoxyl radical $\beta$-fragmentation reactions, carried out under oxidative or reductive conditions, are included to illustrate their potential in the synthesis of chiral synthons.

\section{INTERMOLECULAR CARBON-CARBON BOND-FORMING PROCESSES}

Free-radical chemistry at the anomeric center has attracted a great deal of attention owing to the unusual diastereoselectivity (see Stereoselective Radical Reactions) of glycopyranos$1-y l$ radical reactions. These radicals react with electrophilic acceptors to give axial-substituted adducts preferentially, in contrast to cyclohexyl radicals which react principally in the equatorial mode., ${ }^{8,9}$ The reactivity strongly depends on two main stereoelectronic stabilizing effects: the anomeric effect (interaction between the singly occupied molec- ular $\mathrm{p}$ orbital (SOMO) and the adjacent high- est occupied molecular orbital (HOMO) of the pyran oxygen lone pair) and the $\beta$-oxygen effect 


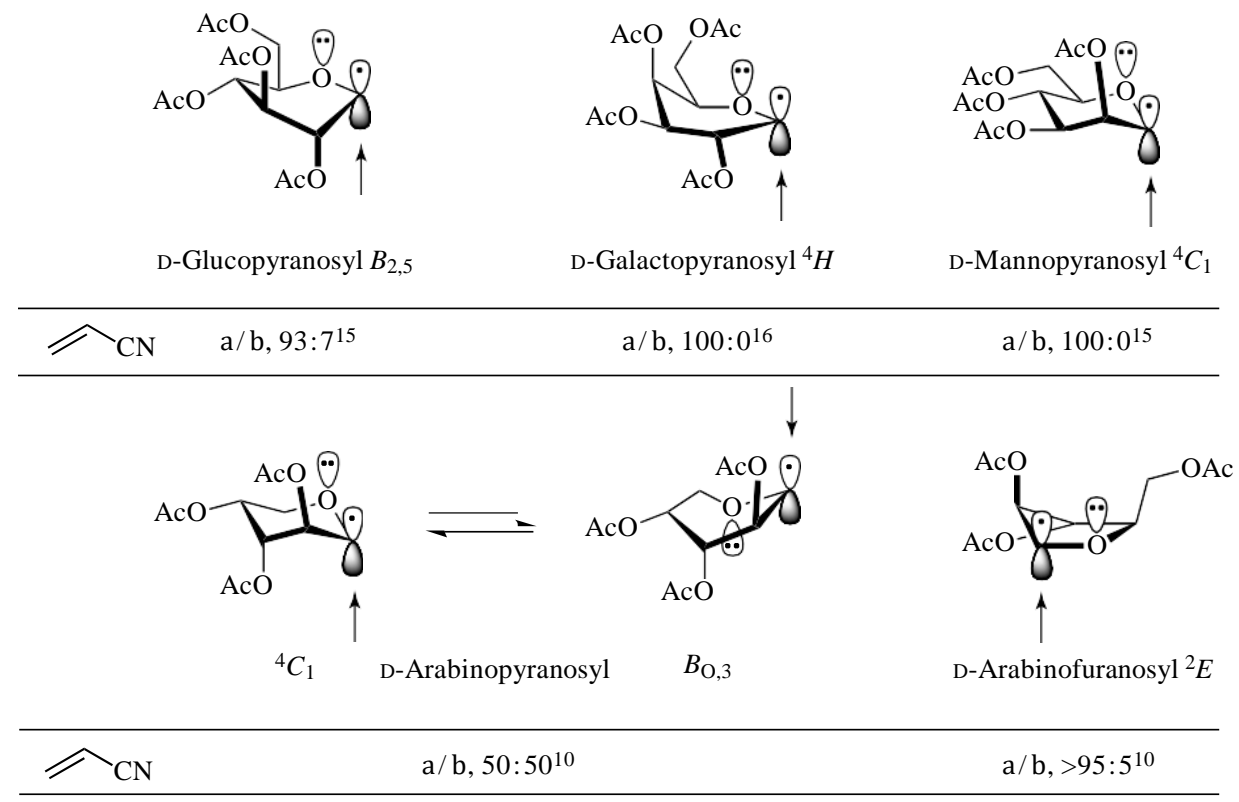

Figure 1 Stereoelectronic effects and conformation of glycos-1-yl radicals. The preferred addition to acrylonitrile is shown by arrows.

(interaction between the SOMO and the $\sigma{ }^{*}$-lowest unoccupied molecular orbital (LUMO) of the coplanar $\beta$-C-OR bond). ${ }^{10} \mathrm{~A}$ combination of both effects, the so-called quasi-homo-anomeric effect, has been used by Giese to explain the stereose- lectivity of a variety of carbohydrate radical reac- tions (Figure 1). ${ }^{11-13}$ This quasi-homo-anomeric effect may also induce conformational changes in the glycopyranos1-yl radical with respect to the original carbohydrate in order to maximize orbital interactions. For instance, the electron para- magnetic resonance (EPR) (see Analysis of Rad- icals by EPR) data for d-glucopyranosyl and d-galactopyranosyl radicals have been interpreted by Giese in terms of a slightly twisted $B_{2,5}$ boat and a ${ }^{4} H$ half-chair conformations, respectively, instead of the original ${ }^{4} C_{1}$ shape of $d$ glucose and d-galactose. ${ }^{14}$ In contrast, the dmannopyranosyl radical remains in the ${ }^{4} C_{1}$ chair conformation of the d-mannose. As the configuration at C-2-C-4 in xylose and lyxose is identical to those of glucose and mannose, respectively, similar conformations for dxylopyranosyl $\left(B_{2,5}\right)$ and d-lyxopyranosyl $\left({ }^{1} C_{4}\right)$ radicals were observed by EPR. ${ }^{12}$ The much more flexible d-arabinopyranosyl radical exists an equilibrium between the $B_{0,3}$ conformation, and their reactions with alkenes are unselective. However, d-arabinofuranosyl radicals adopt a ${ }^{2} E$ conformation and react with high diastereoselectivity. The diastereoselective ratios and preferential acrylonitrile attack on the anomeric radicals maintaining the stabilizing interaction with the lone pair of the ring oxygen are shown in Figure $1.15,16$

\subsection{Synthesis of $C$-Glycosides}

Since its introduction by Keck and Yates ${ }^{17}$ in 1982 , allyltributylstannane has frequently been used for the synthesis of $C$-glycosyl compounds. The radical chain reaction (see The History of Free Radical Chemistry) is initiated by thermolysis of azobisisobutyronitrile (AIBN) or irradiation, and the mechanism is depicted in Figure 2. The glycosyl radical $\mathbf{I}$ is generated from the precursor by $\mathrm{X}$ (halide, xanthate, thioether, or selenide) abstraction of the stannyl radical. The formed adduct radical II undergoes a rapid $\beta$-fragmentation of the $\mathrm{C}-\mathrm{Sn}$ bond to give the allylated compound and the chain propagation tin radical $\mathbf{I I I} .^{18}$

The reaction has been applied to pyranose, ${ }^{19-22}$ furanose 1,19,23 and $N$-acetylneuraminic acid $\mathbf{2}$ derivatives $^{24-26}$ (Scheme 1). As a consequence 


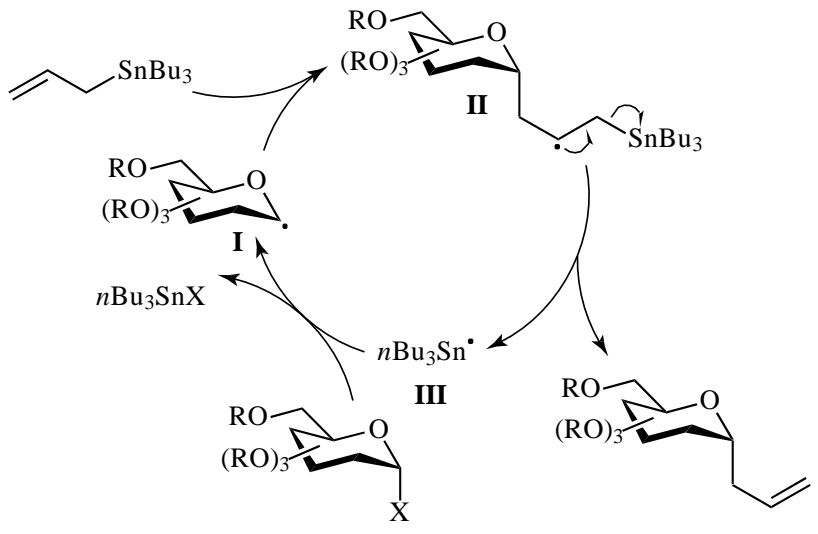

Figure 2 Radical chain reaction mechanism of Keck allylation. X: halide, xanthate, thioether, or selenide.

of the $a$-axial quenching of d-glycopyranos-1-yl radicals, ${ }^{10,14} \quad 3-C$-(a-d-glycopyranosyl)-1-propene derivatives are formed predominantly. Notwithstanding, the presence of a bulky substituent at C-2 $\left(N\right.$-phthalimido, ${ }^{21} N$-tetrachlorophthalimido $\quad \mathbf{3}^{22}$ ) reverses the stereochemical outcome to form $\beta-C$ glycosides 4. A novel approach to the synthesis of 3-C-( $\beta$-d-glycopyranosyl)-1-propene derivatives has been reported by Praly et al.${ }^{27}$ in a one-pot, two-step sequence involving allylation and reductive dehalogenation of 1-bromo- $\beta$-d-glycopyranosyl chloride 5 . The reaction may be effected even with electrophilic glycosyl radicals; a-d-arabino-hexopyranosyl-2-ulose bromide 6 reacts with methyl 2(tributylstannylmethyl)acrylate albeit in moderate yield. ${ }^{28}$ A study of the conformation-anomeric effect-stereoselectivity relationship in the anomeric radical reaction of pentopyranoses has been reported. Selectivity was increased by conformational restriction of the pentopyranose ring in ${ }^{4} C_{1}$-chair 7 and completely inverted by flipping the conformation from the ${ }^{4} C_{1}$ - into the ${ }^{1} C_{4}$-chair 8 , because of the kinetic anomeric effect. ${ }^{29}$ Allylthio compounds are also effective anomeric radicaltrapping agents for the synthesis of $C$-allyl glycosides. Thus, the ultraviolet (UV) irradiation of a-d-galactopyranosyl bromide with allylic sulfides and sulfones in the presence of hexabutylditin gave the corresponding 3-C-(a-d-galactopyranosyl)1-propene derivatives with excellent diastereoselectivity. 30

d-Gluco-1-yl radicals can also be generated by reaction of d-glucosyl iodide 9 with 1-ethylpiperidine hypophosphite (EPHP) (Scheme 2).
The anomeric radicals add efficiently to pentafluorophenyl acrylate as electron-deficient olefin to give $C$-glycoside $10 .{ }^{31} \mathrm{EPHP}$ is a mild alternative to tin reagents in radical chemistry. The chemoselective radical reduction of the iodine atom in a series of 1-deoxy-1-halo-1-iodo-alditols and the addition of the intermediate radicals to acryloni- trile has been described. ${ }^{32}$ One-carbon extended $C$ glycosylation to glycopyranosides $\mathbf{1 3}$ can be achieved by radical acylation of peracetylated gluco- and galacto-pyranosyl bromide $\mathbf{1 1}$ with phenylsulfonyl oxime ether $\mathbf{1 2}$ in the presence of hexamethyldiestannane under photochemically initiated conditions. ${ }^{33}$ The reaction may also be applicable to the preparation of $C$-branched sugars (see 71 in Scheme 8). In the addition of 1-fucos-1-yl radical to $a, \beta$-unsaturated ester $\mathbf{1 4}$, two 1,3 -distant stereocenters are created with high diastereoselectivity: the first one results from a totally selective $a-C$-glycosylation under stereoelectronic control and the second by a hydrogen-atom transfer (HAT) reaction which proceeded preferentially to the 2,3-syn isomer $\mathbf{1 5} .^{34}$ Some limitations associated with the use of glycosyl bromides of 2-amido sugar as radical precursors, which in some cases led only to the corresponding oxazoline, prompted Gallagher ${ }^{35,36}$ to examine alternative radical precursors in these compounds. The anomeric selenides derived from d-GlcNAc, dManNAc, and d-GalNAc 16 underwent smooth CSe homolysis and the resulting radicals were trapped with electron-deficient olefins to give $C$-glycosides 17. Since the pioneering work on the synthesis of showdomycin by Barton in 1990, ${ }^{37}$ 

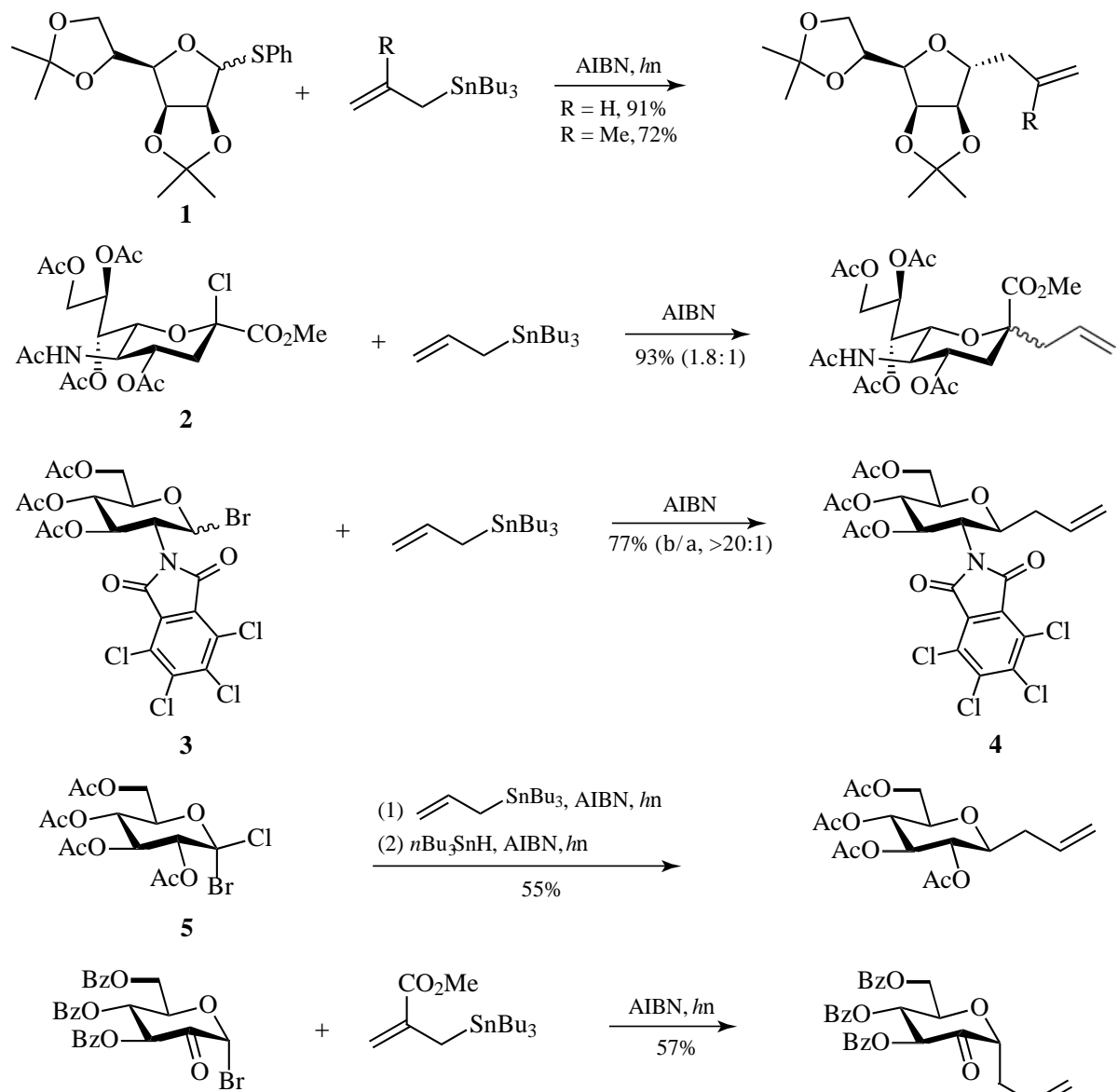

6
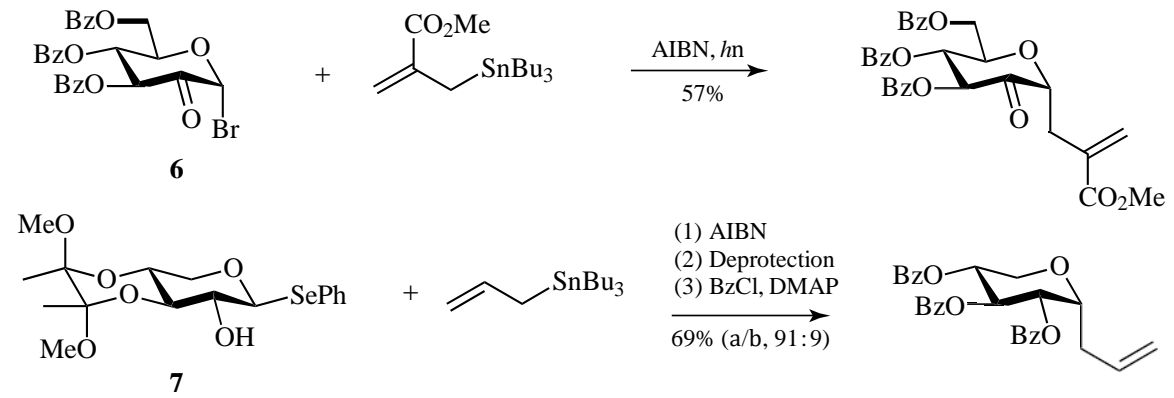

(1) AIBN
(2) Deprotection
(3) BzCl, DMAP
$\underset{69 \%(a / b, 91: 9)}{\longrightarrow}$
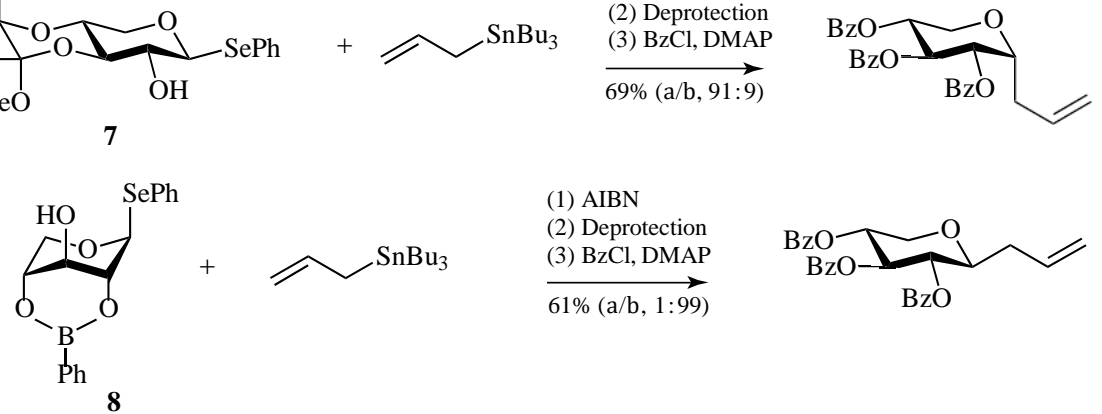

(1) AIBN
(2) Deprotection
(3) BzCl, DMAP
$\underset{61 \%(\mathrm{a} / \mathrm{b}, 1: 99)}{\longrightarrow}$

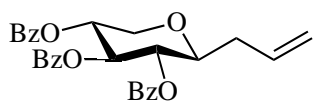

Scheme 1 Synthesis of $C$-allyl glycosides by intermolecular trapping of glycos-1-yl radicals with allylstannanes.

some attention has been paid to the preparation of glycosyl tellurides as a source of 1-glycosyl radicals. Yamago and Yoshida ${ }^{38}$ have shown that anomeric radicals generated photochemically or thermally from glycosyl tellurides such as $\mathbf{1 8}$ add to alkynes to give vinyl $C$-glycosides $\mathbf{1 9}$ in good yield as a mixture of anomers $(a / \beta$, $75: 25$ ) (see Halogen and Chalcogen Transfer Chemistry and $\mathbf{S b}, \mathbf{B i}, \mathbf{T e}$, and I-Transfer Polymerization and Applications). Interestingly, under 

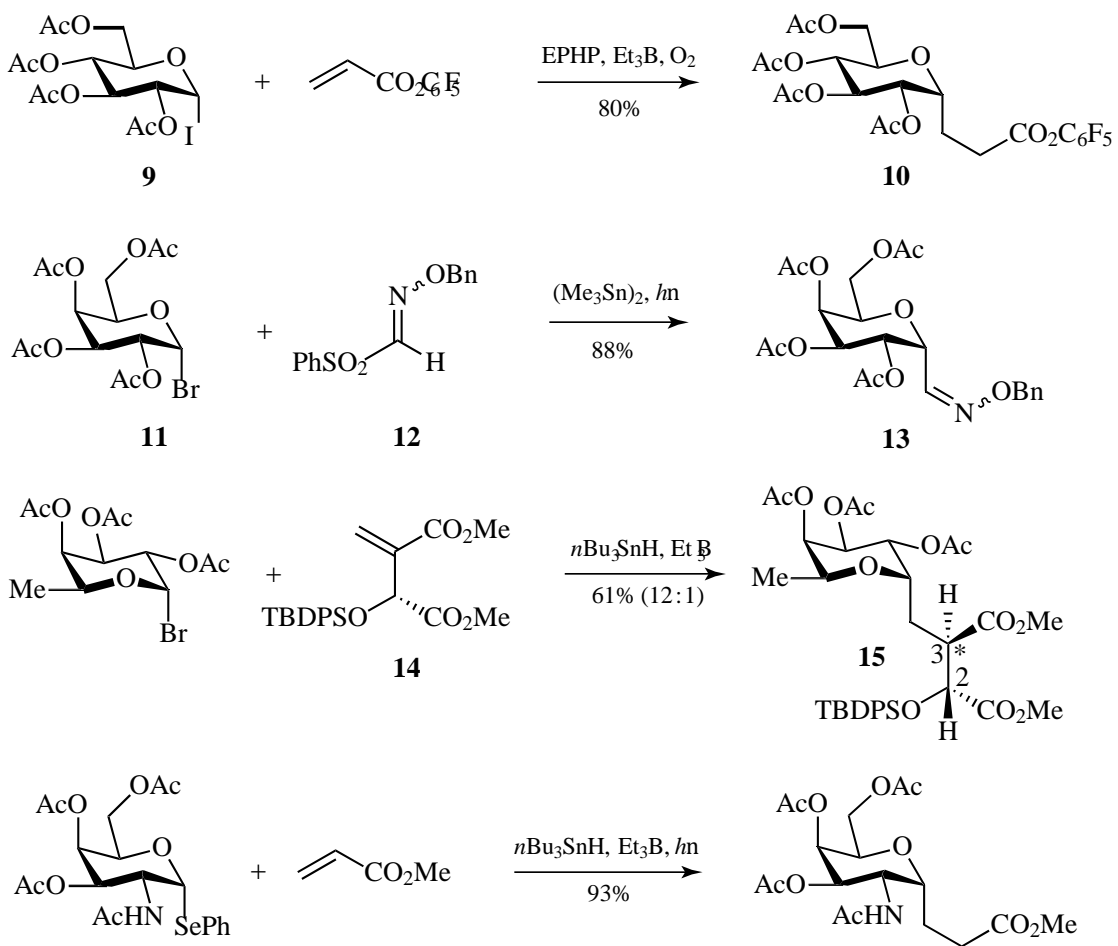

16

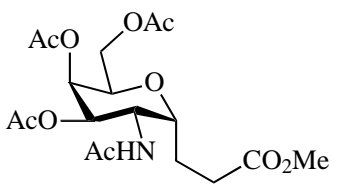

17

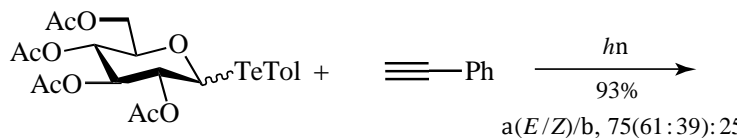

18
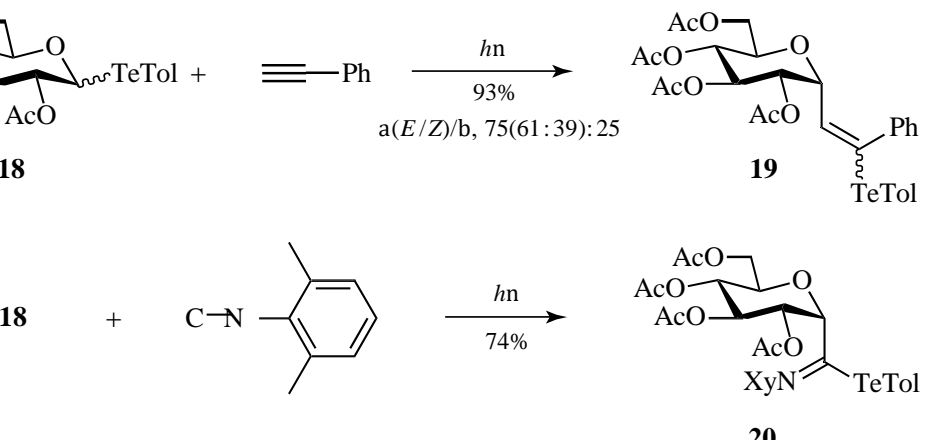

Scheme 2 Synthesis of $C$-glycosides by intermolecular addition of glycos-1-yl radicals to unsaturated compounds. EPHP, 1 ethylpiperidine hypophosphite.

these conditions the reactivity of electron-deficient and electron-rich alkynes is similar, which is surprising given that glycos-1-yl radicals behave as nucleophilic species. This Japanese group also studied the imidoylation of these organotellurium compounds with isonitriles; the reaction of $\mathbf{1 8}$ with 2,6-xylylisonitrile under photochemical con- ditions afforded imine $\mathbf{2 0}$ in good yield and high a-selectivity. ${ }^{39}$ The known steric influence of the C-2 substituent has also been observed in this imidoylation reaction; a bulky $N$-phthalimido group at this position reverses the stereochemical outcome to form $\beta$ - $C$-glycosides exclusively. The reaction of pentopyranosyl and hexopyranosyl tellurides with electron-deficient heteroaromatic bases has been studied by Togo and Yokoyama and $C$-nucleoside analogs have been synthesized in moderate yields. ${ }^{40}$ 

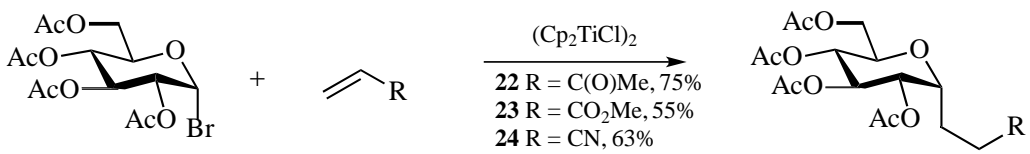

21 $\mathrm{R}=\mathrm{CN}, 63 \%$
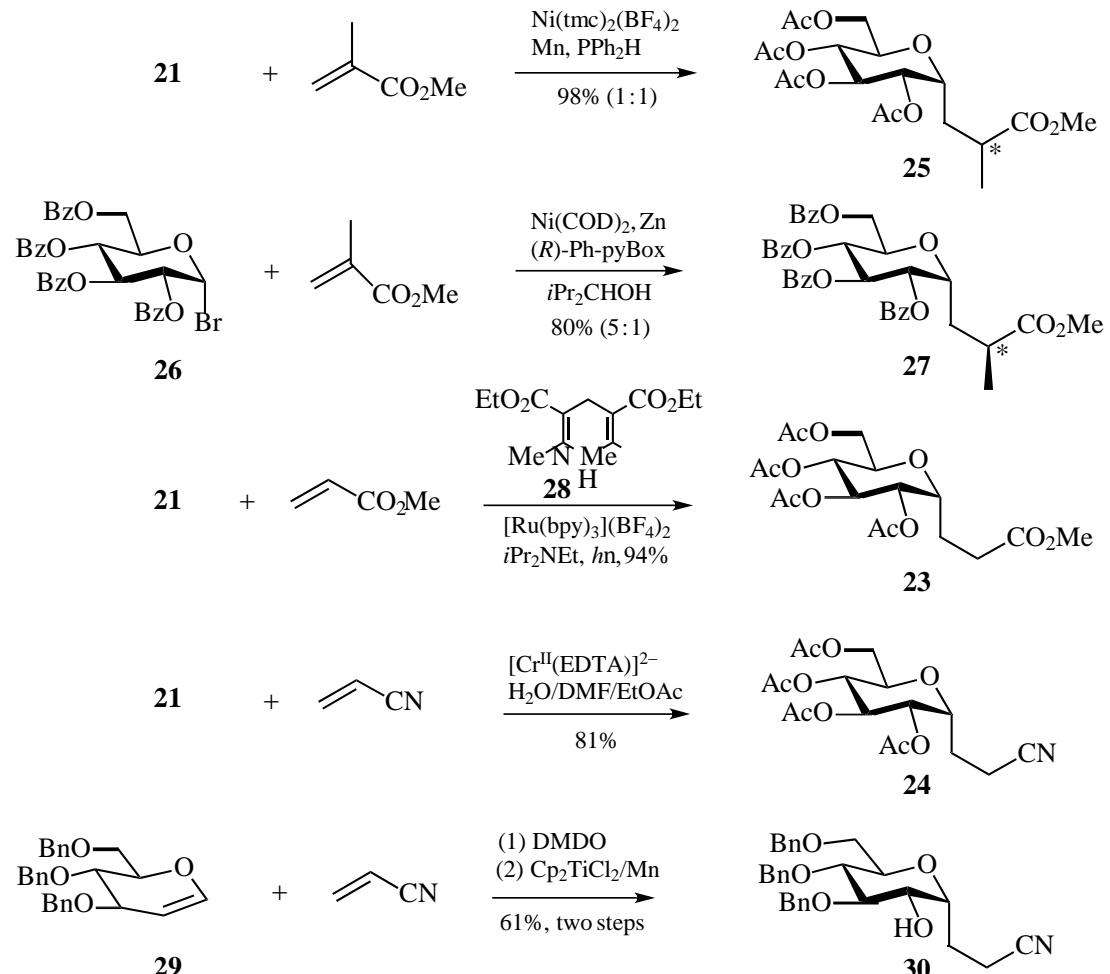

Scheme 3 Synthesis of $C$-glycosides by intermolecular trapping of glycos-1-yl radicals with unsaturated compounds using trasition-metal

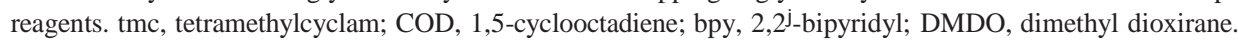

Several coordination complexes and salts of the transition metals such as Ti(III) (see Epox- ides in Titanocene-Mediated and -Catalyzed Radical Reactions), $\mathrm{Ni}(\mathrm{II}), \mathrm{Ru}(\mathrm{II}), \mathrm{Cr}(\mathrm{II})$, and $\mathrm{Sm}(\mathrm{III})$ (see Organic Synthesis Using Samarium Diiodide) have been used in the formation of anomeric radicals from glycosyl halides, and some examples are outlined in Scheme 3. Spencer and Schwartz have demonstrated that titanocene(III) chloride, a mild, nontoxic, and relatively inex- pensive reducing reagent, is effective in the the diastereoselective conversion of glucosyl bromide 21 into $C$-glycosides. ${ }^{41,42}$ The anomeric radical rather than an intermediate organotitanium species seems to be involved. In case of hexopyranosyl halides, when methyl vinyl ketone, methyl acrylate, and acrylonitrile are used as radical traps, exclusive a-selectivity has been observed in the addi- tion products 22-24. 1-Gluco-, 1-manno-, and 1galacto-pyranosyl radicals can also be generated from the corresponding bromides using nickel(II) salts as catalysts. For example, the reaction of glucosyl bromide 21 with $\mathrm{Ni}$ (tetramethylcyclam $)_{2}\left(\mathrm{BF}_{4}\right)_{2}$ (20 $\mathrm{mol} \%)$ and an excess of manganese dust with methyl methacrylate as an electron-deficient radical acceptor gave $a-C$-glycoside $\mathbf{2 5}$ in excellent yield. ${ }^{43}$ Gagne' have reported another stereose- lective method for the Ni-catalyzed synthesis of $a-C$ alkylglycosides. ${ }^{44,45}$ The reaction of benzoyl glucosyl bromide 26 with methyl methacrylate using catalytic $\mathrm{Ni}(\mathrm{COD})_{2}$ complex as precursor, $(R)-\mathrm{Ph}$-pyBox as ligand, $\mathrm{Zn}$ dust as terminal 

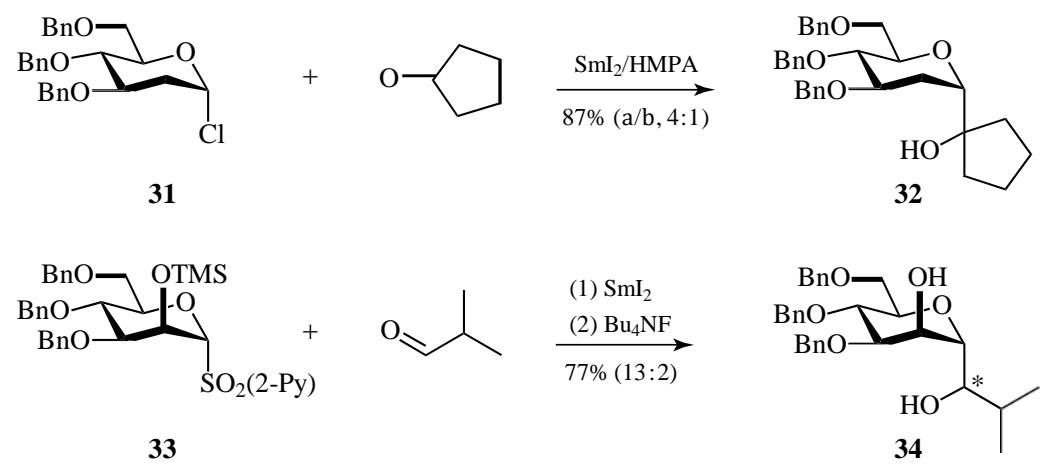

33
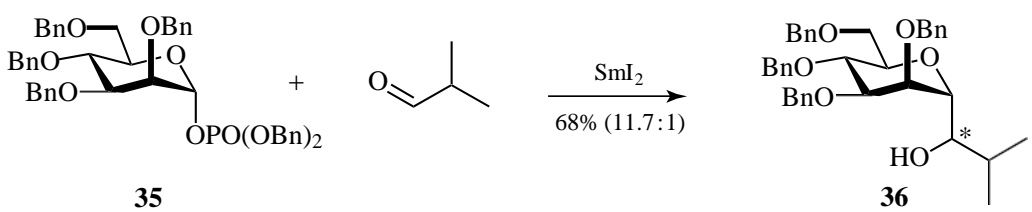

35

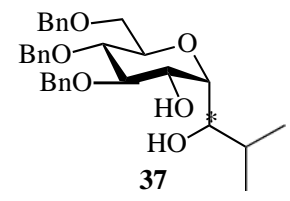

29

Scheme 4 Synthesis of $C$-glycosides via glycos-1-yl samarium intermediates.

reductant, and $i \mathrm{Pr}_{2} \mathrm{CHOH}$ as proton source afforded a-C-glycoside $\mathbf{2 7}$ in high yield and diastereoselectivity. The same authors recently reported that irradiation of glucosyl bromide $\mathbf{2 1}$ with visible light in the presence of an excess of Hantzsch ester $\mathbf{2 8}$ and catalytic amounts of $\mathrm{Ru}(\mathrm{bpy})_{3}\left(\mathrm{BF}_{4}\right)_{2}$ generated glucopyranos-1-yl radicals that reacted intermolecularly with electron-deficient olefins to

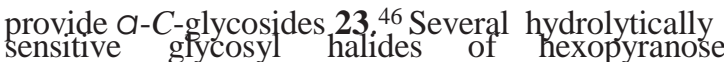
and pentopyranose series of carbohydrates have been transformed into $C$-glycosides with $\left[\mathrm{Cr}^{\mathrm{II}}(\mathrm{EDTA})\right]^{2-}$ and electron-deficient alkenes under mild aqueous reaction conditions. For example, the two-phase reaction of an aqueous solution of the chromium complex and the glucosyl bromide 21 and acrylonitrile in ethyl acetate afforded the d-glycero-1-gulo-nonononitrile derivative 24. ${ }^{47}$ The anomeric radical produced by the reductive ring-opening of 1,2-anhydro sugars with titanocene(III) chloride can be trapped with electrophilic olefins to give exclusively $a-C$-glycosides such as 30, with the free hydroxyl group at C-2 available for further elaboration. ${ }^{48}$ The reaction proceeded in two steps from the corresponding glycal 29 by preliminary epoxidation with dimethyl dioxirane (DMDO).

Sinay in 1993 reported that reductive samariation of 2-deoxy-a-d-arabino-hexopyranosyl chloride $\mathbf{3 1}$ by the $\mathrm{SmI}_{2} /$ hexamethylphosphoramide (HMPA) system in the presence of cyclopentanone provided the corresponding $a$ - $C$-glucoside $\mathbf{3 2}$ in high yield (Scheme 4). ${ }^{49}$ They also found that under these conditions a-d-glucopyranosyl phenyl sulfones and bromides gave mainly 1,2-elimination products. In the absence of carbonyl compounds 1,2-elimination occurs exclusively and glucals are formed in synthetically useful yields. ${ }^{50}$ Subsequently, Beau and Skrydstrup have thoroughly studied the samarium diiodide reduction of glycosyl pyridyl sulfones with aldehydes or ketones for the stereospecific formation of 1,2-trans-C-glycosides. ${ }^{51,52}$ Mannosylpyridyl sulfones such as $\mathbf{3 3}$ gave $a-C$-glycosides 34 in good yield, while glucosyl and galacto- syl pyridyl sulfones gave $\beta$ - $C$-glycosides only in moderate to low yields. In this last case, the major by-product was the corresponding glucal and the reaction needed to be catalyzed with $\mathrm{NiI}_{2}$ to prevent the 1,2-elimination drawback. ${ }^{53}$ Similarly, Hung and Wong ${ }^{54}$ used samariation of 
mannosyl phosphate $\mathbf{3 5}$ with simple aldehydes to give $a$ - $C$-mannoside 36 . The two-step/one-pot DMDO oxidation- $-\mathrm{SmI}_{2} / \mathrm{NiI}_{2}$ intermolecular reductive coupling sequence of glycals, such as $\mathbf{2 9}$, with carbonyl compounds developed by Chiara and Sesmilo ${ }^{55}$ provides a new methodology for the synthesis of 2-hydroxy $C$-glycosides 37 . The stereoselectivity, which can be significantly modified by the addition of a proton source, was also very sensitive to steric effects. With aldehydes, $a-C$ glycosides were predominantly or exclusively obtained, whereas ketones gave the corresponding $\beta$-isomers as major products.

Motherwell ${ }^{56}$ has prepared difluoromethylenelinked $C$-glycosides and $C$-disaccharides by addition of electrophilic and nucleophilic radicals to gem-difluoro-exo-glycals. The reaction of gulofuranose derivative 38 with 6-deoxy-6- iodoglucopyranose 39, under the tin hydride system, to give $\quad g e m$-difluoro- $C$-disaccharide $\mathbf{4 0}$ is representative of the addition to nucleophilic radicals (Scheme 5). The use of electrophilic radicals gave somewhat better results; thus the reaction of $\mathbf{3 8}$ with ethyl bromoacetate afforded $a-C$-glycoside $\mathbf{4 1}$ in $51 \%$ yield. As an interesting extension of this approach, the authors have reported the addition and concomitant 5-exo-trig ring closure of allyl iodomalonate $\mathbf{4 2}$ to exo-glycal $\mathbf{3 8}$ to afford the 1oxaspiro[4.4]nonane bicycle derivative $\mathbf{4 3}$ in a onepot, two-step sequence. Two new routes to $\mathrm{a}-\mathrm{CF}_{2}-$ glycosides by the addition of difluoromethyl radicals to 2-O -alkoxy glycals have been described.<smiles>CC1(C)OCC([C@H]2COC(C)(C)C(=C(F)F)O2)O1</smiles>

38

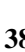

8

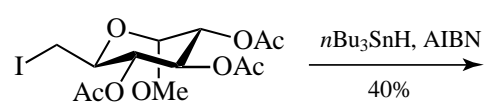

39

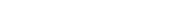<smiles>CCOC(=O)CBr</smiles>

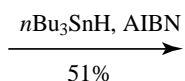<smiles>CC1COC(C)(C)O1</smiles><smiles>CCOC(=O)CC(F)(F)[C@H]1OC[C@H]2OC(C)(C)O[C@@H]12</smiles>

(1) $\left(\mathrm{Bu}_{3} \mathrm{Sn}\right)_{2}, h \mathrm{n}$

38<smiles>C=CCC(I)(C(=O)OCC)C(=O)OCC</smiles>

42

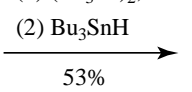<smiles>CC1COC(C)(C)O1</smiles><smiles>CCOC(=O)C1(C(=O)OCC)C[C@@H](C)[C@]2(OC[C@H]3OC(C)(C)O[C@H]32)C1(F)F</smiles>

43

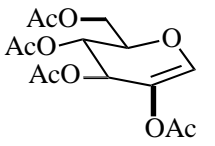<smiles>FC(F)(Cl)Br</smiles>

$\underset{73 \%(\mathrm{a} / \mathrm{b}, 14: 1)}{\stackrel{\mathrm{Na}_{2} \mathrm{~S}_{2} \mathrm{O}_{4}, \mathrm{NaHCO}_{3}}{\longrightarrow}}$

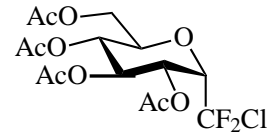

44
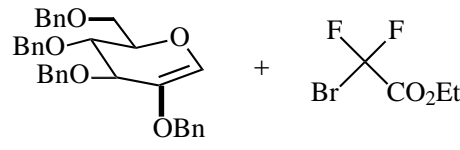

45

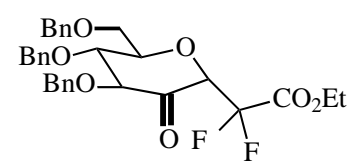

46

Scheme 5 Synthesis of $C$-glycosides by intermolecular addition of alkyl radicals to unsaturated carbohydrate acceptors. 
Miethchen $^{57}$ prepared 1,1-difluoroheptitol 45 by reaction of 2-O -acetyl-1,5-anhydrohex-1-enitol 44 with bromochlorodifluoromethane in the presence of sodium dithionite, which acts as radical initiator but also as reducing agent. In the other approach, the triethylborane-mediated reaction of ethyl bromodifluoroacetate with 2- $O$-benzyl glycals to give 2,2-difluoro-4-ulosonic ester $\mathbf{4 6}$ has been developed by Leclerc. ${ }^{58}$

\subsection{Synthesis of C-Disaccharides}

Since Giese and Witzel published their semi- nal work in $1986,{ }^{59}$ radical chemistry has been transformed into a useful alternative for the synthesis of $C$-disaccharides, which are important nonhydrolizable $O$-disaccharide mimetics with potential activity as enzymatic inhibitors. The utility of Giese $C$-glycosylation is exemplified by the synthesis of the analog of kojibiose

a-d-Glcp-(1 $\rightarrow$ 2a)-2a-carba-a-d-Glcp 48 by reaction of the a-methylene lactone 47 with glucosyl bromide $\mathbf{2 1}$ (Scheme 6). The intermolecular radical addition occurs in $70 \%$ yield with high diastereoselectivity. ${ }^{60}$ Vogel has used this tinbased methodology to add a number of glycosyl halides to enone 50, a versatile chiral synthon prepared from a "naked sugar".61 The radical addition products were subsequently and conveniently transformed into $C$-disaccharides by a multistep sequence. For example, the reaction with mannosyl bromide 49 afforded $a$-d-Man $p$ -

$(1 \rightarrow$ 3a)-3a-carba-d-Gal $p$ NAc 51, while a slight modification of the synthetic procedure permitted the C-2 isomer $a-d-M a n p-(1 \rightarrow 3 a)-3 a-c a r b a-d-$

Tal $p$ NAc to be prepared. Another example of the

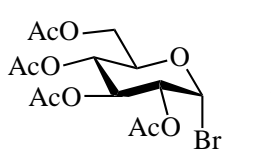

21

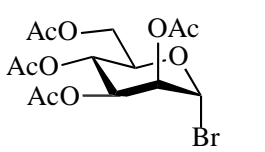

49

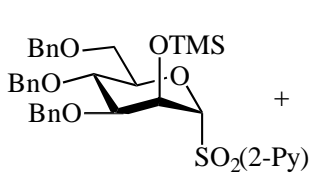

33

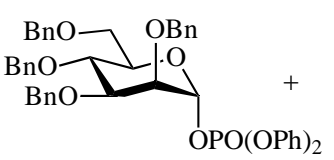

54

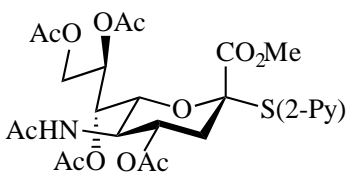

57<smiles>C=C1C(=O)O[C@H](CO[18O])[C@@H](O)[C@@H]1Br</smiles>

47

(1) $n \mathrm{Bu}_{3} \mathrm{SnH}, \mathrm{AIBN}, 70 \%$

(2) Two steps

(1) $\mathrm{Ph}_{3} \mathrm{SnH}$, AIBN, $56 \%$ (2) Eight steps

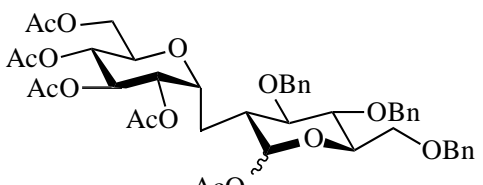

$48 \mathrm{AcO}$
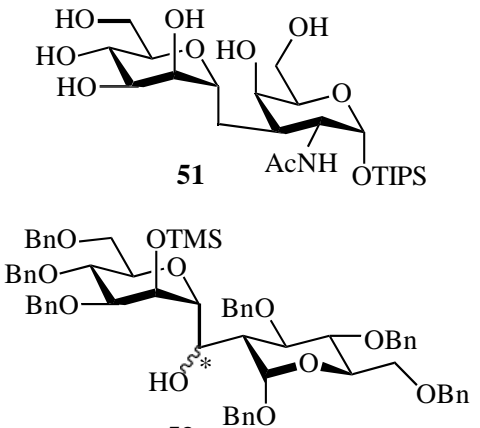

53
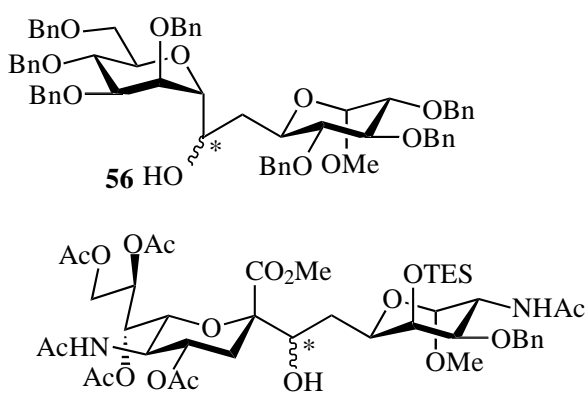

59

Scheme 6 Intermolecular synthesis of $C$-disaccharides. 
Table 1 Synthesis of $C$-disaccharides by intermolecular samariation.

\begin{tabular}{|c|c|c|c|}
\hline Entry & $C$-Disaccharide & Yield (\%) & Reference \\
\hline 1 & 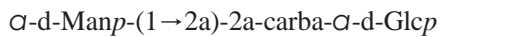 & 74 & 51,52 \\
\hline 2 & a-d-Man $p$ - $(1 \rightarrow 2 \mathrm{a})-2 \mathrm{a}-$ carba-a-d-Man $p$ & $73-85$ & 63 \\
\hline 3 & a-d-Manp-(1 $\rightarrow 3 \mathrm{a})-3 \mathrm{a}-\mathrm{carba-a-d-Man} p$ & $23^{a}$ & 64 \\
\hline 4 & a-d-Man $p-(1 \rightarrow 4 a)-4 a-c a r b a-a-d-M a n p$ & 55 & 65 \\
\hline 5 & a-d-Manp-(1 $\rightarrow 4 \mathrm{a})-4 \mathrm{a}-$ carba-a-d-Glc $p$ & 42 & 73 \\
\hline 6 & a-d-Glc $p$ NAc- $(1 \rightarrow 6 a)-6 a-c a r b a-a-d-G l c p$ & $60^{b}$ & 66 \\
\hline 7 & $\beta$-d-Glcp-(1 $\rightarrow$ 6a)-6a-carba-a-d-Man $p$ & $83^{c}$ & 53,67 \\
\hline 8 & $\beta$-d-Galp-(1 $\rightarrow$ 6a)-6a-carba-a-d-Man $p$ & $85^{c}$ & 53 \\
\hline 9 & a-d-Manp-(1 $\rightarrow$ 6a)-6a-carba-a-d-Man $p$ & $88^{c}$ & 53,64 \\
\hline 10 & $\beta$-1-Fucp-(1 $\rightarrow 6 a)-6 a-c a r b a-a-d-M a n p$ & $89^{c}$ & 53 \\
\hline 11 & $\begin{array}{l}\text { a-d-Manp-(1-3a)-3a-carba-[a-d-Manp- } \\
\quad(1 \rightarrow 6 a)-6 a-c a r b a]-a-d-M a n p\end{array}$ & $46^{a}$ & 64 \\
\hline 12 & a-d-Manp-(1 $\rightarrow$ 6a)-6a-carba-a-d-Glc $p$ & 73 & 54 \\
\hline 13 & a-Neup5Ac- $(2 \rightarrow 6 a)-6 a-c a r b a-a-d-G a l p$ & 82 & 68,69 \\
\hline 14 & a-Neup5Ac- $(2 \rightarrow 6 a)-6 a-c a r b a-a-d-M a n p$ & 80 & 68,69 \\
\hline 15 & $a-N e u p 5 A c-(2 \rightarrow 6 a)-6 a-c a r b a-a-d-G a l p N A c$ & 93 & 69,70 \\
\hline 16 & $a-N e u p 5 A c-(2 \rightarrow 3 a)-3 a-c a r b a-a-d-G a l p$ & 88 & 71 \\
\hline 17 & $a-K d o p-(2 \rightarrow 6 a)-6 a-c a r b a-a-d-G a l p$ & 77 & 72 \\
\hline
\end{tabular}

${ }^{a}$ Three-step overall yield, including the radical deoxygenation of the interglycosidic alcohol.

${ }^{b} \mathrm{dr} a / \beta, 4: 1$.

${ }^{c}$ A catalytic amount of $\mathrm{NiI}_{2}$ was added.

utility of unsaturated ketones as acceptors and the tin hydride method is the reaction of 2,6-anhydro- 1deoxy-1-iodo-d-glycero-d-gulo-heptitol with levoglucosenone to give $\beta$-d-Glc $p-(1 \rightarrow 4 \mathrm{a})-4 \mathrm{a}$-carba3-deoxy-d-Glc $p$ due to Witczak et al . ${ }^{62}$

Over the past several years, Beau and Skrydstrup ${ }^{51-53,63-70}$ have conducted a detailed study on the samarium diiodide reduction of glycosyl pyridyl sulfones with carbohydrate aldehydes under Barbier conditions which led to the intermolecular formation of $C$-disaccharides in a highly efficient and stereoselective manner. With regard to the samariation mechanism, the reduction of the glycosyl sulfone is believed to proceed through two consecutive one-electron processes. The resulting anomeric organosamarium species subsequently adds to the carbonyl compound. The reaction proceeds efficiently in the manno series to give 1,2-trans- $C$-disaccharides in high yield and excellent diastereoselectivity. In the gluco and especially in the galacto series, the presence of $\mathrm{NiI}_{2}$ as a catalyst is necessary; otherwise, significant amounts of 1,2-eliminated products (gly- cals) are obtained. ${ }^{53}$ As a representative example, the samariation of 2-pyridyl sulfone $\mathbf{3 3}$ in the presence of aldehyde $\mathbf{5 2}$ to give $C$-disaccharide 53 in good yield is shown in Scheme 6.51,52 The use of a glycosyl phosphate group 54 as an acceptor in the initial electron-transfer reaction and subsequent addition to aldehyde $\mathbf{5 5}$ to give the a-d-Manp-(1 $\rightarrow$ 6a)-6a-carba-a-d-Glcp derivative 56 has been proposed by Hung and Wong. ${ }^{54}$ $C$-Disaccharides with the four possible linkages $(1 \rightarrow 2 a),(1 \rightarrow 3 a),(1 \rightarrow 4 a)$, and $(1 \rightarrow 6 a)$ have been prepared using this methodology, and the structures and yields are summarized in Table 1 (Entries 1-12). Of special interest are the samariation of d-GlcpNAc which gave a $C$-disaccharide with an anomalous 1,2-cis disposition preferentially, attributable to strong complexation between the $N$ acetamido group and the samarium ion (Entry 6), the $\mathrm{Ni}(\mathrm{II})$-catalyzed reactions (Entries 7-10), and the synthesis of a $C$-trisaccharide in a single step from a 3,6-diformylmanno derivative (Entry 11). Since the first synthesis of an $a-C$-disaccharide of $N$ -acetylneuraminic acid by Linhardt in $1997,{ }^{71}$ a number of these compounds have been prepared, which are given in Table 1 (Entries 13-17). In a recent example, the 2-pyridyl sulfide of the Neup5Ac derivative $\mathbf{5 7}$ reacts with aldehyde $\mathbf{5 8}$ in a type of samarium-Reformatsky process to

give stereoselectively 59 (Scheme 6). ${ }^{69,70}$ The procedure worked equally well with anomeric pyridyl sulfones of 3-deoxy-d-manno-2-octulosonic acid as donor using 6-formylgalactopyranoside as acceptor to give the $a$ - $C$-disaccharide 
of KDO [a-Kdop-(2 $\rightarrow$ 6a)-6a-carba-a-d-Gal $p]$ (Entry 17). ${ }^{72}$

\subsection{Synthesis of $\boldsymbol{C}$-Ketosides}

$C$-Ketosides (bis- $C, C$-glycosides) are a class of carbohydrate analogs that have received increased attention of synthetic chemists owing to their relationship with $C$-glycosides of ulosonic acid and as versatile chiral synthons for a large range of natural complex molecular synthesis.

Since the first reports on the use of a reductive denitration of 1-nitro- $C$-glycosides $\mathbf{6 0}$ by Giese et al.$^{15,74}$ in 1985 , a few more examples have been found in the literature for the preparation of $C$ ketosides under radical intermolecular con- ditions, which are outlined in Scheme 7. The introduction of the required two tethers in a sin- gle step has been achieved by Praly ${ }^{75}$ by reac- tion of 1 -bromo- $\beta$-dglucopyranosyl chloride $\mathbf{5}$ with an excess of allyltributylstannane. The diallylcompound 61 was subsequently transformed into an anomeric spiro sugar (6-oxaspiro[4.5]dec-2-ene system) by way of ring-closing metathesis (RCM). $C$ Ketosides based on d-gluco, d-manno, and dgalacto series of $N$-acetyl-2-amino sugars 62 have been prepared by homolytic cleavage of the $\mathrm{C}-\mathrm{Se}$ bond and $a$-trapping the resulting anomeric radical with tert -butyl acrylate and under Keck ally- lation conditions with allyltributylstannane. Styrene, which is not an efficient trapping agent for anomeric nucleophilic radicals, was also used, although, as expected, the corresponding addition product was obtained in low yield (29\%). ${ }^{76}$ The reaction can also be extended to seleno- $C$-glycoside $\mathbf{6 3}$, the interesting carbohydrate-based $\delta$-amino acid derivative 64 being obtained as a single diastereomer. A diastereoselective synthesis of the starting compound 63 has been achieved using a radical azidoselenation of exo-glycals as the key step (see $\mathbf{1 9 3}$ in Scheme 26). ${ }^{77}$ The preparation of $C$-ketosides from $N$-acetylneuraminic acid and other ulosonic
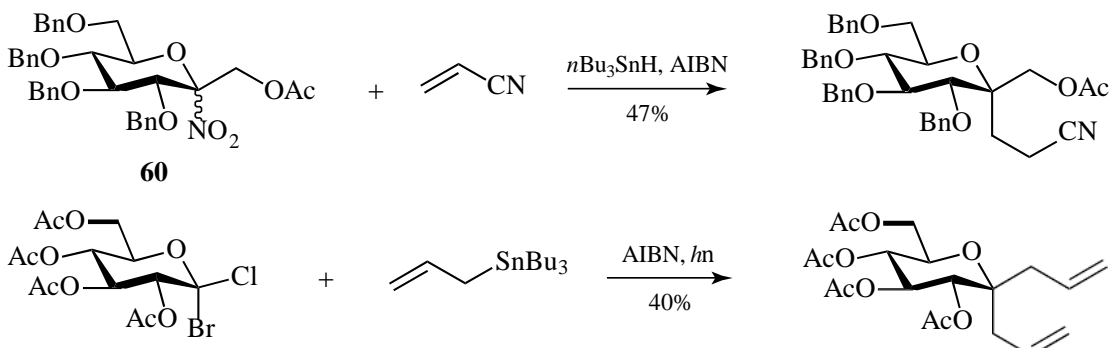

5
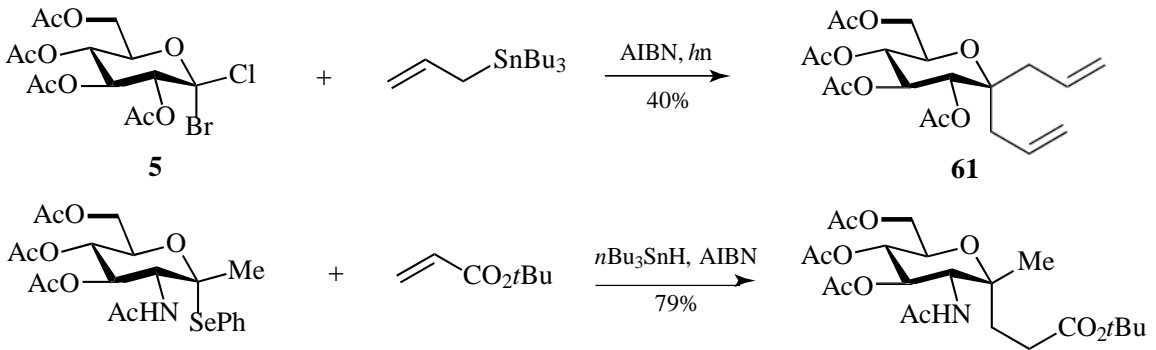

62

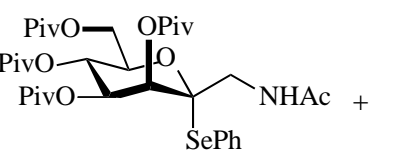

63

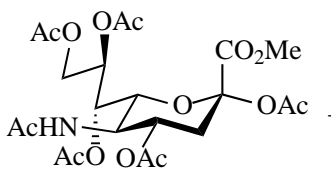

65

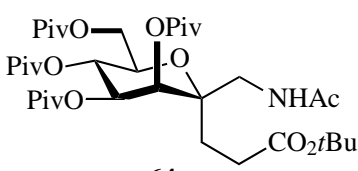

64

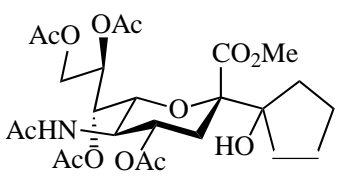

Scheme 7 Synthesis of $C$-ketosides by intermolecular addition of $C$-glycos-1-yl radicals to double bonds. 
acid derivatives has been extensively studied. A variety of anomeric substituents such as chloride, ${ }^{78}$ phenyl sulfone, ${ }^{79}$ 2-pyridyl sulfide, ${ }^{69,70}$ 2-pyridyl sulfone, ${ }^{71}$ and acetate $\mathbf{6 5}^{80}$ are useful precursors through reductive samariation in the presence of carbonyl compounds (see also 2 in Scheme 1).

\subsection{Synthesis of Branched-Chain Sugars}

Cerium(IV) ammonium nitrate (CAN) mediated radical addition of malonates (see Manganese(III) Acetate, CAN, and Fe(III) Salts in Oxidative Radical Chemistry) to glycals has been thoroughly investigated by Linker ${ }^{81}$ and constitute a general and convenient strategy for the synthesis of 2-C-malonyl carbohydrates. The reaction has been applicable to glycals of the hexose and pentose series and to disaccharide systems, and the corresponding 1,2-trans addition products were always obtained. For instance, acetyl glucal 66 with anhydrous CAN in methanol afforded a mixture of methyl $\beta$-d-glucoside 67 and $a$-d-mannoside 68 in excellent yield (Scheme 8). This work follows the pioneering $\mathrm{CAN}$-mediated radical azidonitration of glycals by Lemieux and Ratcliffe. ${ }^{82}$ The benzophenone-initiated photoaddition of methanol to endocyclic conjugated $a$-enones developed by Fraser-Reid ${ }^{83}$ provides a method for the preparation of $\mathrm{C}-2$ and $\mathrm{C}-4$ branched

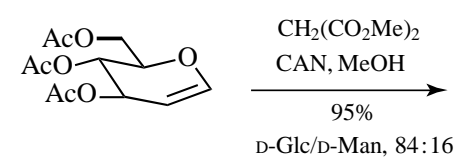

66

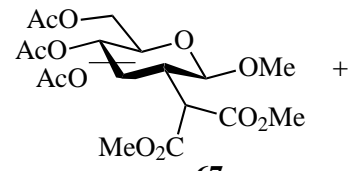

67

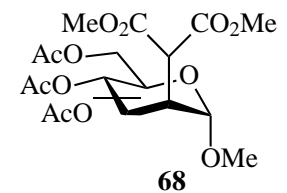

68

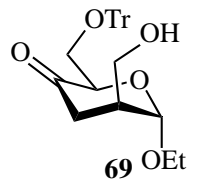

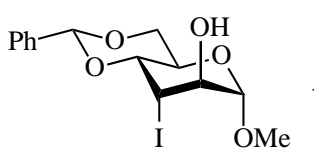

70<smiles>C=CC[SnH2]CCCCC(C)(C)C</smiles>

72

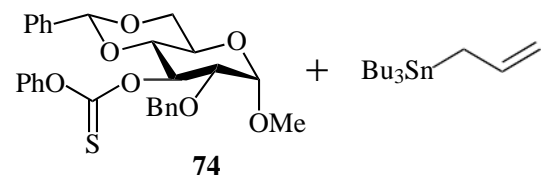

74<smiles>C=C[C@H]1OC[C@H](OC(C)(C)O)[C@@H]1OC</smiles>

76<smiles></smiles>
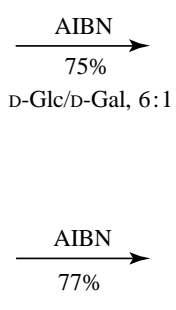

(1) DLP (15 mol\%), 93\% (2) DLP (1.4 equiv), $57 \%$

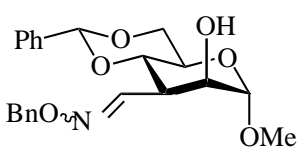

71

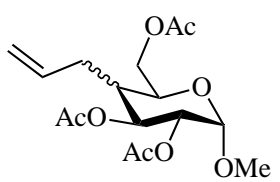

73

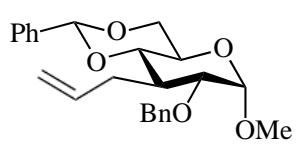

75

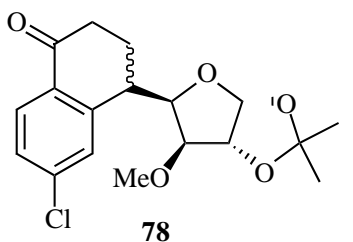

Scheme 8 Synthesis of branched-chain sugars. DLP, dilauroyl peroxide. 


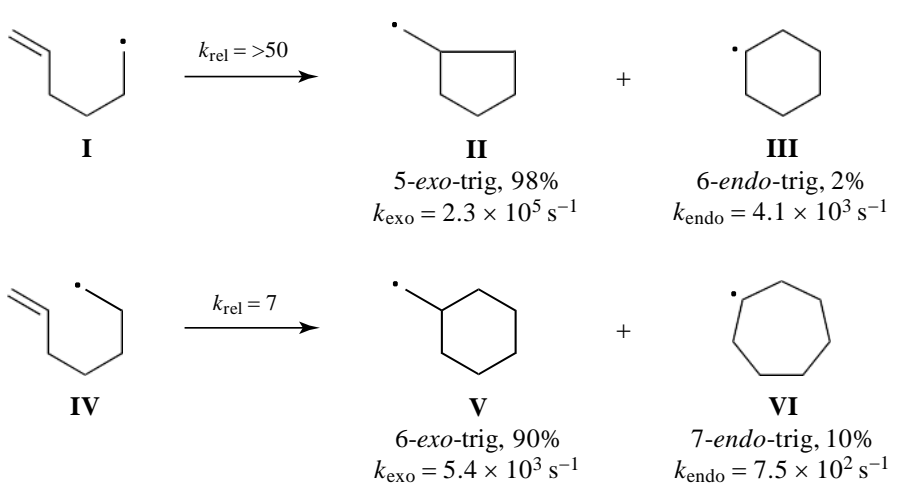

Figure 3 Ring-closure of 5-hexenyl and 6-heptenyl radicals. Rate constants taken from Ref. 89.

sugars such as 69. The analogous additions of isopropanol to carbohydrate $Y$-lactones have been reported by Mann and Weymouth-Wilson. ${ }^{84}$ The one-carbon extended $C$-glycosylation of $\mathrm{Kim},{ }^{33}$ already described in Scheme 2, has also been applied by the authors to C-2, C-3, and C-6 positions of the sugar skeleton. For instance, ultraviolet irradiation of 3-iodo-d-mannoside $\mathbf{7 0}$ in the presence of phenylsulfonyl oxime ether 12 provided C-3-branched-chain glycoside 71 with total inversion of configuration. Postema et al ., ${ }^{85}$ during the development of a general methodology for the synthesis of $\beta$ - $C$-disaccharides by RCM, prepared $\mathrm{C}-2, \mathrm{C}-3$, and $\mathrm{C}-4$ allyl branched-chain sugars. The reaction of iodine glycoside $\mathbf{7 2}$ with allyltributylstannane under Keck allylation conditions afforded a mixture of d-Glc/d-Gal 73 in a diastereomeric ratio, 6 : 1. Similarly, Castillo' $\mathrm{n}^{86}$ also used Keck conditions to prepare C-3 and C-4 allyl-substituted carbohydrates such as 3-allyl-d-glucoside $\mathbf{7 5}$ from the 3-O -xanthate 74. We have also included in this section the new strategy for the synthesis of naturally occurring $C$-arylglycosides that has been developed by Cordero-Vargas et al.$^{87}$ The xanthate-mediated radical addition-cyclization sequence (see Xanthates and Related Derivatives

as Radical Precursors) of xanthate $\mathbf{7 7}$ onto olefin 76 afforded tetralone 78, which was subsequently aromatized.

\section{INTRAMOLECULAR CARBON-CARBON BOND-FORMING PROCESSES}

The ability of free-radical chemistry to construct polyfunctionalized carbocyclic and heterocyclic frameworks by intramolecular cyclization of acyclic carbohydrates has received considerable attention among synthetic organic chemists. ${ }^{6}$ By far, the most frequently used radical cyclizations involve the formation of five- and six-membered rings. According to the Baldwin rules, 5-hexenyl I and 6heptenyl IV radicals cyclize predominantly through favored exo-trig processes to give the smaller rings II and V, respectively, the minor products III and VI being formed by endo-trig cyclizations (Figure 3). ${ }^{88}$ The 5-hexenyl I and 6-heptenyl IV cyclization reactions proceed under kinetic control to give the thermodynamically less stable primary radicals II and $\mathbf{V}$ much faster than the secondary radicals. Beckwith has explained this regioselectivity on the basis of steric and stereoelectronic effects, suggesting that a major factor is the strain engendered in the transition states (TSs). ${ }^{89,90}$ The regioselectivity changes if the 5-hexenyl radical cyclization is reversible and the reaction is run under thermodynamic conditions; six-membered rings are formed predominantly. ${ }^{91}$ Substitution at the double bond or the presence of a silicon group in the chain can also favor the formation of six-membered rings. ${ }^{18}$ Calculated TSs for the ring closures of $\omega$ alkenyl radicals have been extensively studied by different computational methods and are in excellent agreement with the stereo- and regioselectivity observed. ${ }^{92}$

\subsection{Synthesis of C-Glycosides}

$C$-Glycosides can be prepared by the addition of a glycos-1-yl radical donor onto an acceptor group suitably anchored to the sugar ring by 


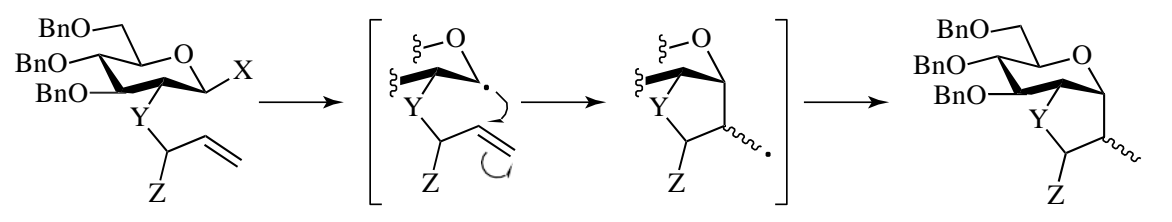

\begin{tabular}{clcc}
\hline Precursor & \multicolumn{1}{c}{ Conditions } & Product $($ yield $\%, R / S)$ & References \\
\hline $\mathrm{X}=\mathrm{SePh}, \mathrm{Y}=\mathrm{O}, \mathrm{Z}=\mathrm{H}$ & $n \mathrm{Bu}_{3} \mathrm{SnH}, \mathrm{AIBN}, \mathrm{PhH}$, reflux & $\mathbf{8 0}(95,1: 1.1)$ & 94 \\
$\mathrm{X}=\mathrm{OP}(\mathrm{O})(\mathrm{OPh})_{2}, \mathrm{Y}=\mathrm{O}, \mathrm{Z}=\mathrm{H}$ & $\mathrm{SmI}_{2}, \mathrm{THF}$ & $\mathbf{8 0}(63,1: 1)$ & 54 \\
$\mathrm{X}=\mathrm{SO}_{2} \mathrm{Ph}, \mathrm{Y}=\mathrm{O}, \mathrm{Z}=\mathrm{H}$ & $\mathrm{SmI}_{2} / \mathrm{HMPA}, \mathrm{THF}$ & $\mathbf{8 0}(78,1: 1)$ & 50 \\
$\mathrm{X}=\mathrm{SePh}, \mathrm{Y}=\mathrm{NH}, \mathrm{Z}=\mathrm{H}$ & $n \mathrm{Bu}_{3} \mathrm{SnH}, \mathrm{Et}{ }_{3} \mathrm{~B}, \mathrm{PhH}$ & $\mathbf{8 1}(76,1: 0)$ & 95 \\
$\mathbf{7 9}, \mathrm{X}=\mathrm{SePh}, \mathrm{Y}=\mathrm{O}, \mathrm{Z}=\mathrm{OMe}$ & $n \mathrm{Bu}_{3} \mathrm{SnH}, \mathrm{AIBN}, \mathrm{PhH}$, reflux & $\mathbf{8 2}(89,1: 1)$ & 96 \\
\hline
\end{tabular}

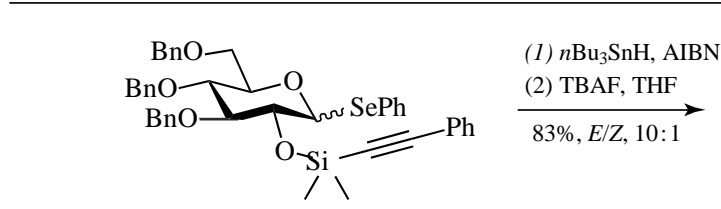

83
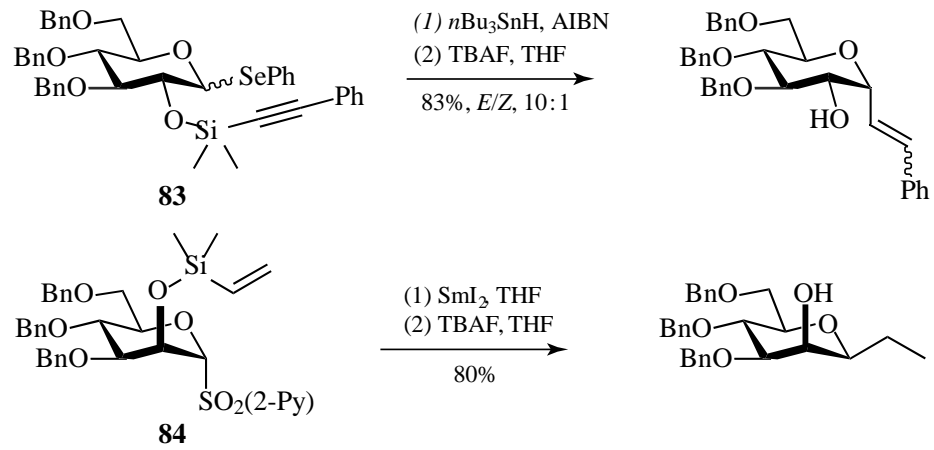

Scheme 9 Synthesis of $C$-glycosides by intramolecular addition of glycos-1-yl radicals to an unsaturated acceptor. TBAF, tetrabutylammonium fluoride.

carbon or heteroatom linkage. An early example of this methodology is the formation of bicyclic dideoxy sugars by intramolecular radical cyclization after Giese. ${ }^{93}$ De Mesmaeker et al.${ }^{94}$ Hung and Wong, ${ }^{54}$ Sinay",50 and Czernecki et al.${ }^{95}$ took advantage of this protocol for the synthesis of different cyclic $C$-glycosides 80-82 (Scheme 9). De Mesmaeker demonstrated, moreover, the usefulness of an easily removable acetal-linked group in $\mathbf{7 9}$ to obtain an acyclic 1,2-cis- $\mathrm{C}$-glycoside through the corresponding fused cyclic $a$-C-glycoside $\mathbf{8 2} .{ }^{96} \mathrm{~A}$ noteworthy extension of this strategy by Stork achieves this challenge by the cyclization of an acceptor group tethered to the sugar ring through a temporary silicon linkage, such as $\mathbf{8 3 .} .^{97}$ Subsequently, Skrydstrup and Beau demonstrated that the silicon-tether approach is also compatible with samarium diiodide reduction of mannosylpyridyl sulfone $\mathbf{8 4}$ to develop stereocontrolled radical cyclizations. $^{98}$

Sinay" transferred this temporary silicon linkage methodology to the synthesis of $\quad a_{-}{ }^{99-103}$ and $\beta$ - $C$-disaccharides ${ }^{104,105}$ based on eight or nine endo-trig radical cyclizations from two silaketal-tethered linked monosaccharides. The selective synthesis of a $\beta$ - $C$-disaccharide 85 was accomplished successfully through an eightmembered TS (Scheme 10). ${ }^{105}$ Shuto planned to use this type of radical coupling reaction for synthesizing $\mathrm{a}-\mathrm{C}$-glycosidic analogs of natural adenophostin A. ${ }^{106}$ The tin-promoted glucopyranos-1-yl radicals from 86 triggered a nine-membered TS cyclization to give the $a-C$-disaccharide $\mathbf{8 7}$ in good yield and modest diastereoselectivity. A similar process for the 1,2-cis- $C$-disaccharide generation is also achievable using samarium diiodide. Starting from suitable anomeric radical precursors such as sulfones $\mathbf{8 8}$ and $\mathbf{9 0}, a-C$-disaccharides $\mathbf{8 9}^{107}$ and $\mathbf{9 1}^{98,108}$ were obtained, respectively.

\subsection{Synthesis of $C$-Ketosides}

We envisaged a simple methodology for the preparation of $C$-ketosides, using an intramolecular HAT reaction as the key step. ${ }^{109} \mathrm{~A}$ conveniently 

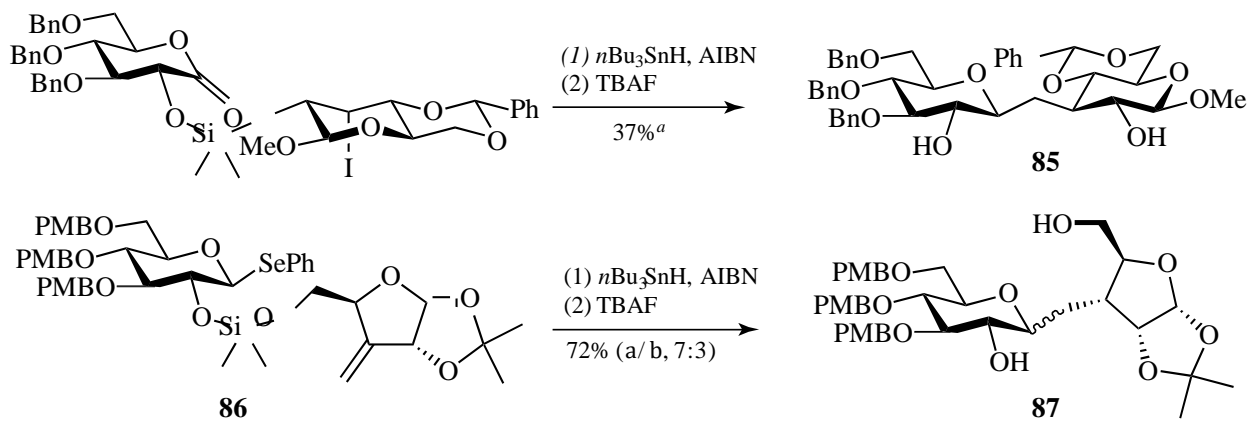

86

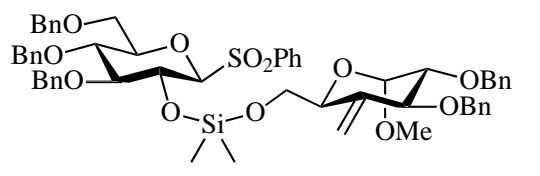

(1) $\mathrm{SmI}_{2} / \mathrm{HMPA}$

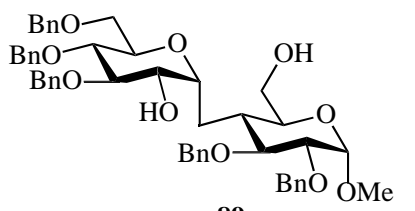

88

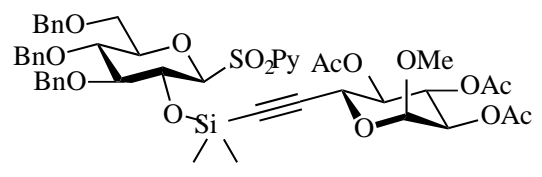

(1) $\mathrm{SmI}_{2}, \mathrm{THF}$

(2) TBAF

$\underset{48 \%}{\stackrel{(3)}{\stackrel{2}{2} \text { Two steps }}}$

90

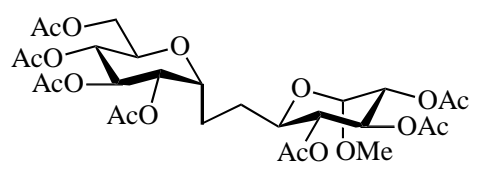

91

Scheme 10 Synthesis of $C$-disaccharides by intramolecular addition of carbohydrate radicals to an unsaturated acceptor, using a temporary silicon linkage. ${ }^{a}$ Overall yield from starting monosaccharides.

disposed alkoxyl radical generated from phthalimide 92 would trigger the HAT reaction, and the Cradical intermediate could be added to allylstannane to give $C$-ketoside 93 as depicted in Scheme 11. The stereochemistry of the quaternary carbon, carrying two differently functionalized tethers, is stereoelectronically controlled and independent of that of the starting isomer. In a recent work, we prepared new spirocyclic $C$ ketoside derivatives by a diastereocontrolled Norrish-Yang photocyclization of 2,3-diulose 94 (see Synthetic Radical Photochemistry). ${ }^{110}$ The 2-hydroxy-cyclobutanone 95 intermediate could be converted into $Y$-ketoester 96 through oxidative ring cleavage with periodic acid.

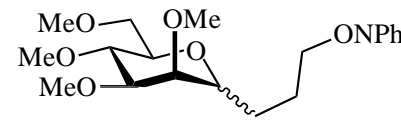

92

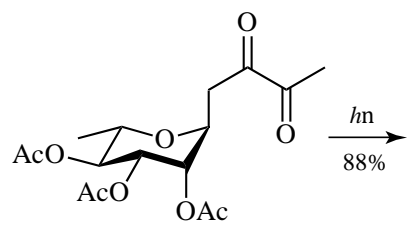

94

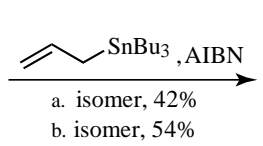

b. isomer, $54 \%$

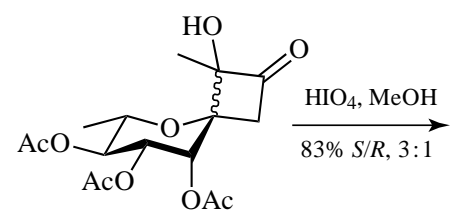

95

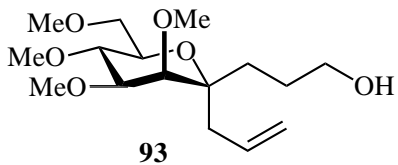

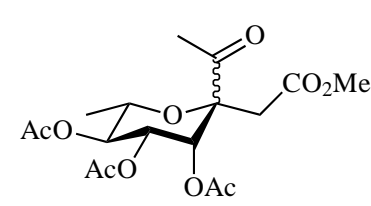

96

Scheme 11 Intramolecular synthesis of $C$-ketosides. 


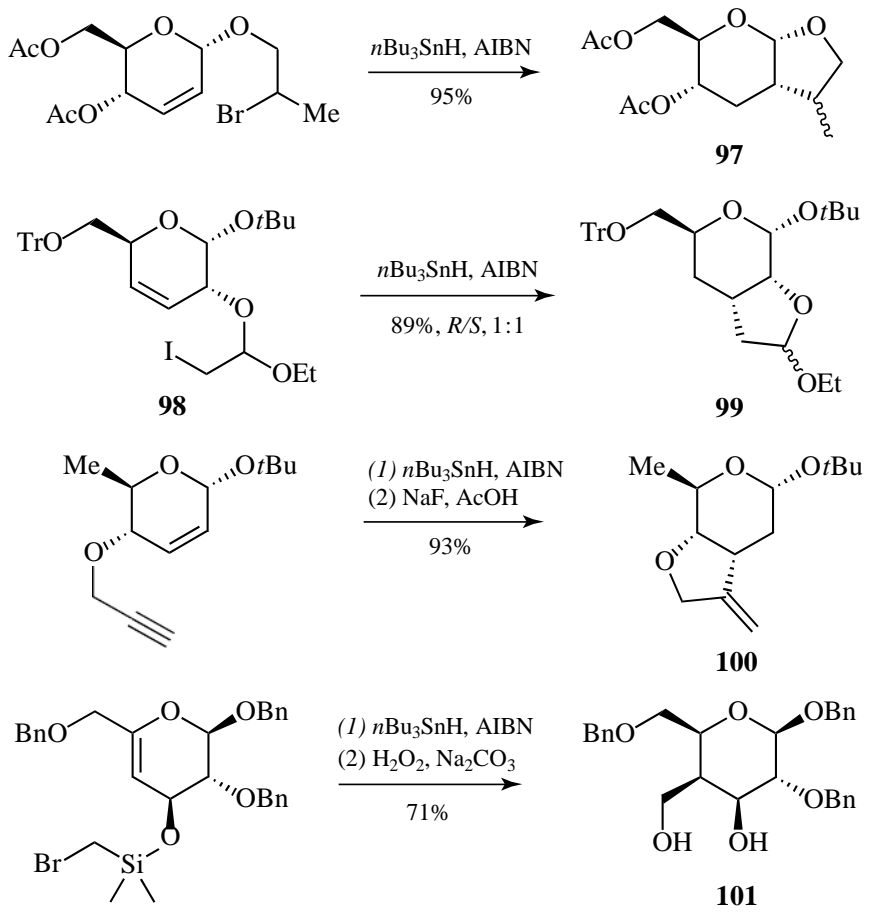

Scheme 12 Synthesis of branched-chain sugars by intramolecular addition of tethered radicals to unsaturated carbohydrates.

\subsection{Synthesis of Branched-Chain Sugars}

For the introduction of carbon chains on a carbohydrate template, two main approaches can be considered. In the first one, an unsaturated sugar model acts as a radical acceptor while a $\mathrm{C}$ rad- ical is generated on a tether carbon chain. The reverse principle is applied in the second version, in which the radical donor is generated on the sugar template and cyclizes onto a tether radical accep- tor. The radical addition on unsaturated carbohy- drates has been successfully used with 2,3-, 3,4-, and 4,5unsaturated sugars to form C-2, C-3, and C-4 branched-chain carbohydrates (Scheme 12). In the first example, De Mesmaeker studied the stereochemical outcome of the 5-exo-trig cyclization to form cis-fused $4 H$-furo[2,3- $b$ ]pyran bicycle 97. ${ }^{111}$ Similarly, Chapleur ${ }^{112}$ and Fraser-Reid ${ }^{113}$ used the radical cyclization of temporary $a$-halogen acetal tethers to synthesize $\mathrm{C}-2$ or $\mathrm{C}-3$ branched-chain sugars with predictable stereochemistry. The reaction of iodo acetal 98 to give $a$-fused product 99 is illustrative. ${ }^{112}$ Furthermore, Chapleur also demonstrated that vinylic radicals, generated by tributyltin hydride addition on triple bonds, add efficiently on 2,3-double bonds. ${ }^{114}$ In recent times, Kelly and Picton ${ }^{115}$ and Chiara ${ }^{116}$ have proficiently used this methodology. The Chiara application is shown for the stereoselective synthesis of $\mathbf{1 0 0}$, the glycosidic moiety of antifungal GM222712. The strategy of the silyl ether temporary link- age, developed by Nishiyama et al..$^{117}$ and Stork and Sofia, ${ }^{118}$ was used by Sinay", ${ }^{119}$ Herdewijn, ${ }^{120}$ and Fraser-Reid. ${ }^{113}$ This procedure has been successfully employed for the hydroxymethylation of sugars at positions 3,4 , and 6 . The synthesis of 4 deoxy-4-hydroxymethyl- $\beta$-d-galactose derivative 101 is a representative example. ${ }^{119}$

Radical addition to an unsaturated carbohydrate model generates an intermediate $\mathrm{C}$ radical located on the sugar template which may subsequently add inter- or intramolecularly to a new radical acceptor via a serial radical pro- cess. The pioneering works on sequential radical cyclizationintermolecular trapping reactions were developed by Ferrier and Petersen ${ }^{121}$ on differ-

ently tethered unsaturated sugar derivatives, such as 102, and Fraser-Reid ${ }^{113}$ during the reaction 

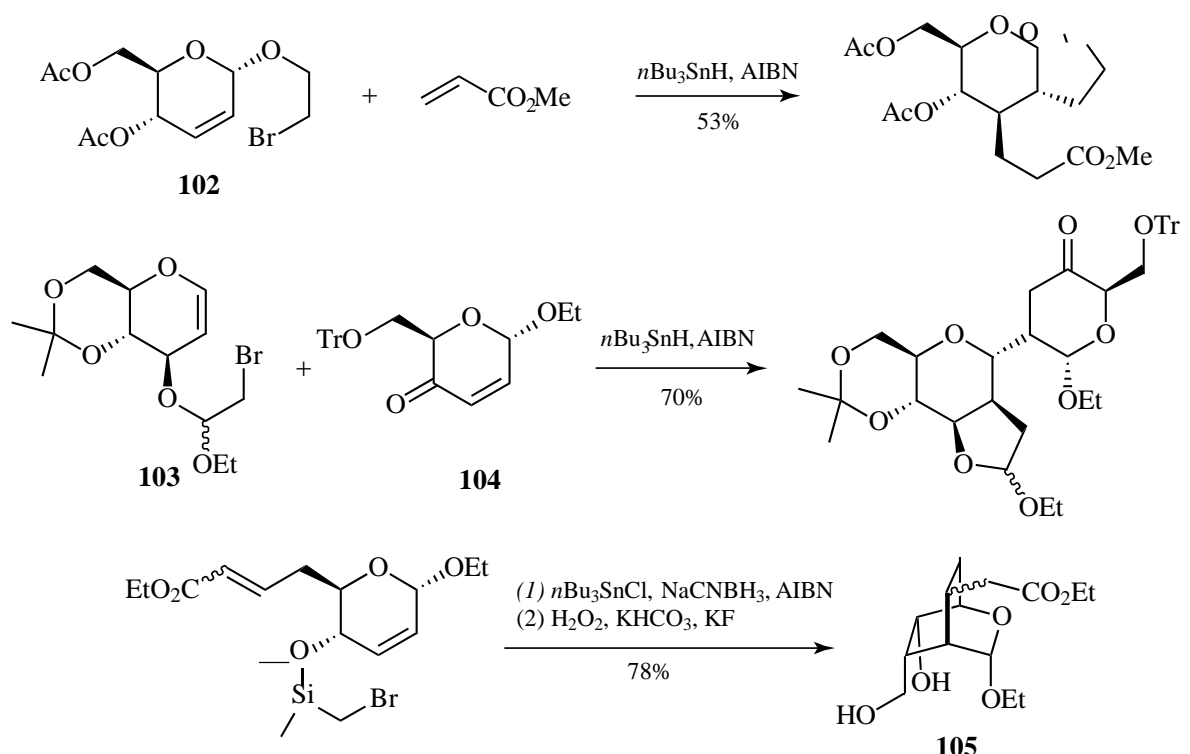

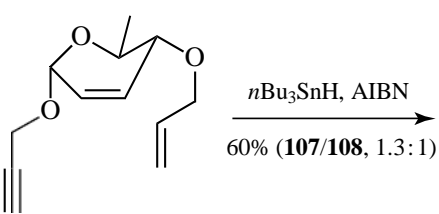

106

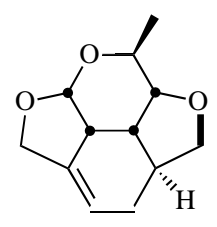

107

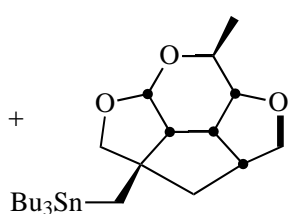

108

Scheme 13 Synthesis of branched-chain sugars by sequential addition of radicals to unsaturated carbohydrates.

of glycal 103 with enone 104 (Scheme 13). Alternative intramolecular trapping processes were described by Fraser-Reid ${ }^{122}$ for the stereocontrolled synthesis of Woodward's densely functionalized intermediate $\mathbf{1 0 5}$ for reserpine synthesis and by Kelly and Picton ${ }^{123}$ who reported successful alkyne-alkene-alkene and alkyne-alkene-alkyne tin-initiated catalytic cascade tricyclizations, in which the three new rings are constructed in a single step. The cyclization of 4- $O$-allyl-1- $O$-propargyl sugar 106 produced the expected tetracycle 107 and an additional noncatalytic compound $\mathbf{1 0 8}$.

In the second version of the intramolecular synthesis of branched carbohydrates, the radical is generated on the sugar template and adds to an exocyclic acceptor. As in the preceding approach, several different connections of the acceptor partner onto the sugars, such as acetal, ${ }^{124-128}$ ether, ${ }^{63,129}$ carbon, ${ }^{130-132}$ or silyl linkages, ${ }^{133,134}$ have been used. The pioneering works for the synthesis of C-2 branched pyranosides where the radical acceptor is linked by an acetal group came from Beau ${ }^{124}$ and De
Mesmaeker et al . ${ }^{125}$ who used $O$-alkenyl (such as 109 or 110) or alkynyl iodo glycosides to synthesize cis-fused bicycles by treatment with $n \mathrm{Bu}_{3} \mathrm{SnH}(\mathbf{1 1 2}$ or 113, respectively), confirming that the cyclization is under kinetic control and proceeds exclusively via the favored exo mode (Scheme 14). Consequently, Togo used a similar synthetic approach from glycoside 111 to bicyclic sugar 112, but using $\mathrm{Ph}_{4} \mathrm{Si}_{2} \mathrm{H}_{2}$ which is a less toxic radical reagent. ${ }^{126}$ Moreover, Hoffmann developed a stunning radical tandem cyclization of $2 \beta$-iodo glucopyranosides $114 .{ }^{127}$ The process afforded doubly annulated enantiomerically pure glycoside $\mathbf{1 1 5}$, in a 5-exo-trig, 6-endo-dig cascade. Subsequently, Choe and Jung described a new method to prepare 2-formyl-glucoside $\mathbf{1 1 6}$ employing a radical formyl transfer process driven by the formation of a stable benzyl radical. ${ }^{128}$ This was similarly used by Skrydstrup and Beau to prepare 2-formyl-mannopyranoside 117, this time using an ether connection to the carbohydrate sugar at C$3 .{ }^{63}$ Ongoing with the ether linkage, Sharma achieved the first total synthesis of xylobovide by an 


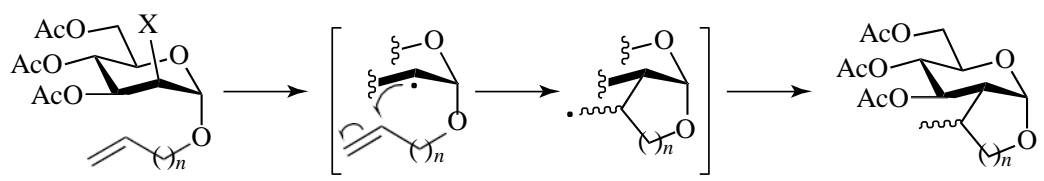

\begin{tabular}{lllc}
\hline \multicolumn{1}{c}{ Precursor } & \multicolumn{1}{c}{ Reagent } & Product (yield \%) & References \\
\hline $\mathbf{1 0 9}, \mathrm{X}=\mathrm{I}, n=1$ & $n \mathrm{Bu}_{3} \mathrm{SnH}, \mathrm{AIBN}$ & $\mathbf{1 1 2}, n=1(60-85)$ & 124,125 \\
$\mathbf{1 1 0}, \mathrm{X}=\mathrm{I}, n=2$ & $n \mathrm{Bu}_{3} \mathrm{SnH}, \mathrm{AIBN}$ & $\mathbf{1 1 3}, n=2(60)$ & 124 \\
$\mathbf{1 1 1}, \mathrm{X}=\mathrm{Br}, n=1$ & $\mathrm{Ph}_{4} \mathrm{Si}_{2} \mathrm{H}_{2}, \mathrm{Et}{ }_{3} \mathrm{~B}$ & $\mathbf{1 1 2}, n=1(84)$ & 126 \\
\hline
\end{tabular}
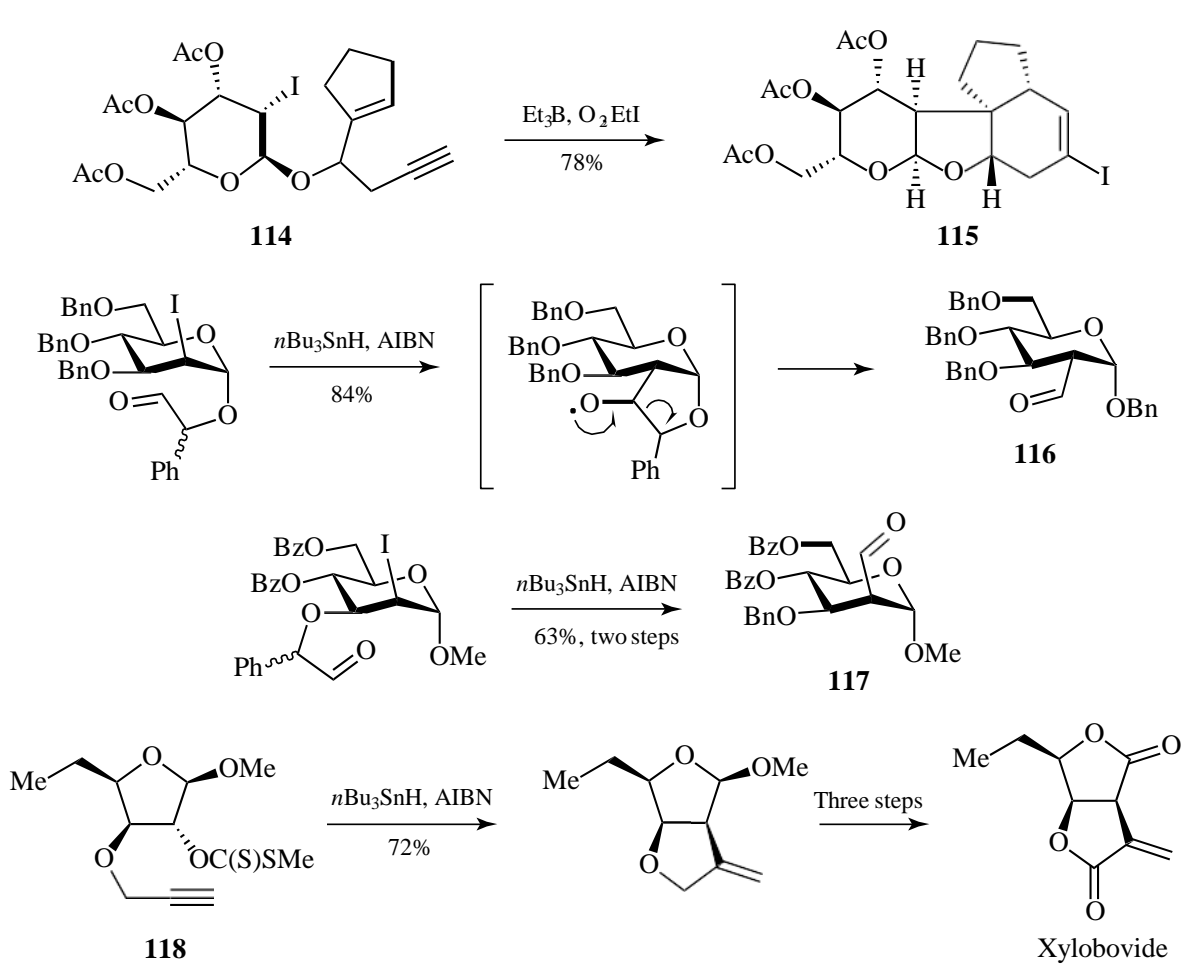

Scheme 14 Synthesis of C-2 branched-chain sugars by intramolecular addition of radicals positioned on the carbohydrate skeleton to unsaturated tethers.

intramolecular radical cyclization-based route promoted by a xanthate precursor 118. ${ }^{129}$

The earliest works for the synthesis of branched pyranosides in which the radical acceptor is linked to the sugar by a carbon atom are from Hashimoto for the synthesis of cyclopentane-annelated pyranosides. ${ }^{130}$ Subsequently, Fraser-Reid took advantage of this strategy for preparing densely functionalized natural products or segments thereof from carbohydrate precursors as shown in Scheme 15 for the synthesis of the tricyclic dihydrofuran portion of azadirachtin 119. ${ }^{131}$ Chattopadhyaya developed an intramolecular free-radical ring-closure reaction between a radical generated at $\mathrm{C}-2$ and a distant $\mathrm{C}=\mathrm{N}$ double bond of an oximino-

ether 120. ${ }^{132}$ Finally, some appealing approaches to branched-chain nucleosides have also been described. ${ }^{133-135}$ Chattopadhyaya used silicontethered acetylene to accomplish a 5-exo-trig cyclization giving exclusively the cis-fused isomer 121. ${ }^{133}$ Some studies implemented by Matsuda ${ }^{134}$ and Mayon and Chapleur ${ }^{135}$ on $O$-linked vinylsilicon tethers emphasize that the presence of a silicon atom in the tether strongly influences the cyclization process. The thermodynamic 6-endo product $\mathbf{1 2 2}$ is formed only at low concentration of 

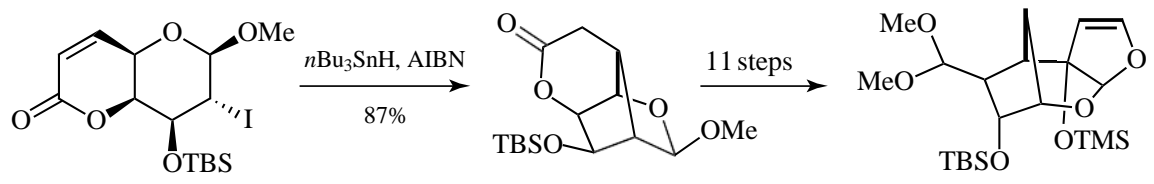<smiles>Cc1cn([C@@H]2O[C@](CC=NCBr)(COBr)[C@@H](O)[C@H]2OC(=O)O)c(=O)[nH]c1=O</smiles><smiles>Cc1cn([C@@H]2O[C@]3(COCc4ccccc4)C[C@H](C(=O)O)[C@@H](NCc4ccccc4)[C@@H]23)c(=O)[nH]c1=O</smiles><smiles>Cc1cn([C@@H]2O[C@H](COC(C)C)[C@@H](O)[C@H]2O[Si](C)(C)C#Cc2ccccc2)c(=O)[nH]c1=O</smiles><smiles>COC[C@H]1O[C@@H](n2cc(C)c(=O)[nH]c2=O)[C@H]2O[Si](C)(C)/C(=C\c3ccccc3)[C@@H]12</smiles>

121

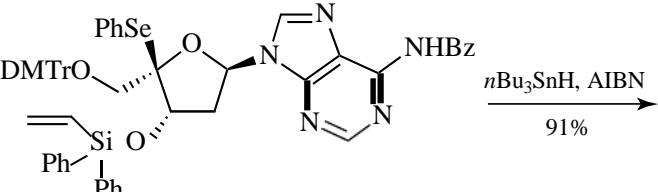

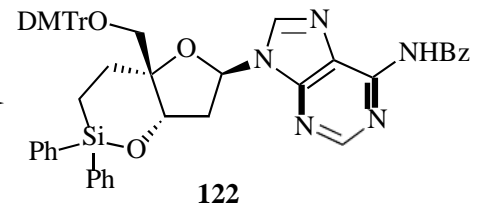

Scheme 15 Synthesis of branched-chain sugars by intramolecular addition of radicals positioned on the carbohydrate skeleton to unsaturated tethers. MMTr, 4-monomethoxytrityl; DMTr, 4,4j-dimethoxytrityl.

hydride; at higher concentrations the corresponding 5-exo product was exclusively produced. ${ }^{134}$

\subsection{Synthesis of Carbocycles from Acyclic Sugar Derivatives}

Carbasugars, previously known as pseudosugars, are a family of carbohydrate mimics that has been attracting great interest among chemists and biochemists for the last two decades. ${ }^{136}$ They are structurally similar to normal sugars, although the hemiacetal ring oxygen has been replaced by a methylene group. Go'mez and Lo'pez have recently reported a comprehensive review that exemplifies the progress made in the synthesis, conforma- tional studies, and biological aspects of carbasug- ars. ${ }^{6}$ Earlier reviews by Fraser-Reid and Tsang, ${ }^{137}$ Ferrier, ${ }^{138}$ RajanBabu, ${ }^{139}$ and Mart'inez-Grau and
Marco-Contelles ${ }^{140}$ can also be found in the literature.

\subsubsection{Synthesis of Carbafuranoses and Polyfunctionalized Cyclopentane Analogs}

The 5-exo cyclization is especially useful for the synthesis of cyclopentanes. In this field, Wilcox developed the first example of the radical 5-exo-trig cyclization derived from unsaturated halo-aldoses to prepare epimeric cyclopentanes $\mathbf{1 2 3}$ and $\mathbf{1 2 4}$ (Scheme 16). ${ }^{141}$ It was observed that the cyclization of the $Z$ isomer proceeded with a greater degree of stereocontrol and the major product had an exo orientation of the ester group. In a similar reaction, Kita found that the use of V-70L instead of AIBN as radical initiator made it possible to achieve a higher stereoselective synthesis 

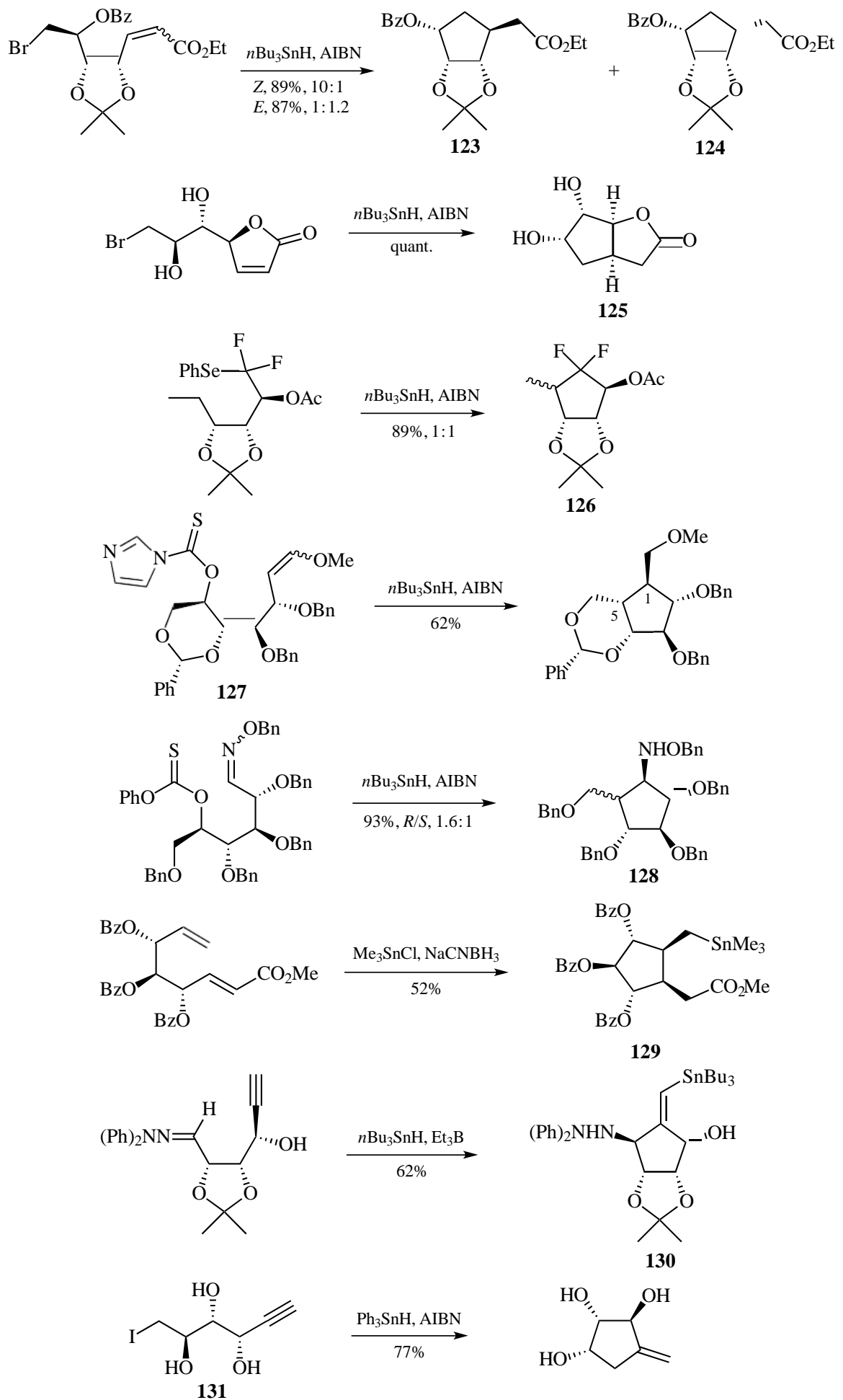

Scheme 16 Synthesis of cyclopentane derivatives via 5-exo-cyclizations with tin reagents. 
of 123 and 124. ${ }^{142}$ Roberts used an analogous methodology to synthesize different carbafuranoses starting also from primary haloderivatives, ${ }^{143}$ while Lundt applied a related strategy for the synthe- sis of carbapentofuranoses such as $\mathbf{1 2 5}$ starting from bromodeoxyheptonolactones. ${ }^{144}$ Similarly, Leclerc devised a general route to difluorinated carbocyclic 5-deoxypentofuranose analogs $\mathbf{1 2 6}$ but using a phenylselenenyl group. ${ }^{145}$ In a related study, RajanBabu successfully employed secondary imidazole carbothioate 127, observing that the corresponding hex-5-enyl radical cyclizes efficiently with exclusive formation of a cis-fused bicyclic system and 1,5-trans stereochemistry. ${ }^{146}$ Bartlett opened up a straightforward approach to aminocarbafuranoses as $\mathbf{1 2 8}$ using a radical cyclization of carbohydrate-derived oxime ethers. ${ }^{147}$ This procedure has been extended subsequently by a number of groups for the preparation of aminocyclopentitols. ${ }^{148}$ Hanessian reported that trimethylstannyl radicals add to the unsubstituted terminal olefinic carbon atom of activated and unactivated dienes to produce cyclopentane compounds such as $\mathbf{1 2 9}$ with the preponderance of the isomer with a syn orientation of the carbon substituents. ${ }^{149}$ Similarly, Marco-Contelles disclosed the first examples of $n \mathrm{Bu}_{3} \mathrm{SnH}$-promoted free-radical cyclization of $\delta$-alkynyl tethered oximes, imines, and $N, N$-disubstituted hydrazones to provide a simple synthesis of enantiomerically pure aminocyclitol derivatives as $\mathbf{1 3 0}$ in moderate yields. ${ }^{150}$ The 5-exo-dig radical cyclization of

1,2,6-trideoxy-6-iodo-1 -arabino-hex-1-ynitol

131 could be a useful method to prepare exocyclic methylene cyclopentanes in good yields. ${ }^{15}$

A useful alternative to trialkyltin hydride-based reductive coupling is supplied by one-electron reducing agents such as samarium diiodide. In a pioneering approach to carbafuranoses, Enholm described, in 1989, the stereoselective $\mathrm{SmI}_{2}-$ mediated intramolecular cyclization of alde- hydes and electron-deficient alkenes, as depicted in 132, to give cyclopentanols (Scheme 17). ${ }^{152}$ It was observed that a cis-olefin in the starting<smiles>CC(=O)/C=C\C1OC(C)(C)O[C@H]1[C@@H](O)C=O</smiles>

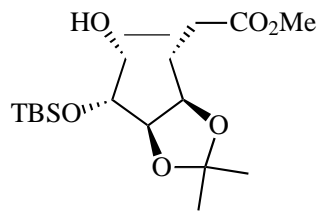
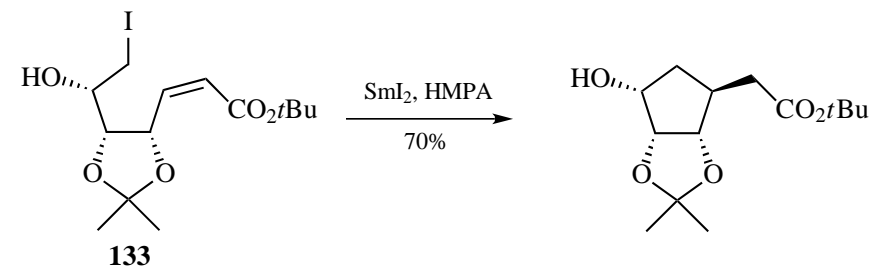

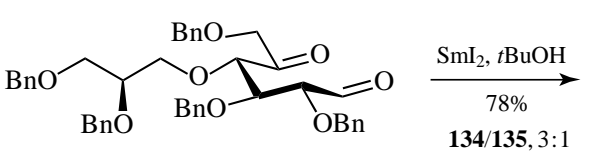

134/135, $3: 1$

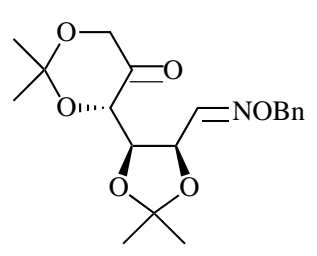

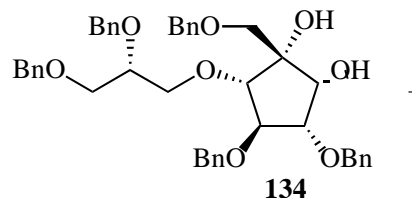
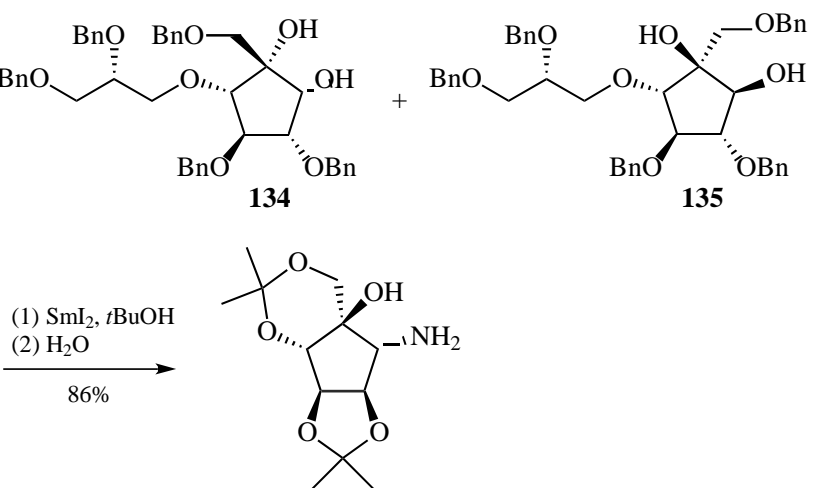

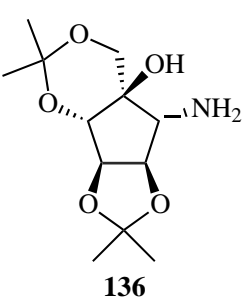

Scheme 17 Synthesis of cyclopentane derivatives by $\mathrm{SmI}_{2}$-mediated reductive coupling. 
substrate favored a syn product, while a trans-olefin gave preferably the anti product. More recently, Holzapfel $^{153}$ and Matsuda ${ }^{154}$ have also applied this methodology to convert selectively substituted carbohydrates into the analogous stereodefined cyclopentanols. Subsequently, Zhou and Bennett ${ }^{155}$ used the $\mathrm{SmI}_{2} / \mathrm{HMPA}$ system to perform the radical cyclization of d-ribonolactone-derived alkenyl halides 133. Sinay" reported in 1995 a $\mathrm{SmI}_{2}-$ promoted stereoselective ring contraction of methyl hexodialdo-pyranosides to give highly functionalized cyclopentanes. ${ }^{156}$ More recently, this method was applied by Jenkins and Potter ${ }^{157}$ and Iadonisi ${ }^{158}$ to develop a pinacolization in carbohydrate derivatives and by Sinay ${ }^{* 159}$ to give an inseparable mixture of two cis-diol intermediates $\mathbf{1 3 4}$ and $\mathbf{1 3 5}$ in the total synthesis of calditol. The Giese ${ }^{160}$ and Chiara et al.$^{161}$ groups have described one of the most suitable methods for the synthesis of aminocyclopentitols such as $\mathbf{1 3 6}$ by $\mathrm{SmI}_{2}$-based reductive couplings of polyhy- droxylated oxime ethers $^{162}$ or $N, N$-disubstituted hydrazones ${ }^{163}$ in studies toward the synthesis of trehazolamine.

Besides samarium diiodide, there are also other alternatives to tributyltin hydride-promoted reductive coupling, such as the use of tellurium, cobalt, mercury, and titanium derivatives (Scheme 18). Barton designed a new source of alkyl radicals by radical exchange. ${ }^{164}$ The process involves the use of

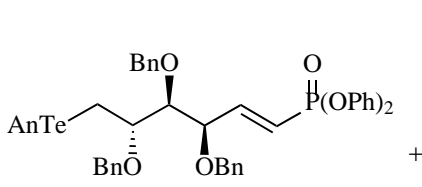

137<smiles>C=CC1OC(C)(C)O[C@H]1[C@H](Br)CI</smiles><smiles>C=CC1OC(C)(C)O[C@@H]1/C=C\C(=O)OCC</smiles>

141

(1) $\mathrm{Hg}(\mathrm{OAc})_{2}, \mathrm{AcOH}$ (2) $\mathrm{NaBH}(\mathrm{OMe})_{3}$

$53 \%$

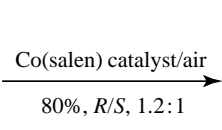

138<smiles>CCCCCCCCCCCCC</smiles><smiles>COC[C@H]1O[C@H](C(=O)C(C)=O)[C@H](OC)[C@H](OC)[C@H]1OC</smiles>
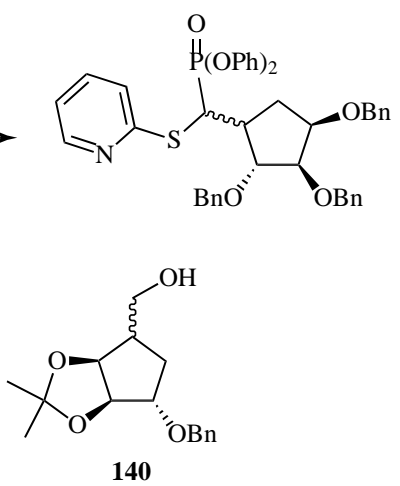

140

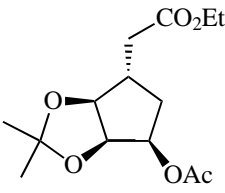

142<smiles>[R20][C@H]1[C@H](O)[C@@H](O)[C@H](CO)[C@H]1O[B]</smiles>

$143 \mathrm{R}=\mathrm{Bn}, 40 \%$

$144 \mathrm{R}=\mathrm{H}, 13 \%$<smiles>COC[C@H]1O[C@H](C(=O)C(C)=O)[C@H](OC)[C@H](OC)[C@@H]1OC</smiles><smiles>COCC(=O)[C@@H](OC)[C@H](OC)[C@H](/C=C(\O)C(C)=O)OC</smiles>

145
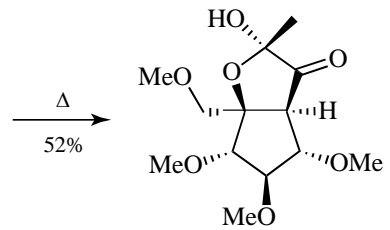

146

Scheme 18 Alternatives to tin and samarium reagents for the synthesis of cyclopentane derivatives. An, anisyl. 
the acetyl derivative of $N$-hydroxy-2-thiopyridone 138 as a convenient source of methyl radical which can react with an anisyltelluride deriva- tive such as $\mathbf{1 3 7}$ to afford the desired alkyl radi- cal intermediate. This $\mathrm{C}$ radical is able to cyclize intramolecularly with a proper olefin to generate the corresponding carbocycle. On the other hand, Prandi developed a cobalt-catalyzed radical cycliza- tion of 6-iodohex1-enitol derivative $\mathbf{1 3 9}$ to give the expected hydroxymethyl-substituted cyclopen- tane 140. ${ }^{165} \mathrm{~A}$ process involving chemoselective mercuriation of diene 141, followed by reductive radical cyclization, has been described by Gallos for the synthesis of carbocycle 142. ${ }^{166}$ Chiara has shown that the reductive cross-coupling of epoxides with carbonyl groups promoted by titanocene chloride can also be successfully applied to the stereoselective synthesis of highly functionalized branched cyclitols such as $\mathbf{1 4 3}$ and 144 from readily available hexose precursors. ${ }^{167}$ Recently, we developed a conceptually different approach for the synthesis of branched cyclopentitols such as $\mathbf{1 4 6}$ by photolysis of 4,8-anhydro-2,3-diuloses. The proposed mechanism implies a HAT reaction promoted by a Norrish type II photoelimination followed by a highly diastereoselective thermally induced enolexo aldol cyclization of an isolable photoenol intermediate $\mathbf{1 4 5}$ which acts as a preformed enolate. ${ }^{168}$<smiles>C=C[C@H](OC(C)=O)[C@@H](OC(C)C)[C@H](OC(C)=O)[C@@H](C)OC(C)=O</smiles>

147

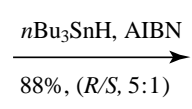

$\mathrm{AcO \overline {O }}$

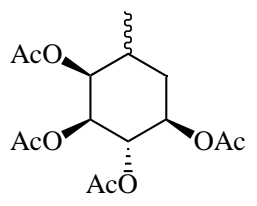

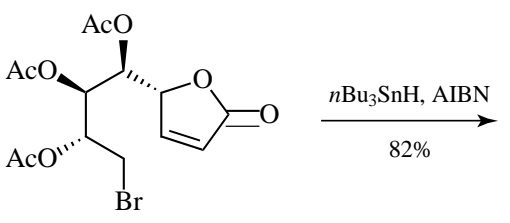<smiles>CC(=O)O[C@H]1[C@H]2OC(=O)C[C@H]2C[C@@H](O)[C@H]1OC(C)=O</smiles><smiles>C#C[C@H]1OC(C)(C)O[C@H]1[C@H](CC=O)OC</smiles>

149<smiles>C#C[C@H](OCc1ccccc1)[C@@H](OCc1ccccc1)[C@@H](OCc1ccccc1)C(C)COCc1ccccc1</smiles>
(1) $n \mathrm{Bu}_{3} \mathrm{SnH}, \mathrm{AIBN}$
$\underset{80 \%,(R / S, 1.6: 1)}{\text { (2) } \mathrm{AcOH}, \mathrm{H}_{2} \mathrm{O}}$ MOMŌ
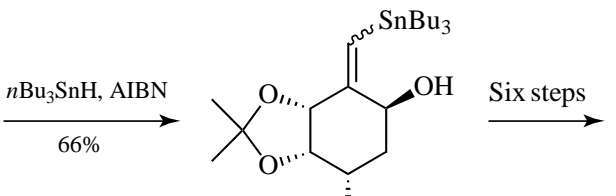

(+)-allo-Quercitol<smiles>O[C@@H]1[C@H](O)[C@H](O)[C@@H](O)C[C@H]1O</smiles><smiles>C=C1C[C@H](COCc2ccccc2)[C@@H](OCc2ccccc2)[C@H](O)[C@@H]1OCc1ccccc1</smiles>

150

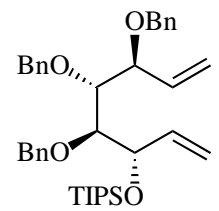

$$
\underset{64 \% \text {, two steps }}{\stackrel{\text { (1) } \mathrm{O}_{3}, \mathrm{Me}_{2} \mathrm{~S}}{\text { (2) } \mathrm{SmI}_{2}}}
$$
TIPSŌ<smiles>O[C@H]1[C@H](O)[C@H](O)[C@H](O)[C@@H](OCc2ccccc2)[C@H]1O</smiles>

151

Scheme 19 Synthesis of cyclohexane derivatives. 


\subsubsection{Synthesis of Carbapyranoses and Polyfunctionalized Cyclohexane Analogs}

The cyclization of 6-heptenyl radicals proceeds much more slowly than that of the 5-hexenyl radicals (Figure 3). In consequence, there are relatively few examples for the preparation of carbapyranoses by 6-exo or 6-endo radical ring closure.

Although the first examples of the synthesis of a 5a-carbapyranose by 6-exo-trig radical cyclization were published almost simultaneously by Samuelsson ${ }^{169}$ and Schmid and Whitesides, ${ }^{170}$ Redlich reported a comprehensive study on the scope of the radical ring closure of 7-deoxy-7-iodohept-1enitols as $\mathbf{1 4 7}$ leading to several 6-deoxy-5acarbapyranoses (Scheme 19). ${ }^{171}$ Marco-Contelles showed that, if the 6-exo-trig radical cyclization occurs on an $a, \beta$-unsaturated ester, ${ }^{172}$ an enol-ether double bond, ${ }^{173}$ or an oxime ${ }^{172}$ the resulting carbasugars are useful building blocks for the preparation of differently substituted inositols. On other hand, Lundt extended the previous work developed on carbafuranoses $^{144}$ to 8 -bromo-8-deoxy-oct-2-eno-1, 4-lactones for the regio- and stereoselective preparation of carbapyranoses $148 .{ }^{174}$ Yadav reported the first examples of the 6-exo-trig radical cycloisomerization of polyoxygenated alkyne-tethered aldehydes, of the type depicted by $\mathbf{1 4 9}$, to prepare

$(+)$-allo-quercitol and (+)-talo-quercitol with high diastereoselectivity. ${ }^{175}$ The synthesis of carbasugars involving 6-exo-dig radical cyclization was first shown by McDevitt and Fraser-Reid ${ }^{176}$ and afterward by Wightman. ${ }^{177}$ More recently, Go'mez and Lo'pez have studied the different factors that favor the 6-endo versus 5-exo radical ring clo- sure to lead to carbapyranoses. ${ }^{178}$ They found that enyne 150, which includes at least two regiodi- recting features (vinyl radical and substitution at C-5), is able to undergo 6-endo-trig radical cycliza- tion in good yields. Since the original works by Chiara and Mart' 1 -Lomas $^{179}$ and Mioskowski ${ }^{180}$ on $\mathrm{SmI}_{2-}$ promoted pinacol coupling in a carbohydrate 1,6dialdehyde to provide an inositol ring, others such as Kornienko and d'Alarcao ${ }^{181}$ or Matsuda ${ }^{182}$ have recently performed further studies in this field. As a representative example, the synthesis of a myoinositol derivative $\mathbf{1 5 1}$ from a d-xylose deriva- tive is shown in Scheme 19. ${ }^{181}$

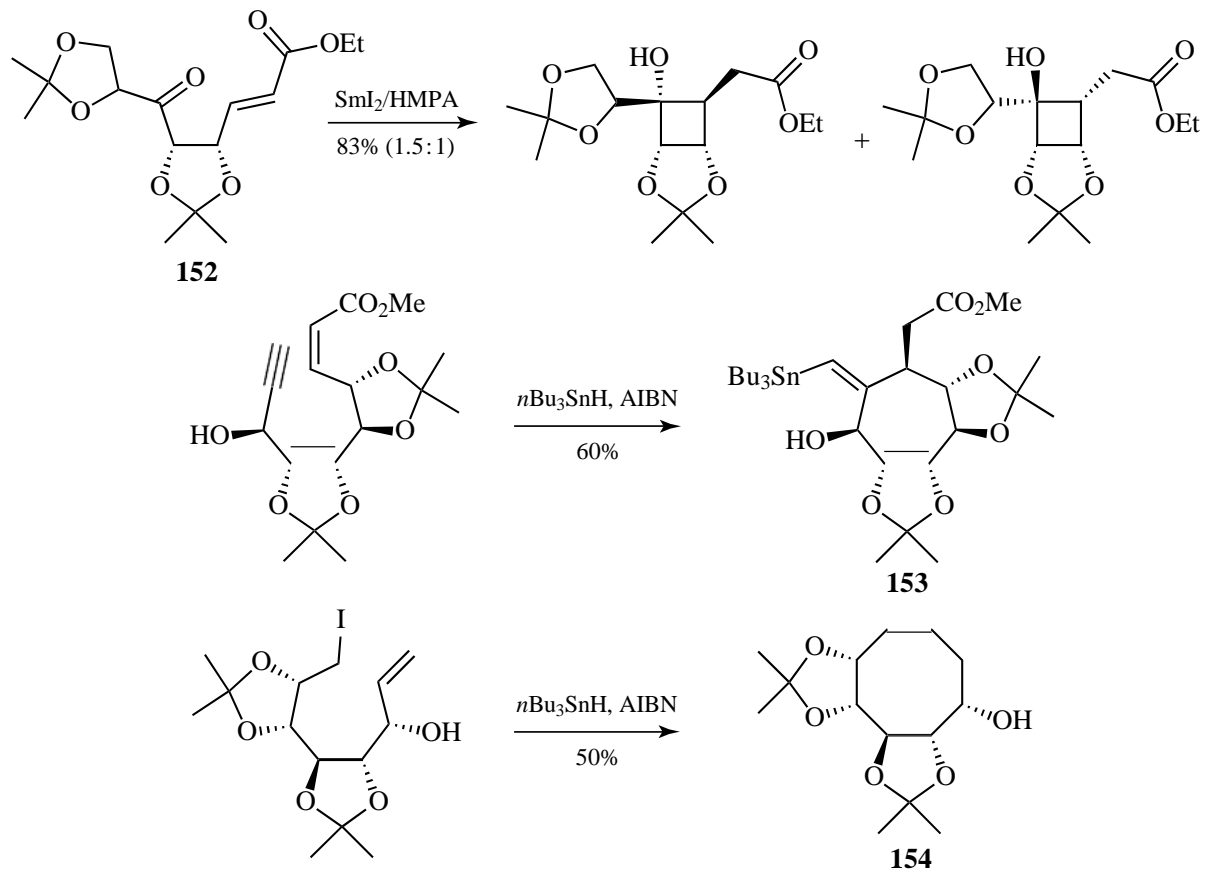

Scheme 20 Synthesis of of four-, seven-, and eight-membered carbocycles. 


\subsubsection{Synthesis of Four-, Seven-, and Eight-Membered Carbocycles}

Chiral, nonracemic cyclobutanols form integral parts of various antiviral and sedative agents. In this field, Williams developed a procedure for the conversion of carbohydrate precursors into highly functionalized cyclobutanes employing $\mathrm{SmI}_{2}$ by pinacol coupling, ${ }^{183}$ or 4 -exo-trig cyclization, as in 152 (Scheme 20). ${ }^{184}$ On other hand, an emerg- ing interest in the preparation of carbasugars containing rings larger than five or six members has arisen in recent years. In the radical approach, Marco-Contelles has described 7-exo and 8-endo free-radical carbocyclization of acyclic radical precursors derived from sugars for the synthesis of highly functionalized medium-sized rings such as 153 and 154. ${ }^{185}$

\section{CARBON-HYDROGEN BOND-FORMING PROCESSES}

In this section, we focus our attention on the deliberated reduction, namely formation of carbon-hydrogen bonds concerning anomeric and non-anomeric $\mathrm{C}$ radicals generated under reduc- tive conditions in carbohydrate models of significant synthetic interest.

\subsection{Synthesis of Anhydroalditols}

Hydrogen quenching of anomeric $\mathrm{C}$ radicals constitutes a simple method not only for the synthesis of anhydroalditols but also for the stereoselec- tive preparation of $\beta-C$ - or $\beta-O$-glycosides and 2deoxy-sugars. In this context, Praly in 2001 reported a comprehensive review that exemplifies the progress made in the structure of anomeric glycosyl radicals and their transformations under reductive conditions. ${ }^{14}$ Auge' and David pub-

lished the first example of radical synthesis of 1,5anhydroalditols starting from glycosyl chlorides by treatment with $n \mathrm{Bu}_{3} \mathrm{SnH}$ and $\mathrm{AIBN} .{ }^{186}$ Later work by Kocienski employed more reactive glycosyl bromides and photochemical initiation. ${ }^{187}$ Recent selected examples include the synthesis of the disaccharide 1,5-anhydromaltitol by Vismara ${ }^{188}$ and the reduction of galactopyranosyl bromide $\mathbf{1 1}$ to give 1,5-anhydro-galactitol $\mathbf{1 5 5}$ in nearly quantitative yield by Thiem (Scheme 21). ${ }^{189}$ In addition to glycosyl halides, 1,5-anhydrohexitols
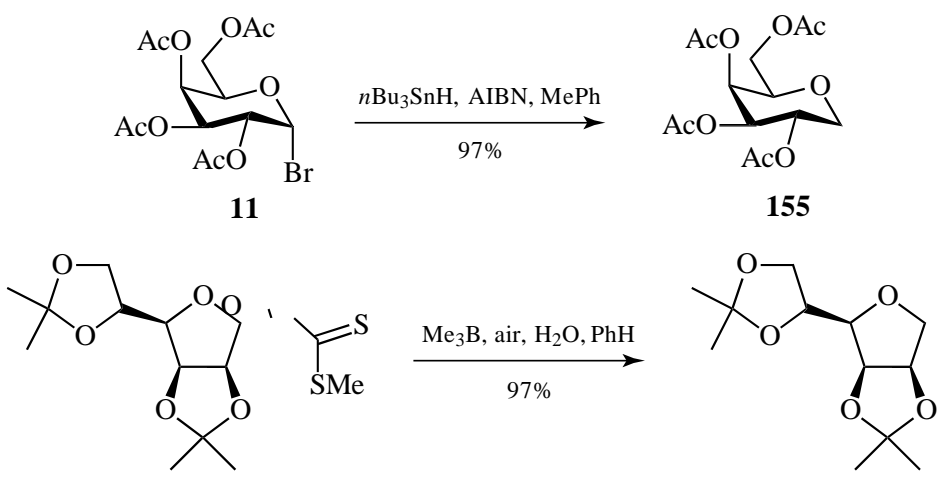

156

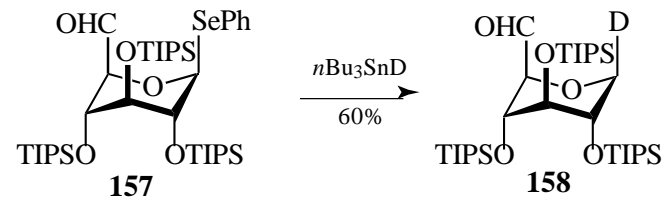

Scheme 21 Synthesis of anhydroalditols. 
have also been frequently prepared in good yields from phenylselenides, ${ }^{190,191}$ xanthates, ${ }^{192}$ or organotellurides, ${ }^{193}$ among others. Apart from tin reagents, other alternative reductants such as tris(trimethylsilyl)silane (TTMSS) (see Silanes as Reducing Reagents in Radical Chemistry), ${ }^{194}$ hypophosphorous salts, ${ }^{195}$ and arylthiols ${ }^{193}$ for the case of telluroglycosides have been used as well. Compared that of to 1,5-anhydrohexitols, the preparation of 1,4-anhydroalditols has received only limited attention, although a few examples can be found in the recent literature starting from anomeric xanthates. ${ }^{196,197}$ For instance, Wood ${ }^{197}$ used a trialkylborane/air/water system to accomplish the radical-mediated deoxygenation of xanthate 156. To analyze the stereoselectivity of the HAT reaction promoted by anomeric $\mathrm{C}$ radicals, some deuterium studies have been carried out. It was observed that in the $n \mathrm{Bu}_{3} \mathrm{SnD}$ reduction of $\mathrm{a}$ - and $\beta$-d-glucosyl and a-d-mannosyl halides, with the pyranose ring in ${ }^{4} C_{1}$ chair conformation, the stereochemistry of the deuterium in the 1,5-anhydroalditol is very predominantly $a$-axial and independent of the stereochemistry of the starting halide. ${ }^{198,199}$ Recently, Shuto studied the stereoselectivity using conformationally ${ }^{1} C_{4}$-restricted glucose derivative 157; deuteration by $\beta$-axial attack gave exclusively the $\beta$-deuterated product 158. ${ }^{191}$ These results reflect that stereoelectronic effects play an important role in radical reactions at the anomeric center, as was commented upon in Section 2.

\subsection{Stereocontrolled Synthesis of $\beta-O$ - and $\beta$-C-Glycosides}

There are two different main routes to give $\beta-O$ - and $\beta$ - $C$-glycosides. The first approach involves a single radical intermediate generated regioselectively and directly at the anomeric center. However, the second route engages a preliminary radical generated somewhere in the molecule which subsequently promotes a favorable regioselective hydrogen-atom abstraction at the anomeric center to lead to the corresponding anomeric C-radical intermediate formed by radical translocation. In both cases, the final hydrogen trapping of the anomeric $\mathrm{C}$ radical is the key step in terms of stereoselectivity.

\subsubsection{Diastereoselective Hydrogen Quenching of Anomeric Radicals}

Within the framework of this first approach, Kahne pioneered the application of alkoxy-substituted anomeric radicals for the synthesis of $\beta-O$-glycosides. ${ }^{200}$ These radicals were prepared from hemithio ortho esters such as $\mathbf{1 5 9}$ by treatment with $n \mathrm{Bu}_{3} \mathrm{SnH}$, observing that hydrogen quenching led preferentially to the $\beta$ anomer in high yields (Scheme 22). Moreover, $\mathrm{Crich}^{201}$ proved that the Barton radical decarboxylation of $O$-acyl thiohydroxamates of 2-ulopyranosonic acids, as depicted by 160 , gave the $\beta$-d-Man $p-(1 \rightarrow 6)-d-d-G l c p$

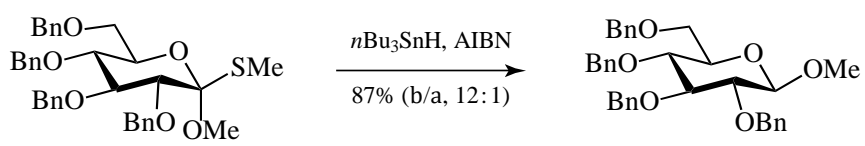

159
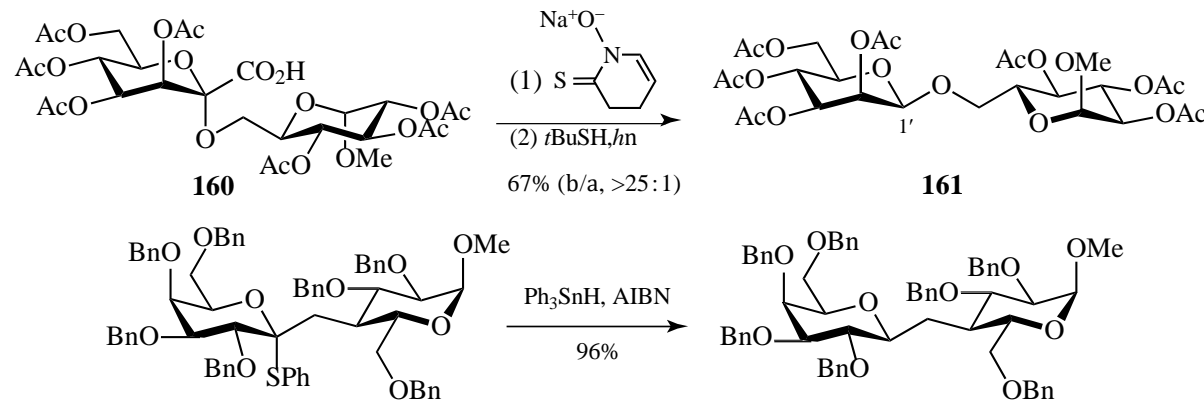

162

Scheme 22 Synthesis of $\beta-O$ - and $\beta-C$-glycosides. 
disaccharide 161 with inversion of configuration at $\mathrm{C}-1^{\mathrm{j}}$. Examples of these decarboxylations in the 2ulofuranosonic acid series have also been reported by Crich and Ritchie ${ }^{202}$ and Garner. ${ }^{203}$ Among $C$ glycosyl derivatives, those having halo- gen atoms or nitro groups attached to the anomeric center and thio- or seleno-glycosides are able to undergo radical-mediated reduction in the presence of tin or silicon hydrides as described earlier for the synthesis of $\beta-C$-glycosides (Schemes 1 and 7). ${ }^{27}$ Aware that monothioketals are usually reduced with excellent stereoselectivity with tin hydrides, Kishi extended this procedure to $C$-disaccharide systems such as 162 to obtain exclusively the $\beta$ isomer. ${ }^{204}$

\subsubsection{Radical Translocation}

The second approach to $\beta-O$ - and $\beta-C$-glycosides involves a sequence of radical reactions involv- ing first an intra- then an intermolecular HAT. This alternative has been applied almost exclusively to manno- or rhamnopyranosides where a silyl or acetal linkage at C-2 could be particularly useful. Curran reported that $\mathrm{a}$-mannoside 163 underwent radical translocation to give two prod- ucts: the inverted $\beta$-mannoside 164 resulting from 1,6-HAT and $a$-glucoside 165 obtained via com- peting 1,5HAT (Scheme 23). ${ }^{205}$ A similar approach starting from the mixed acetal $\mathbf{1 6 6}$ has been devel- oped by Crich, but under their best conditions a relatively low anomeric inversion was obtained. ${ }^{206}$ We have also included in this section the translo- cation between $\mathrm{O}$ and $\mathrm{C}$ radicals observed in the reactions of phthalimides 167 and 170. The alkoxyl radical generated from $C$-mannosyl gly- coside $\mathbf{1 6 7}$ triggered a 1,6-HAT which afforded inverted $\beta-C$ glycoside 168 in moderate yield; by employing $n \mathrm{Bu}_{3} \mathrm{SnD}$ as reductant, it was evident that the major product 169 has been formed via a competitive 1,5HAT process. $^{207}$ Recently, in our laboratory we have implemented a translo- cation methodology based on an intramolecular 1,8-HAT reaction between the two pyranose units
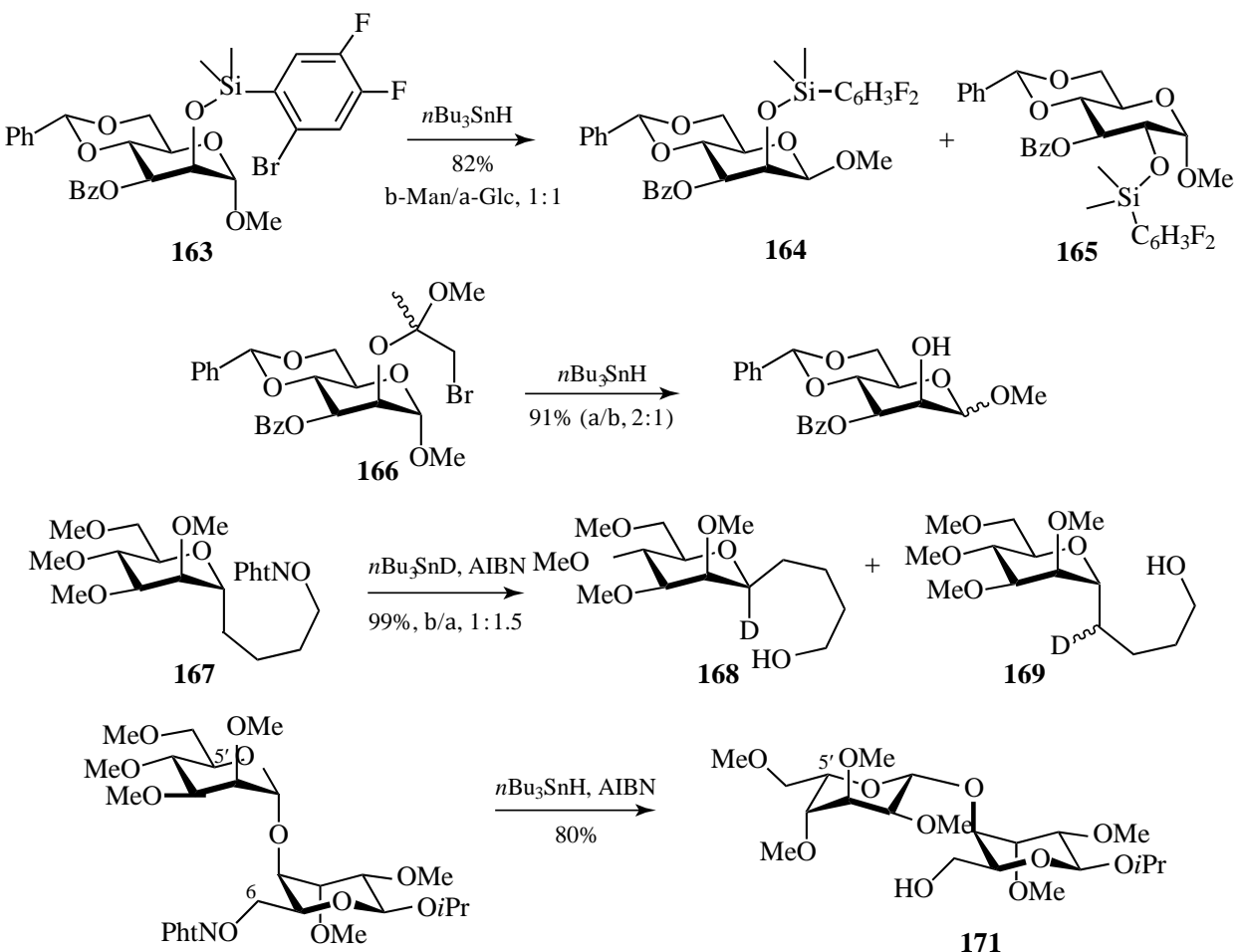

170

Scheme 23 Radical translocation between carbon-carbon and carbon-oxygen radicals. 
in suitably substituted $(1 \rightarrow 4)-O$-disaccharides. ${ }^{208}$ The alkoxyl radical at C-6 was generated by reaction of an $N$-hydroxyphthalimide derivative, such as $\mathbf{1 7 0}(a-\mathrm{d}-\operatorname{Man} p-(1 \rightarrow 4)-\beta-1-\mathrm{Gul} p)$, with the $n \mathrm{Bu}_{3} \mathrm{SnH} / \mathrm{AIBN}$ system and the abstraction occurs exclusively at $\mathrm{C}-5^{\mathrm{j}}$ with predominant inversion of configuration to give the disaccharide 171 $(\beta-1-G u l p-(1 \rightarrow 4)-\beta-1-G u l p)$.

\subsection{Synthesis of 2-Deoxy Sugars by Radical- Induced 1,2-Ester Rearrangement}

The 1,2-migrations of acyloxy and phosphonyloxy groups in the carbohydrate field involve initial generation of an anomeric $\mathrm{C}$ radical and its subse- quent rearrangement to a C-2-centered radical which finally leads to 2-deoxy sugars. ${ }^{209,210}$ The thermodynamic driving force that explains this rearrangement is derived from the formation of the strong anomeric $\mathrm{C}-\mathrm{O}$ bond despite the reduction step occurring through the less electronically stabilized C-2 radical. Giese was the first to expand this 1,2-migration to carbohydrates, observing that, starting from acetylated models, such as 21, or benzoylated glycopyranosyl, or furanosyl halides or selenides, 2-deoxy sugars 172 were obtained in good yields by a cisselective rearrangement (Scheme 24). ${ }^{211,212}$ It was also demonstrated that the slow addition of $n \mathrm{Bu}_{3} \mathrm{SnH}$ required to avoid the direct reduction of the starting substrate may be circumvented by the use of alternative reductants such as TTMSS. ${ }^{213}$ A further alternative to tin hydrides was proposed by Quiclet-Sire and Zard, ${ }^{214}$ using $S$-glycosyl xanthates, such as 173, as radical precursors in refluxing cyclohexane, which surprisingly acts as an effective hydrogen donor, and dilauroyl peroxide (DLP) as initiator to give 2-deoxy carbohydrates $\mathbf{1 7 4}$ in good yields. In contemporaneous works, Crich and Giese firstly described phosphonyloxy radical migration in 1993. ${ }^{215,216}$ The preparative potential of this migration in carbohydrates was recognized and exploited by the Giese group. Thus, although the 2deoxyglycosyl phosphates were too unstable to be isolated, they could be coupled in situ to various acceptors to give 2-deoxy disaccharides or nucleosides such as $\mathbf{1 7 5}$. $^{216}$

\subsection{Non-anomeric C-Radical Reduction}

The radical deoxygenation of thiocarbonyl derivatives, known as the Barton-McCombie reaction, is one of the most widely employed meth- ods for the deoxygenation of primary and sec- ondary alcohols (see Tin Hydrides and Func- tional Group Transformations). ${ }^{217,218}$ In Scheme 25, deoxygenation of a primary $O$-trichlorophenyl thiocarbonate $\mathbf{1 7 6}$ is shown using this procedure. ${ }^{219}$ The well-known and effective classical conditions used trialkyltin hydrides but, considering the toxicity of these tin compounds and
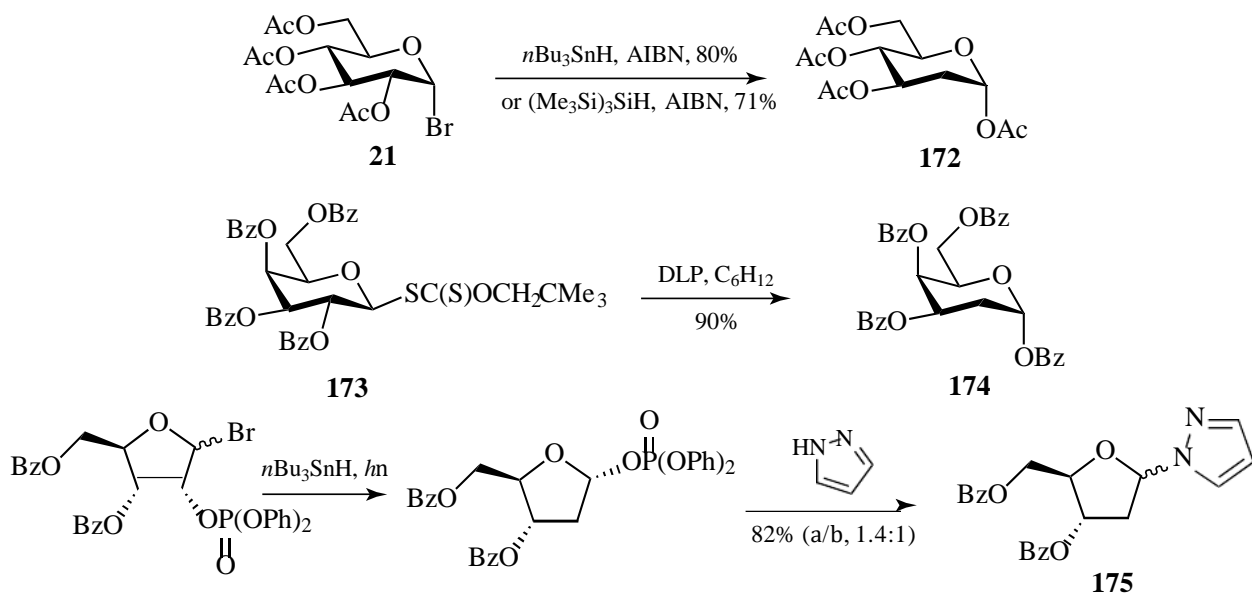

Scheme 24 Synthesis of 2-deoxy sugars by 1,2-ester migrations. 

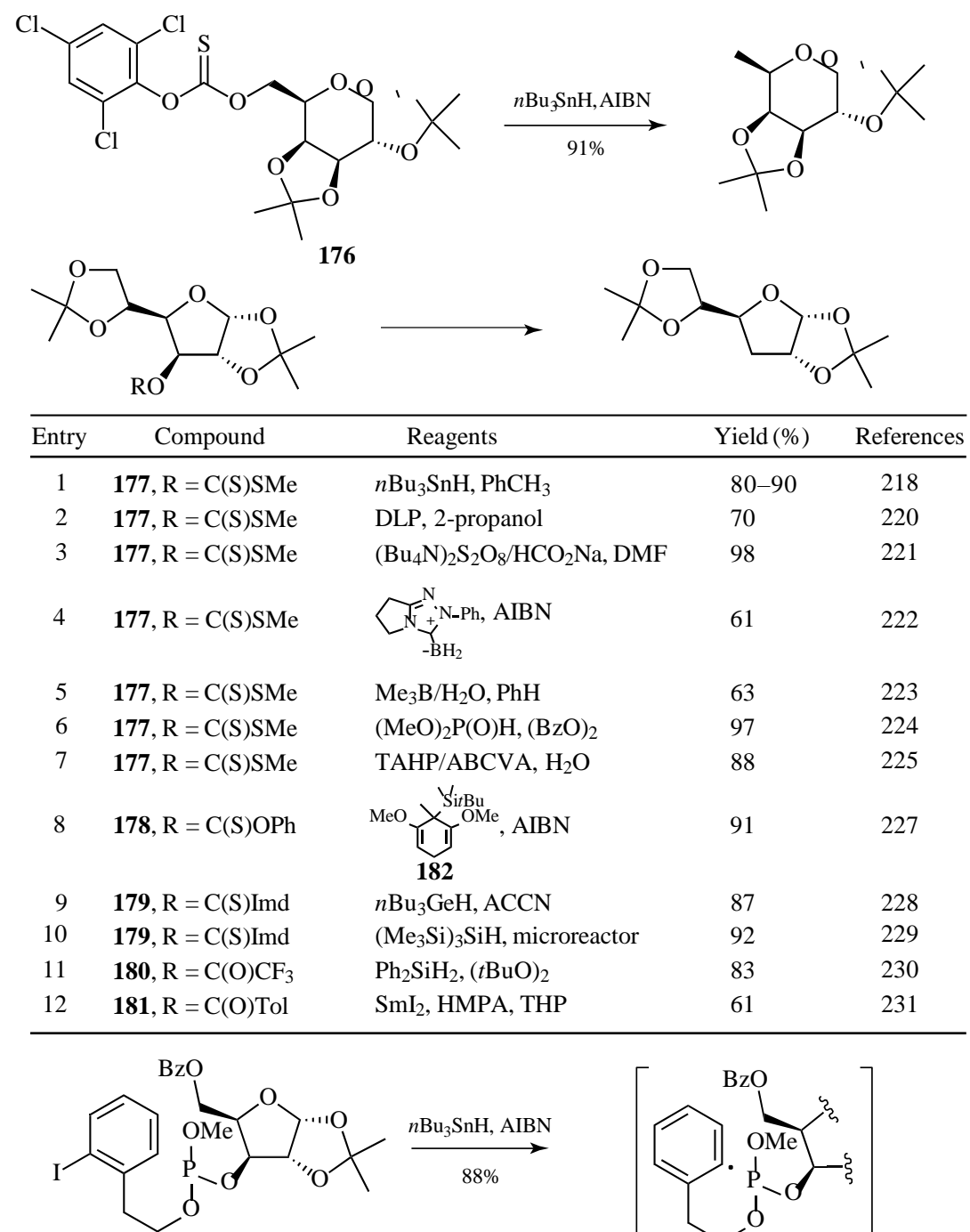

183

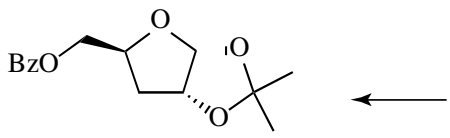

184

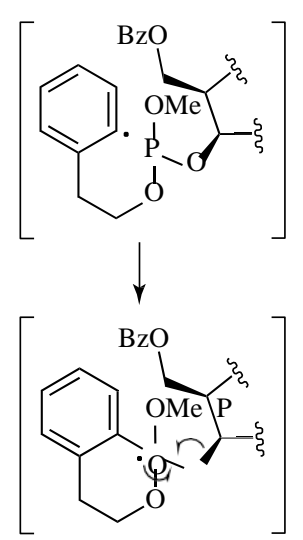

Scheme 25 Deoxygenation of non-anomeric alcohols. TAHP, tetraalkylammonium hypophosphite; ABCVA, 4,4j-azobis(4-cyanovalic acid); ACCN, 1, $1^{\mathrm{j}}$-azobis(cyclohexanecarbonitrile).

the unresolved difficulty of removing tin derivatives, extensive efforts have been focused in recent years in developing more environmentally benign and more easily handled alternatives, as shown for the substrates $\mathbf{1 7 7 - 1 8 1}$. For compara- tive purposes, the deoxygenation of xanthate $\mathbf{1 7 7}$ under the original Barton-McCombie conditions is included in Entry 1.218 Zard reported on a 
simple and efficient method by using 2-propanol as hydrogen-atom donor and DLP as radical initia- tor (Entry 2). ${ }^{220}$ Radicophilic cleavage of thiocar- bonyl derivatives has been studied by Kim using $\left(\mathrm{Bu}_{4} \mathrm{~N}\right)_{2} \mathrm{~S}_{2} \mathrm{O}_{8}$ and $\mathrm{HCO}_{2} \mathrm{Na}$ as a new alkyl radi- cal generator (Entry 3). ${ }^{221}$ In a more recent work, it has been discovered that complexes of boranes and $N$ heterocyclic carbenes are competent radical hydrogen-atom donors to achieve the deoxygenation of secondary xanthates in good yields (Entry 4). ${ }^{222}$ On other hand, Wood provided evidence that the trialkylborane/air system using water as the only hydrogen-atom source is capable of mediat- ing the deoxygenation of xanthate esters (Entry 5). ${ }^{223}$ The utility of hypophosphorous compounds as cheap and ecologically acceptable replacements for triorganostannanes was first demonstrated by Barton (Entry 6). ${ }^{224}$ Recent examples include aque- ous tetraalkylammonium hypophosphites (TAHPs) by Jang (Entry 7), ${ }^{225}$ and the use of dimethyl phosphite employed by Morvan. ${ }^{226}$ Several sily- lated 1,4cyclohexadienes have also been exam- ined as replacements for organotin compounds. ${ }^{227}$ The highly efficient deoxygenation of thiocarbon- ate 178 with silylated cyclohexadiene $\mathbf{1 8 2}$ provides a neat demonstration of the considerable synthetic potential of this methodology. Tributylgermanium hydride has also been described as a useful alternative to trialkyltin hydrides in radical reductions of thiocarbonylimidazolide 179 (Entry 9). ${ }^{228}$ A work from the Seeberger group in 2008 combines the use of TTMSS with a continuous-flow microreac- tor to perform deoxygenation of $\mathbf{1 7 9}$ (Entry 10) (see Radical Chemistry by Using Flow Microreactor Technology). ${ }^{229}$ This technique was also reported to be effective with iodinated sugars. Jang pro- posed an alternative method in which the deoxy- genation of trifluoroacetate derivative $\mathbf{1 8 0}$ is imple- mented efficiently with diphenylsilane (Entry 11). ${ }^{230}$ More recently, Marko' investigated the monoelec- tronic reduction of aromatic esters with $\mathrm{SmI}_{2}$, observing that the toluate moiety $\mathbf{1 8 1}$ could be a particularly useful function to achieve radical deoxygenations (Entry 12). ${ }^{231}$ Also in this field, Koreeda developed a highly versatile method for the deoxygenation of alcohols starting from phos- phites such as $\mathbf{1 8 3} .^{232}$ Initially, an aryl radical is generated that attacks the phosphorous atom to give a phosphoranyl radical, which promotes a favored

$\beta$-scission reaction producing the corresponding
$\mathrm{C}$ radical which should lead to the reduction product 184.

\section{CARBON-HETEROATOM BOND- FORMING PROCESSES}

\subsection{Carbon-Nitrogen Bond-Forming Processes}

Two basic approaches to the homolytic forma- tion of $\mathrm{C}-\mathrm{N}$ bond in carbohydrate systems are available: the amination of carbon-centered radi- cals, and the inter- or intramolecular addition of nitrogencentered radicals. Only a few procedures for the amination of $\mathrm{C}$ radicals in the carbohy- drate field have been reported. The first work used the photolysis of a cobaloxime intermediate in presence of nitrous oxide as an efficient radical trap. The nitroso compound tautomerized readily to an oxime, such as 185, which was subsequently reduced and acetylated to mannosamine $\mathbf{1 8 6}$ as a single stereoisomer (Scheme 26). ${ }^{233}$ Barton conve- niently used diazirines as carbon radical traps. ${ }^{234}$ The carbohydrate carbon-centered radical, pro- duced via radical exchange from the organotelluride 187, adds to 3-(trifluoromethyl)-3-phenyldiazirine, to furnish the imine $\mathbf{1 8 8}$ in good yield. More recently, Renaud reported a practical approach for the azidation of alkyl radicals using sul- fonyl azides as radical traps (see Unusual Radi- cal Acceptors). ${ }^{235}$ The process involves the reac- tion of anomeric dithiocarbonate 189 with ethane- sulfonylazide in the presence of DLP as radi- cal initiator: the anomeric azide $\mathbf{1 9 0}$ is obtained as a single $a$ ofighyerol\$, herstzielophedybseld mattiogn-Gonza'lez et al ., ${ }^{236}$ Czernecki and Randriamandimby, ${ }^{237}$ and Tingoli et al ., ${ }^{238}$ is a powerful heterogeneous procedure that allows the one-pot preparation of phenyl 2-azido-2-deoxy-selenoglycosides such as 191 and 192, regioselectively in high yield. This occurs when glycals are treated with (diacetoxyiodo)benzene (DIB), sodium azide, and diphenyl diselenide to generate an electrophilic azide radical which adds to the electron-rich double bond of the glycal. More recently, Nifantiev performed an improved homogeneous preparative method using trimethylsilyl azide allowing reduced reaction times and reliable scaleup. ${ }^{239}$ The reaction has also been extended to exo-glycals; thus d-gluco-hept-1-enitol 

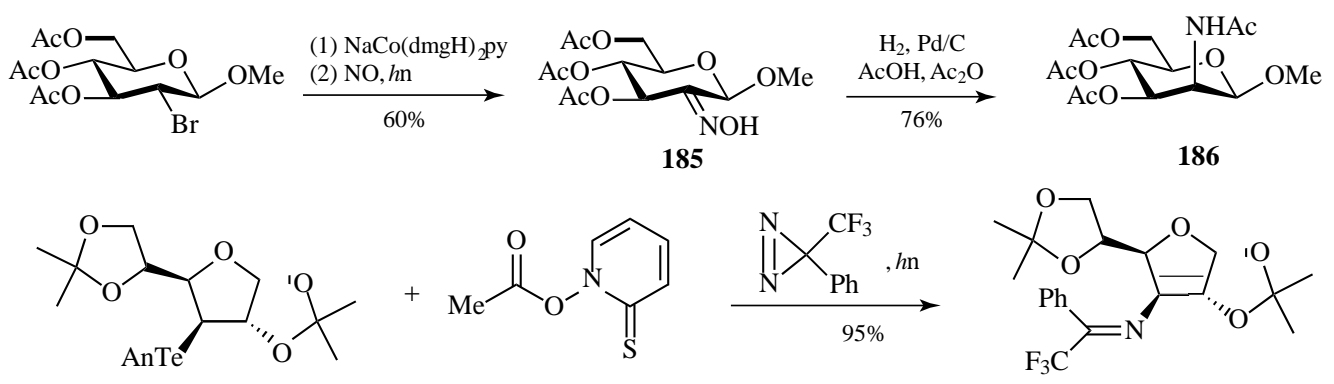

187

188
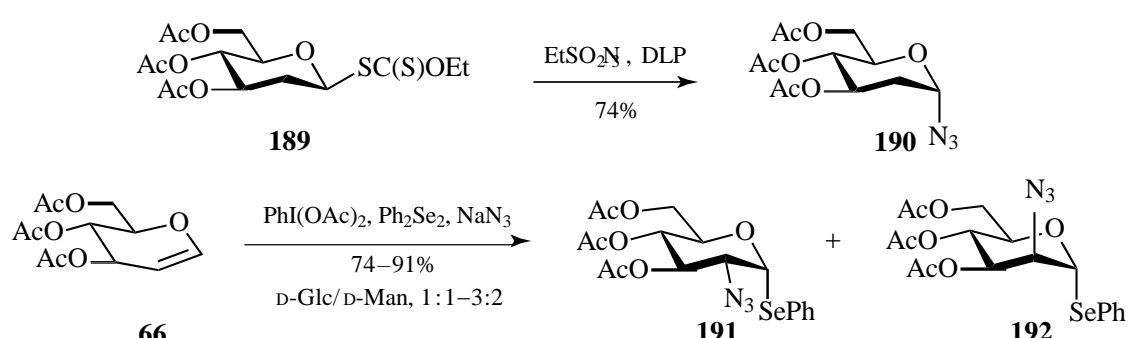

66

191

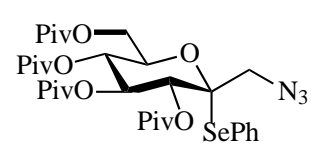

193

194
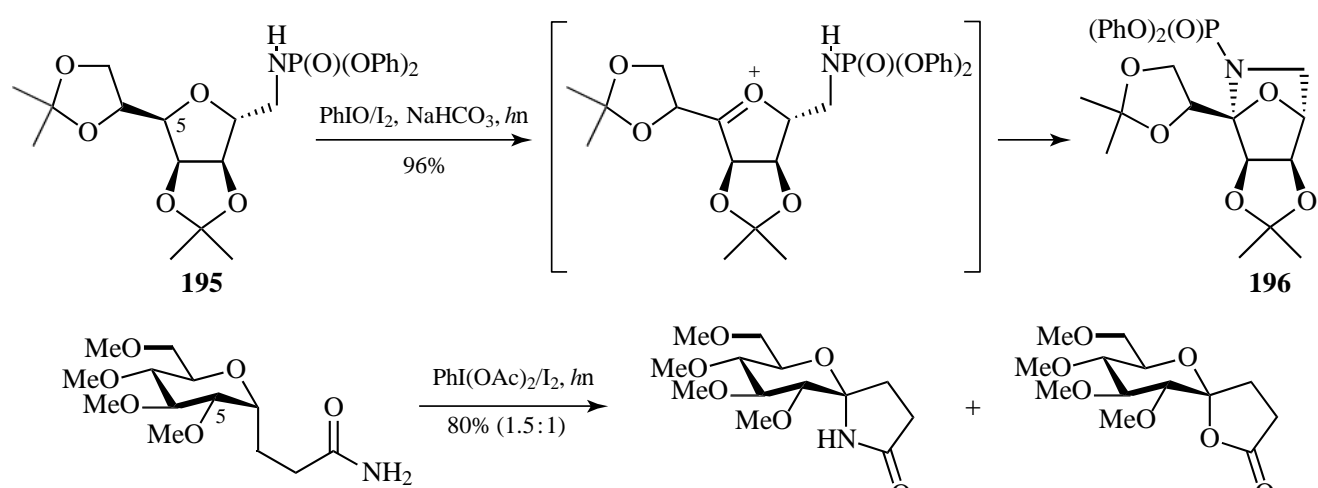

197
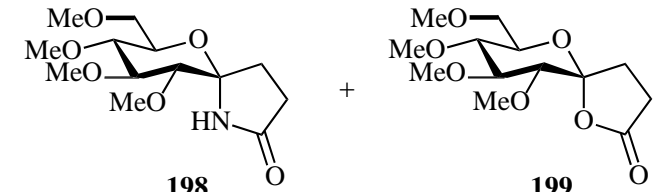

Scheme 26 Radical formation of carbon-nitrogen bonds. dmgH, dimethylglyoxime monoanion.

derivative 193 under the same conditions afforded $C$-glycoside 194 as a single diastereoisomer. ${ }^{77}$ The CAN-mediated azidonitration of glycals of Lemieux and Ratclife provides another efficient method for the introduction of the azide group at C-2.82 We have devoted some attention to the 1,5- or 1,6-HAT promoted by $\mathrm{N}$ radicals, report- ing the synthesis of different pyrrolidines and piperidines in carbohydrate systems. ${ }^{240-243}$ As a representative example, a suitably protected amine $\mathbf{1 9 5}^{240}$ reacts with hypervalent iodine reagents in the presence of iodine to generate an $\mathrm{N}$ radical, which triggers the 1,5-HAT reaction to give the 7-oxa-2azabicyclo[2.2.1]heptane system 196 after oneelectron oxidation and cyclization of the amine group onto the oxocarbenium ion intermediate. Next, this work was extended to the HAT promoted by amidyl radicals generated from 197 , showing that there is an $\mathrm{O}$ - and $\mathrm{N}$-ambident nucleophilic reactivity of the amide group. ${ }^{243}$ This reactivity 
depends on the electrophilicity of the oxocarbenium ion intermediate modulated by tuning the electron-withdrawing ability of the substituents at C-5 to trigger the reaction specifically to give spirolactams 198 or spirolactones 199.

\subsection{Carbon-Phosphorus Bond-Forming Processes}

The addition of phosphorus-centered radicals to olefins on a carbohydrate skeleton was first reported by Whistler in $1968 .{ }^{244}$ The photochem- ically initiated reaction of phenylphosphine with alkene 200 afforded, after oxidation under the reaction conditions, the phosphine oxide 201 (Scheme 27). $C$-Glycosides with difluoromethylene phosphonates and phosphonothioates as anomeric tethers such as 203 have been prepared by Mother- well ${ }^{245}$ starting from exo-glycal 202. The required phosphonyl or thiophosphonyl radicals were generated by $n \mathrm{Bu}_{3} \mathrm{SnH}$ reduction of diethyl(phenylselenenyl)phosphonate or diethyl(phenylselenenyl) thiophosphonate, respectively, using di-tert -butyl peroxide as initiator. Analogously, the radical addition of diethyl phosphite to a difluorinated exo-glycal closely related to 202 using tert butylperoxypivalate as initiator has been described by Sinay“. ${ }^{246}$ Addition of diethyl phosphite or diethyl thiophosphite, in the presence of the triethylborane $/ \mathrm{O}_{2}$ system, to the electron-rich enolether of tri- $O$-acetyl-d-glucal afforded adducts $204(X=O$ or $X=S$, respectively) with complete regio and diastereoselectivity. ${ }^{247}$ Phosphonyl radicals, generated under oxidative conditions from dimethyl phosphite and CAN, added efficiently to pentopyranose, hexopyranose, and disaccharide glycals. ${ }^{248}$ This strategy permitted the preparation of a variety of 2-deoxy-2-phosphonate derivatives, such as 205 and 206. The stereochemistry can be rationalized on the basis of steric interactions; the phosphonyl radical attacks preferentially anti to the substituent at C-3. Related applications of the CANmediated radical addition to glycals have been described in Section 2.4. ${ }^{81,82}$

\subsection{Carbon-Oxygen Bond-Forming Processes}

Intramolecular HAT promoted by alkoxyl radicals is one of the most interesting processes for the radical generation of $\mathrm{C}-\mathrm{O}$ bonds. However, it is
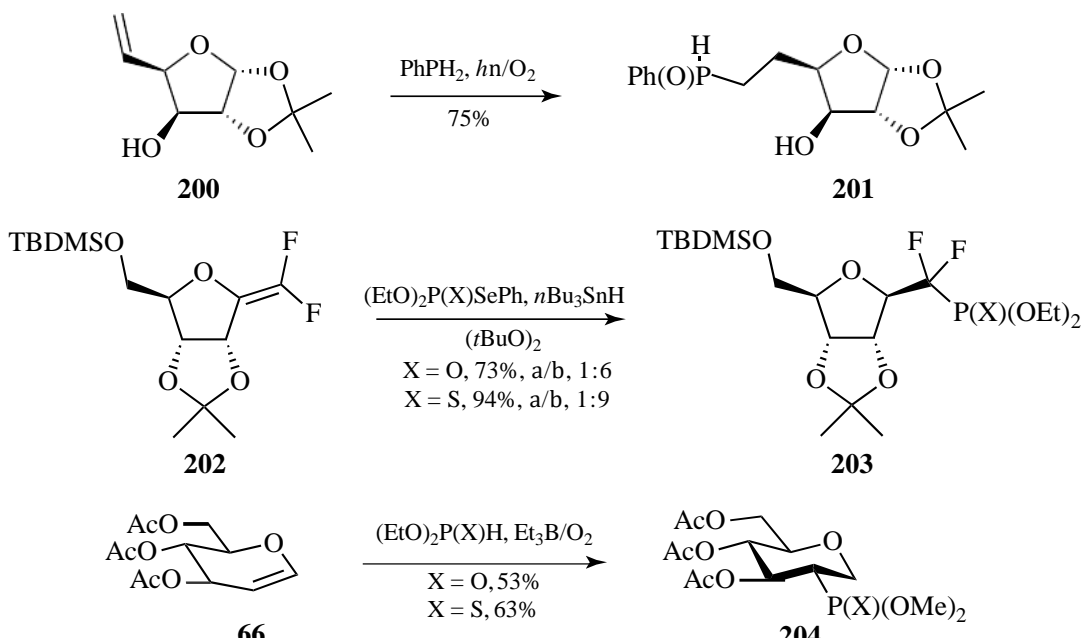

66

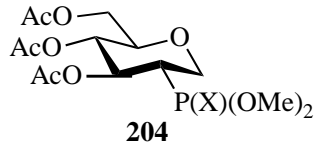

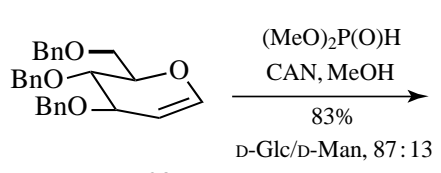

29

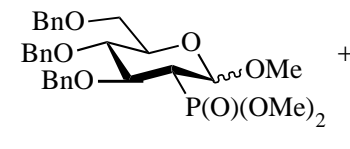

205

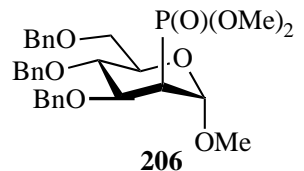

Scheme 27 Radical formation of carbon-phosphorus bonds. 

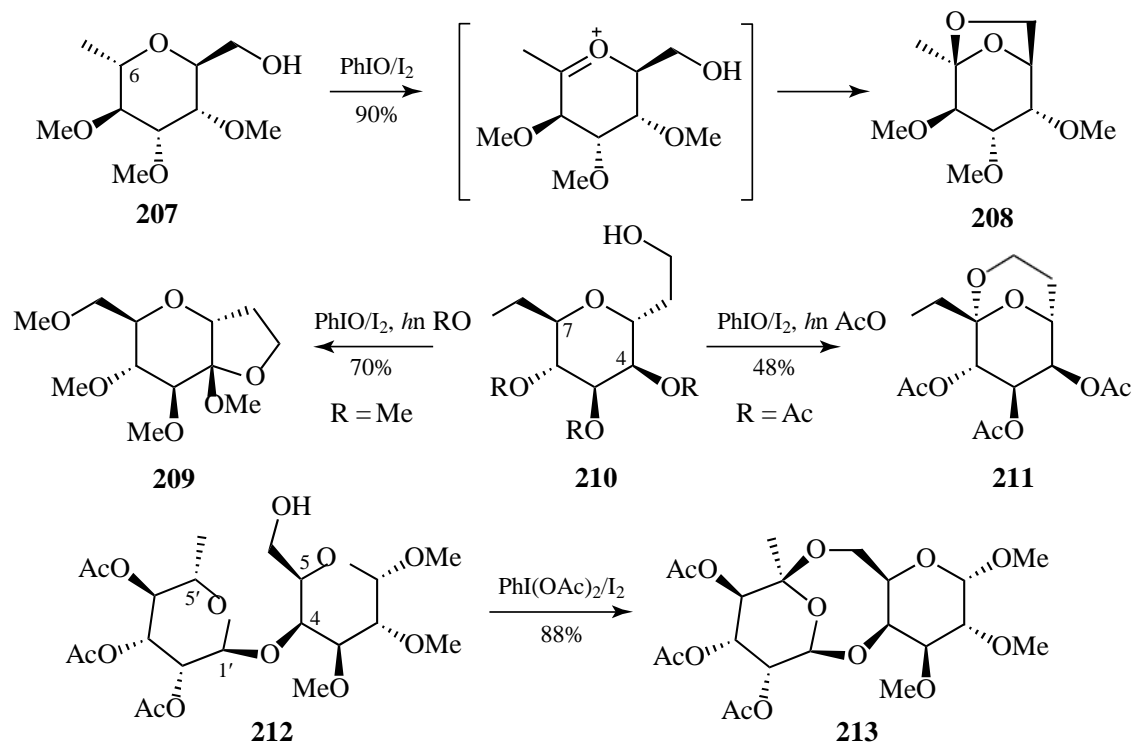

210

211
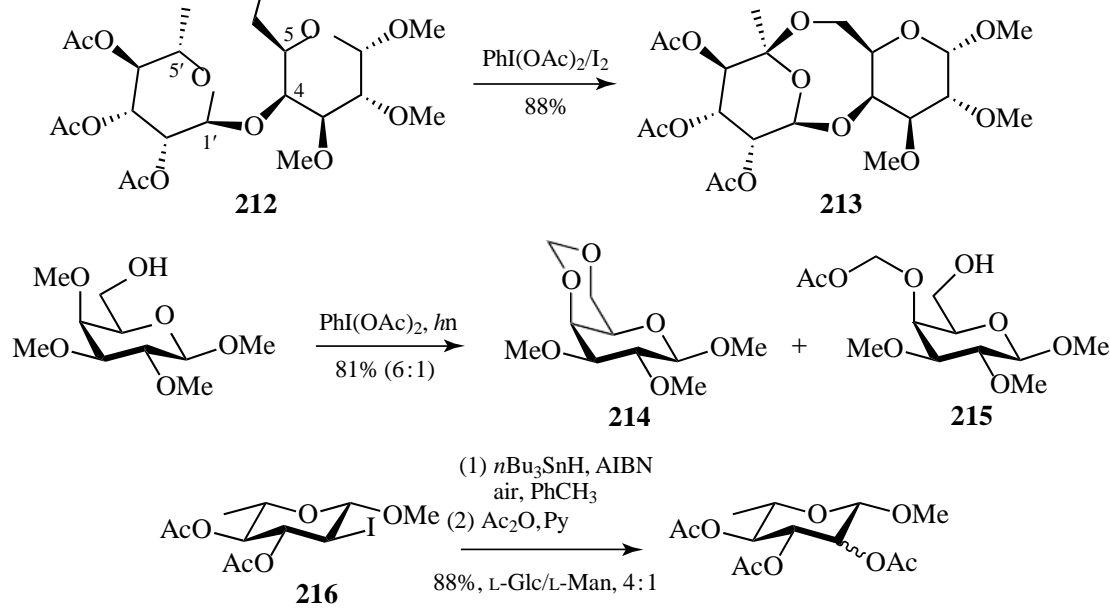

Scheme 28 Radical formation of carbon-oxygen bonds.

worth noting that the $\mathrm{C}-\mathrm{O}$ bond formation does not arise directly from the radical abstraction, but by a mixed method combining a radical HAT step and an ionic cyclization (see below). In carbohydrate chemistry, Descotes ${ }^{249}$ launched the application of this methodology to the synthesis of spiroorthoesters by cyclization of 2-hydroxyethyl glycosides using $\mathrm{HgO} / \mathrm{I}_{2}$ for the generation of the hypoiodite intermediate. We have prepared spiroacetals with 1,6-dioxaspiro[4.5]decane and 1,7dioxaspiro[5.5] undecane bicyclic structures by cyclization at the anomeric center of $C$-glycosides of the 4,8-anhydro-nonitol and 5,9-anhydro-decitol type, respectively, using hypervalent iodine compounds and iodine for the generation of the alkoxyl radicals. $^{250,251}$ Chatgilialoglu has also used this reagent for the preparation of anomeric spironucleotides. ${ }^{252}$ Apart from the anomeric center, some other positions of the carbohydrate skeleton have also been functionalized. For example, we have described that the alkoxyl radical generated from $C$-glycoside 207 abstracts exclusively the hydrogen atom at C-6 to give the 6,8-dioxabicyclo[3.2.1]octane $\mathbf{2 0 8}$ after oxidation of the radical to the oxocarbenium ion intermediate (Scheme 28) ${ }^{253}$ The reaction of $210(\mathrm{R}=\mathrm{Me})$, possessing a two-carbon tether at $\mathrm{C}-3$, abstracts the hydrogen atom at C-4 through a 1,5-HAT affording exclusively 209. Notwithstanding, the presence of an EWG at $\mathrm{C}-4$ as in $\mathbf{2 1 0}(\mathrm{R}=\mathrm{Ac})$ switches the reaction to a 1,6-HAT by abstraction of the C-7 hydrogen to give the 2,9-dioxabicyclo[3.3.1]nonane 211 with complete regioselectivity. ${ }^{254}$ Remote functionalization between the two pyranose units of a $(1 \rightarrow 4)$-disaccharide can also be achieved under these conditions. For instance, the reaction of alcohol 212 with the DIB/I $\mathrm{I}_{2}$ system afforded the 1,3,5-trioxocane derivative $\mathbf{2 1 3}$ through a 
rare 1,8-HAT in good yield. ${ }^{255}$ Taking advan- tage of the strict conformational requirements of the HAT TS, these reactions have been used for the selective deprotection of suitably posi- tioned benzyl ${ }^{256}$ and methyl ethers ${ }^{257}$ in the carbohydrate framework. The reaction of methyl 2,3,4-tri- $O$-methyl- $\beta$-dgalactoside to give a mix- ture of methylenedioxy acetal 214 and acetate 215, which can be subsequently hydrolyzed to methyl 2,3-di-O methyl- $\beta$-d-galactoside, is illustrative. Direct radical transformation of a carbon-halogen bond into a carbon-oxygen bond is possible with molecular oxygen, ${ }^{258}$ as depicted for iodine 216, or TEMPO (see Nitroxides in Synthetic Radical Chemistry). ${ }^{259}$

\subsection{Carbon-Sulfur/Selenium Bond-Forming Processes}

The radical addition of thiols to alkenes (thiol-ene coupling or TEC), known for more than a hundred years, ${ }^{260}$ has recently been considered to be a thioclick process (see Radical Thiol-X Click Chemistry). ${ }^{261,262}$ In the carbohydrate field, the addition of thiyl radicals to endo-glycals has also been known for some time. Igarashi and Honma ${ }^{263}$ reported that the reaction of thioacetic acid with tri$O$-acetyl-d-glucal proceeded with $\mathrm{C}$-2 addition of a thioacetyl radical to give a $7: 3$ ratio of $\mathrm{d}-\mathrm{Man} / \mathrm{d}-$ Glc diastereomers. When the reaction is performed with ethanethiol catalyzed by $\mathrm{CAN}$, a reverse addition at $\mathrm{C}-1$, which finally leads to

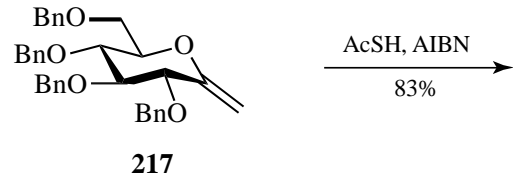<smiles>C=CCNC(=O)O</smiles>

219

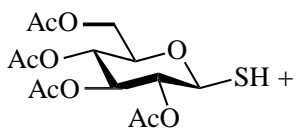

220

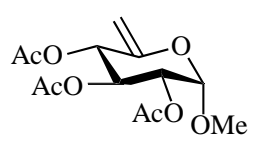

221
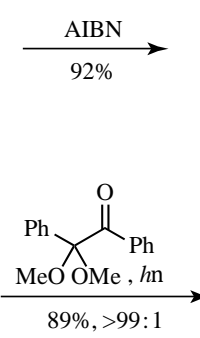

$89 \%,>99: 1$

$(20.90$
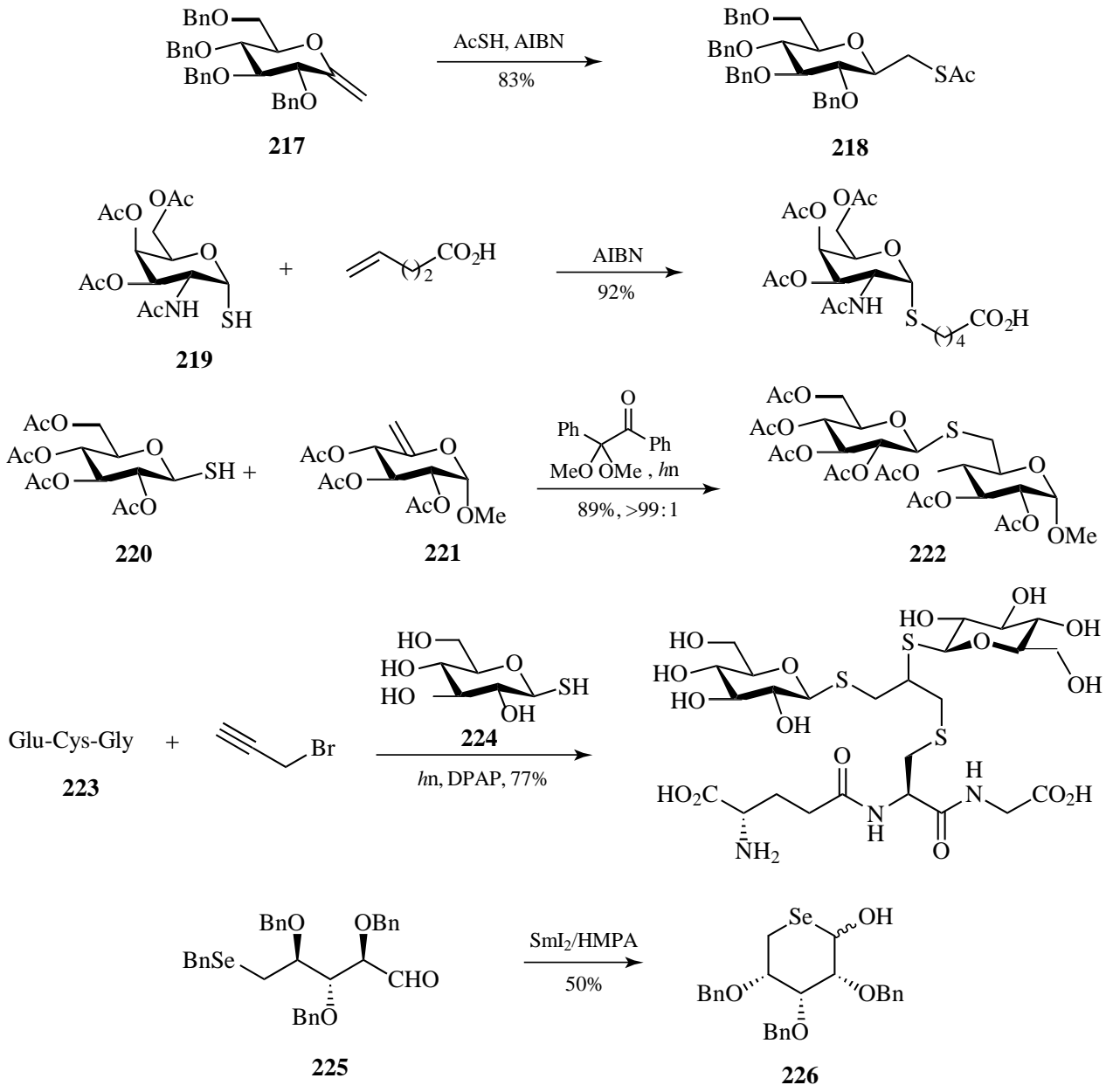

Scheme 29 Radical formation of carbon-sulfur and carbon-selenium bonds. DPAP, 2,2-dimethoxy-2-phenylacetophenone. 
2-deoxy-1-thioglycosides, has been observed. This last result seems to be more consistent with an oxocarbenium ion mechanism. ${ }^{264}$ The diastereoselective radical addition of thioacetic acid to exoglycals of d-Glcp 217 and l-Fucp has also been described (Scheme 29). ${ }^{265}$ In both cases, $\beta-C$ glycoside thioacetates, such as $\mathbf{2 1 8}$, are formed exclusively by axial radical quenching. A number of $a-d-G a l p N A c$ thioconjugates have been prepared by reaction of 1-thio- $a-\mathrm{d}-\mathrm{Gal} p$ NAc derivative 219 with different olefins using AIBN as the radical initiator. ${ }^{266}$ A new photoinduced coupling of glucosyl and mannosyl thiols with hex-5-enopyranosides and pent-4-enofuranosides to give thiodisaccharides has been developed by Dondoni. ${ }^{267}$ The TEC reaction of 1 -thio- $\beta$-d-glucopyranose derivative 220 with the sugar alkene 221 using 2,2dimethoxy-2-phenylacetophenone (DPAP) as photoinitiator to give 1,6-linked $S$-disaccharide 222 is a representative example. A natural extension of the TEC reaction is the radical-mediated hydrothiolation of terminal alkynes, which serves to introduce two thiol substituents across the triple bond. ${ }^{268}$ This methodology has been exploited by Dondoni ${ }^{269}$ for the double $S$-glycosylation of cysteine-containing peptides. The one-pot, two-step sequence comprises the selective $S$-propargylation of the cysteine unit 223 followed by photoinduced radical thiol-yne coupling of 1-thio-a-d-glucopyranose (224). 5-Deoxy5-seleno-d-ribopyranose derivative $\mathbf{2 2 6}$ can be formed from benzylseleno aldehyde 225 with $\mathrm{SmI}_{2}$, presumably via an intramolecular homolytic substitution. 270

\subsection{Carbon-Bromine Bond-Forming Processes}

The discovery that carbohydrate derivatives can be specifically brominated under free-radical conditions was made by Ferrier in 1977271,272 and the results obtained up to 1991 have been thoroughly reviewed by Somsa'k and Ferrier. ${ }^{273}$ In general, bromine, $N$ bromosuccinimide (NBS), or the $\mathrm{KBrO}_{3} / \mathrm{Na}_{2} \mathrm{~S}_{2} \mathrm{O}_{4}$ system are used as brominating agents, and the radical reactions are initiated with either irradiation with visible light, benzoyl peroxide, or AIBN. The reaction occurs preferentially at the C-1 or C-5 (C-4 in furanose systems) positions of the carbohydrate skeleton, and the regioselectivity depends largely on the

substituents at these positions. The reaction of the $1,2,3,4,6$-penta- $O$-benzoyl- $\beta$-d-glucopyranose (227) to give regio- and diastereoselectively the 5bromine derivative $\mathbf{2 2 8}$ is illustrative (Scheme 30). ${ }^{274}$ The bromination of methyl dglucopyranuronate has been studied in some detail, since the 5a-bromo derivative obtained is an intermediate in the synthesis of methyl a-1idopyranuronate, which is a constitutive fragment of heparine. ${ }^{275}$ The bromination of the $a$-isomer derivative 229 afforded regio- and stereoselectively the 5a-bromo derivative 230. Subsequently, free-radical reduction with $n \mathrm{Bu}_{3} \mathrm{SnH}$ gave a $3: 1$ ratio of 1-Ido 231/d-Glc 229 isomers. ${ }^{276,277}$ Interestingly, the reduction of the isomeric methyl 1,2,3,4-tetra- $O$-acetyl-5-bromo- $\beta$-dglucopyranuronate $(\beta$-isomer of 230) gave an inverted $1: 2$ ratio of the respective $1-I d o / d-G l c$ isomers. ${ }^{278}$ Cyclic $C$-glycosides with an elec- tron attractor group at the anomeric center $\left(\mathrm{CN}, \mathrm{CO}_{2} \mathrm{R}\right.$, or $\mathrm{CONH}_{2}$ ) give regioselective bromina- tion at this position, via a captodative stabilized radical. ${ }^{279}$ This situation is similar to that encoun- tered at C-5 of the pyranuronates mentioned earlier. This methodology has been exploited by Somsa' $\mathrm{k}^{280,281}$ in the highly efficient bromination of 2,6-anhydroaldonic acid derivatives $\mathbf{2 3 2}$ and

233. An excellent example of the importance of the captodative effect in the regioselectivity is the bromination of the disaccharide 234; directed by the carboxyl group, the substitution occurs exclusively at $\mathrm{C}-5$ of the glucuronate moiety. ${ }^{282}$

The bromination of 2,5-anhydro-3,4,6-tri- $O$ benzoyl-d-allonamide (235) was used by Harrington and Jung ${ }^{283}$ as a key step in the synthesis of (+)hydantocidin 236. During the synthesis of a

number of analogs of hydantocidin, Fleet ${ }^{284}$ have also applied this bromination of $C$-glycofuranosides to 2,5-anhydro-1-talonic acid derivatives.

\section{$6 \beta$-FRAGMENTATION PROCESSES PROMOTED BY ALKOXYL RADICALS}

The alkoxyl radical fragmentation (ARF) involves the reversible homolytic cleavage of a $\sigma \mathrm{C}-\mathrm{C}$ bond located on the sugar template $\alpha, \beta$ to an $\mathrm{O}$ radical giving rise to a carbon-centered radical and a $\mathrm{C}-\mathrm{O}$ double bond. The conditions that have been employed most frequently in the $\beta$-fragmentation reaction in carbohydrates may be broadly classified into two types: oxidative and reductive methods. ${ }^{285}$ 


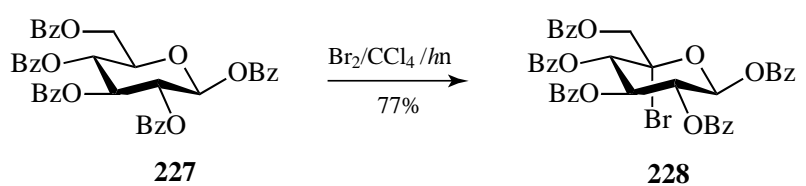

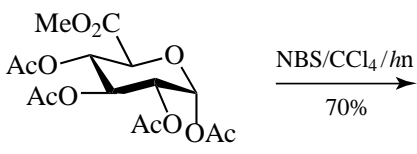

229

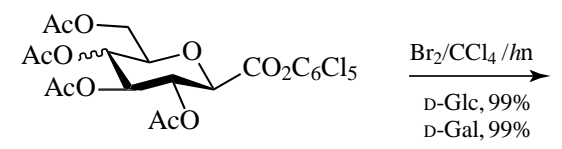

232

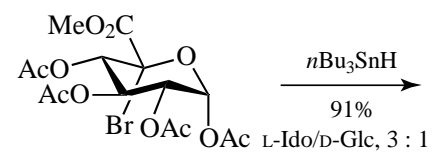

230

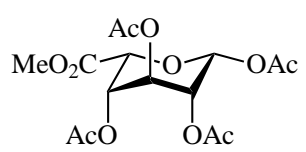

231
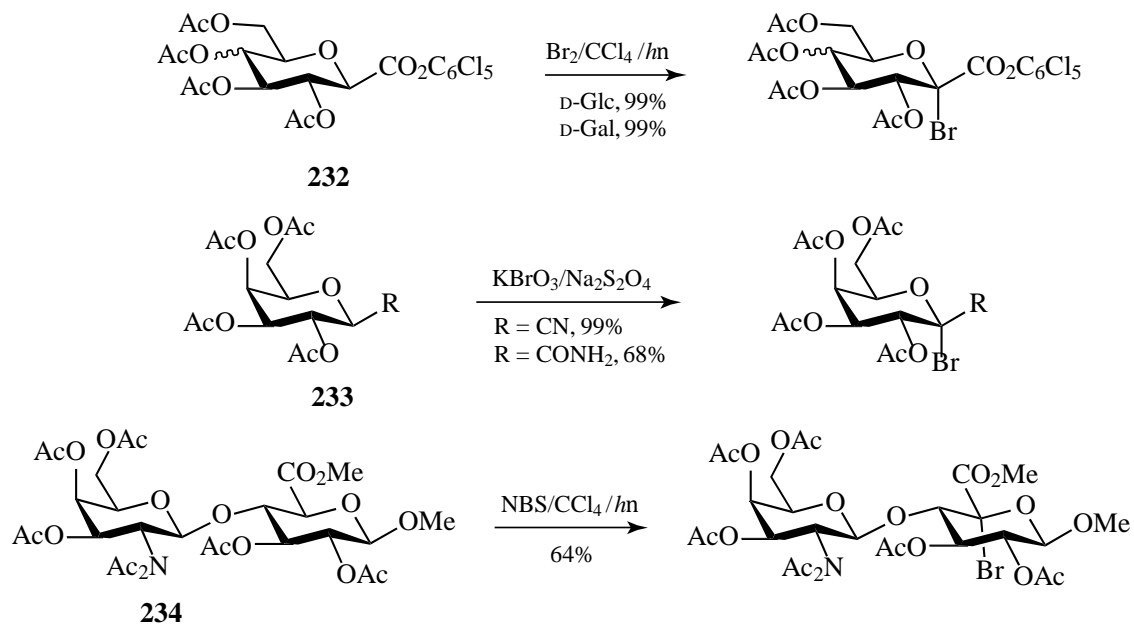

234
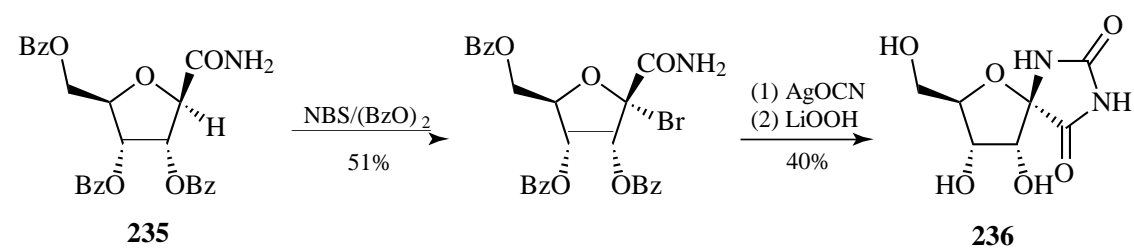

Scheme 30 Radical bromination of sugars.

\subsection{Fragmentation of Alkoxyl Radicals under Oxidative Conditions}

The formation of anomeric alkoxyl radicals and its fragmentation reaction proceed smoothly in high yields using hypervalent iodine compounds, especially DIB, and iodine via the corresponding hypoiodite intermediates. In this process, the equilibrium is strongly displaced to the acyclic $\mathrm{C}$ radical, the anomeric carbon is transformed into a formate group, and the sugar is degraded to a lower member of the aldose series of carbohydrates. Using an electron-donor protecting group at C-2 (e.g., ether, isopropylidene), oxidation of the $\mathrm{C}$ radical to an oxocarbenium ion intermediate $\mathbf{I}$ is favored, which may be trapped intermolecularly by an acetate anion from the medium to give a mixed acetyl acetal (Scheme 31). Nevertheless, the presence of an electron-withdrawing group at C-2 (e.g., ester, carbonate, halogen, 2-deoxy carbohydrate) decreases the electron density at this position, disfavoring the oxidation and allowing the competitive trapping of the $\mathrm{C}$ radical II by an iodine atom. ${ }^{286,287}$ For instance, the methylether 237 gave the acetyl product 238, whereas the benzoyl ester $\mathbf{2 3 9}$ afforded the iodide $\mathbf{2 4 0}$ in good yields. Inanaga applied this procedure to give the corresponding mixed-acetal formates which were further converted to furanose derivatives by acid-catalyzed transacetalization. ${ }^{288} \mathrm{We}$ have 
o<smiles>[R10]O[C@H]1C2OCC([R20])C2O[C@@H]1O</smiles>

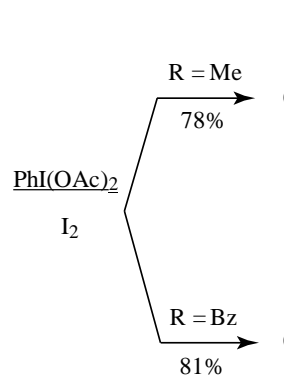<smiles>COC=CC1OC(O)C(OC)C1OC(=O)O</smiles>

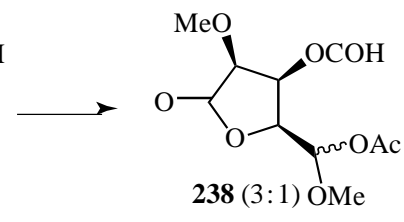

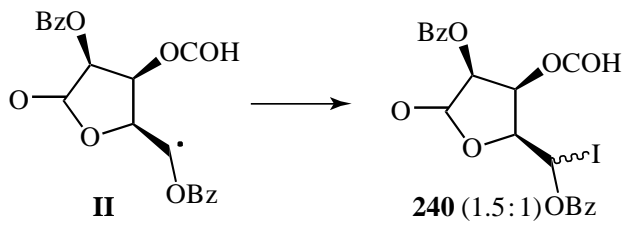<smiles>COC[C@H]1O[C@@H](O)[C@H]2OC(C)(C)O[C@@H]21</smiles><smiles>COc1ncc(C)c(OC)n1</smiles><smiles>COC[C@H](C(=O)O)C12CCC(n3cc(C)c(=O)[nH]c3=O)(OC1)C2=O</smiles>

241

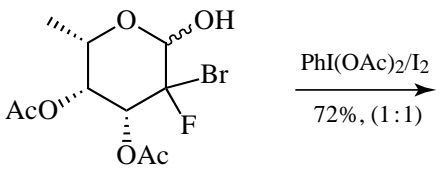

TBDMSO

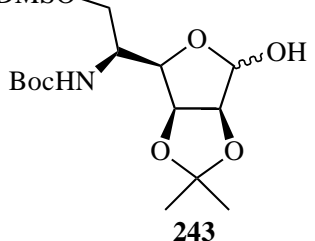

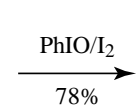

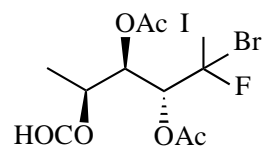

242

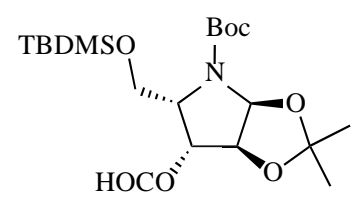<smiles>CC(=O)OC[C@@H](C(=O)O)[C@@H](OC(=O)O)[C@H](N)CI</smiles>

245<smiles>C=C(N)C(OC(C)=O)C(COC(C)=O)C(=O)O</smiles>

246<smiles>CC1(C)OC2C(COCc3ccccc3)O[C@H](O)[C@H](N)C2O1</smiles>

Scheme $31 \beta$-Fragmentation of alkoxyl radicals under oxidative conditions.

demonstrated that both inter- and intramolecular trapping of the oxocarbenium ion intermediate are possible. In the intermolecular approach, besides the acetate anion coming from the reagent, other proper nucleophiles could be added to the reaction medium, such as the thymine base shown in Scheme 31 for the synthesis of the acyclic nucleoside analog 241. ${ }^{289,290}$ In recent years, we have extended this tactic to the synthesis of chiral 1,1-dihaloalditols and 1,1,1-trihaloalditols by ARF of 2-halo- or 2,2dihalo-carbohydrate anomeric alcohols, as described for the synthesis of $\mathbf{2 4 2 .}{ }^{291,292}$ On the 
other hand, the intramolecular trapping requires suitably positioned nucleophiles in the carbohydrate precursor structure. Some of these internal nucleophiles could be hydroxyl groups, ${ }^{293,294}$ for preparing specific furanose or pyranose forms of aldotetroses and aldopentoses; carboxyl groups ${ }^{295}$ giving aldo-pyranosuronic or furanosuronic acid lactones; or amine groups such as $\mathbf{2 4 3},{ }^{296}$ which are particularly interesting since imino sugars could be obtained in high yields. Starting from 3-azido-2,3dideoxy-hexopyranose compounds 244 , we had the opportunity to synthesize chiral $\beta$-iodoazides 245 in good yields, which by subsequent base treatment afforded vinyl azides 246. ${ }^{297}$ Analogously, the corresponding vinyl sulfones could be prepared from the oxidative fragmentation of 2,3-dideoxy- 3phenylsulfonyl-hexopyranoses. ${ }^{298}$ We also reported on an extension of the ARF methodology to 2-azido-2-deoxyaldoses to lead to aldononitriles such as 247 by oxidation to the a-azido cation which delivers nitriles upon loss of nitrogen. ${ }^{299}$

\subsection{Fragmentation of Alkoxyl Radicals under Reductive Conditions}

The required glycopyran-1- $O$-yl or glycofuran- 1-O -yl radicals were generated by reaction of anomeric nitrate esters such as $\mathbf{2 4 8}$ or $N$-phthalimide glycosides with $n \mathrm{Bu}_{3} \mathrm{SnH}$ and $\mathrm{AIBN}$ giving the corresponding alditols with one carbon less (Scheme 32). ${ }^{300}$ Recently, Hartung highlighted the efficiency of alkoxyl radical formation from 5-substituted and unsubstituted

3-alkoxy-4-methylthiazole-2(3H)-thiones under reductive conditions. ${ }^{301} \mathrm{We}$ further extended our methodology to sequential ARF-intermolecular allylation starting from $N$-phthalimide derivatives and using allyltributylstannane as radical trap to give a range of 1,2,3-trideoxyhept-1-enitol deriva- tives such as 249. ${ }^{302}$ Concerning non-anomeric $O$ adicals, Binkley and Koholic, who discovered nitrate esters as good sources of alkoxyl radicals, described the conversion of 3-nitro-d-allofuranose

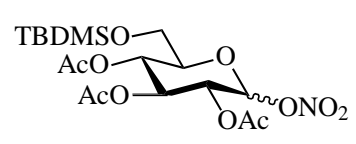

248
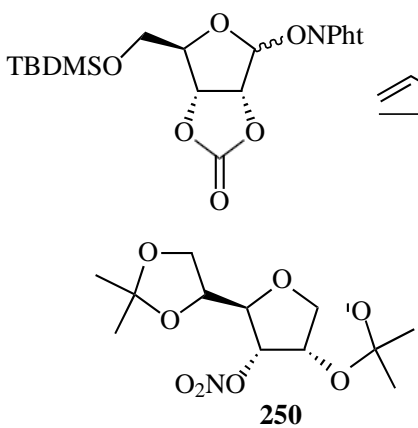

250
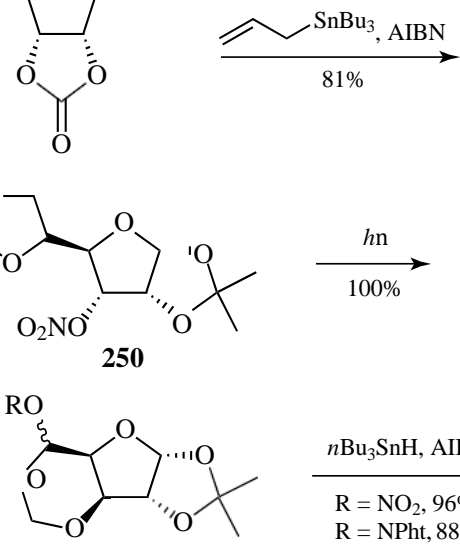

251

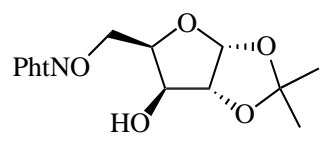

252
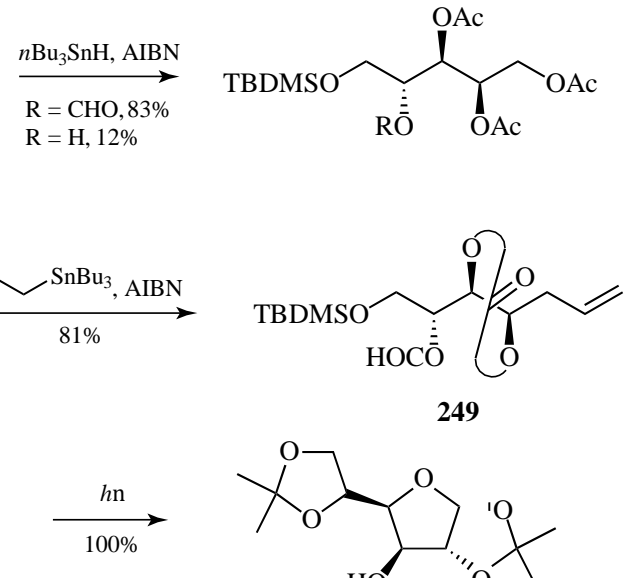

249
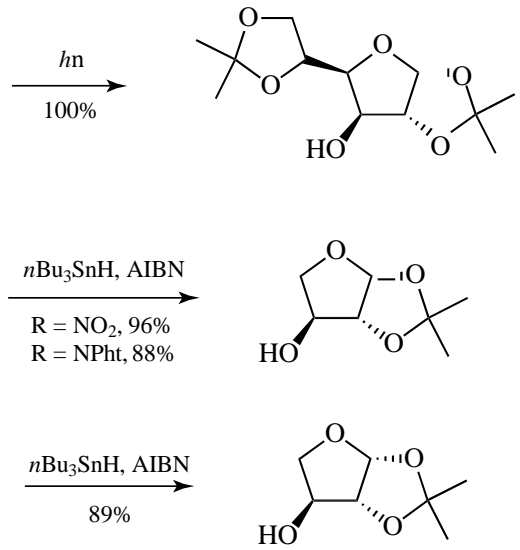

Scheme $32 \beta$-Fragmentation of alkoxyl radicals under reductive conditions. 
250 into the inverted alcohol by a radical $\beta$-fragmentation-recyclization reaction as shown in Scheme 32.303 In our laboratory, a simple synthesis of 1-threose by the ARF of nitrate ester and $N$-phthalimide derivatives of readily available hemiacetal $251(\mathrm{R}=\mathrm{H})$ has been developed. ${ }^{300}$

Along this line, Sa'nchez et al . reported the $\beta$ fragmentation of primary alkoxyl radicals from their corresponding $N$-phthalimide derivative 252, highlighting that an internal hydrogen bond seemed to be the driving force for such a reaction. ${ }^{304}$

\section{CONCLUSIONS}

The selected examples provided in this article have hopefully demonstrated the importance of freeradical reactions in carbohydrate chemistry. The neutral reaction conditions, functional group tolerance, and experimental simplicity make these procedures highly attractive for selective transformations in this field. The predictable stereoselectivity of hexopyranos-1-yl radical reactions suggests that this may be a method of choice for the diastereoselective carbon-carbon bond formation at the anomeric center of carbohydrates. Radical chemistry provides also convenient methods for the synthesis of polyfunctionalized carbocycles by radical cyclization of acyclic carbohydrate precursors and for the introduction of heteroatoms into the sugar ring. Finally, the remote intramolecular functionalization via HAT from alkoxyl radicals and the $\beta$ fragmentation of anomeric alkoxyl radicals offer interesting new perspectives, allowing the preparation of structures that would otherwise be very difficult to synthesize.

\section{ACKNOWLEDGMENTS}

We would like to thank all those who have participated in the work realized in this group at La Laguna whose names appear in the references below.

\section{REFERENCES}

1. A. J. Pearce, J.-M. Mallet, and P. Sinay", Radicals in carbohydrate chemistry, in Radicals in Organic Synthesis, eds. P. Renaud and M. Sibi, Wiley-VCH Verlag GmbH, Weinheim, 2001, vol. 2, pp. 538-577.
2. R. J. Ferrier and J. O. Hoberg, Adv. Carbohydr. Chem. Biochem., 2003, 58, 55-119.

3. C. Taillefumier and Y. Chapleur, Chem. Rev., 2004, 104, 263-292.

4. S. G. Hansen and T. Skrydstrup, Top. Curr. Chem., 2006, 264, 135-162.

5. D. E. Levy and P. Fügedi, eds., The Organic Chemistry of Sugars, CRC Taylor \& Francis, Boca Raton, FL, 2006.

6. O. Arjona, A. M. Go'mez, J. C. Lo'pez, and J. Plumet, Chem. Rev., 2007, 107, 1919-2036.

7. B. Fraser-Reid and J. C. Lo'pez, Curr. Org. Chem., 2009, 13, 532-553.

8. B. Giese, Angew. Chem. Int. Ed. Engl., 1989, 28,969-980.

9. D. P. Curran, N. A. Porter, and B. Giese, Stereochemistry of Radical Reactions, Wiley-VCH Verlag GmbH, Weinheim, 1996, pp. 131-135.

10. B. Giese and H.-G. Zeitz, C-Glycosyl Compounds from Free Radical Reactions, in Preparative Carbohydrate Chemistry, ed. S. Hanessian, Marcel Dekker, New York, 1997, pp. 507-525.

11. J. Dupuis, B. Giese, D. Ru"egge, et al ., Angew. Chem. Int. Ed. Engl., 1984, 23, 896-898.

12. H. G. Korth, R. Sustmann, J. Dupuis, and B. Giese, J. Chem. Soc., Perkin Trans. 2 , 1986, 1453-1459.

13. A. L. J. Beckwith and P. J. Duggan, Tetrahedron, 1998, 54, 4623-4632.

14. J.-P. Praly, Adv. Carbohydr. Chem. Biochem., 2001, 56, 65-151.

15. B. Giese, J. Dupuis, M. Leising, et al ., Carbohydr. Res., 1987, 171,329-341.

16. B. Giese and J. Dupuis, Angew. Chem. Int. Ed. Engl., 1983, 22, 622-623.

17. G. E. Keck and J. B. Yates, J. Am. Chem. Soc., 1982, 104, 5829-5831.

18. B. Giese, Radicals in Organic Synthesis: Formation of Carbon-Carbon Bonds, Pergamon Press, Oxford, 1986.

19. G. E. Keck, E. J. Enholm, J. B. Yates, and M. R. Wiley, Tetrahedron, 1985, 41, 4079-4094.

20. J. L. Marco-Contelles, C. Ferna'ndez, A. Go'mez, and N. Mart'in-Leo'n, Tetrahedron Lett., 1990, 31, 1467-1470.

21. J. Cui and D. Horton, Carbohydr. Res., 1998, 309, 319330.

22. B. A. Roe, C. G. Boojamra, J. L. Griggs, and C. R. Bertozzi, J. Org. Chem., 1996, 61, 6442-6445.

23. C. Lamberth and S. Blarer, Synth. Commun., 1996, 26, 7581.

24. H. Paulsen and P. Matschulat, Liebigs Ann. Chem., 1991, 487-495.

25. J. O. Nagy and M. D. Bednarski, Tetrahedron Lett., 1991, 32, 3953-3956.

26. T. Waglund and A. Claesson, Acta Chem. Scand., 1992, 46, 73-76.

27. J.-P. Praly, G.-R. Chen, J. Gola, and G. Hetzer, Eur. J. Org. Chem., 2000, 2831-2838.

28. F. W. Lichtenthaler, M. Lergenmu" "ler, and S. Schwidetzky, Eur. J. Org. Chem., 2003, 3094-3103.

29. H. Abe, S. Shuto, and A. Matsuda, J. Am. Chem. Soc., 2001, 123, 11870-11882.

30. F. Ponte'n and G. Magnusson, J. Org. Chem., 1996, 61, 7463-7466.

31. S. Caddick, D. Hamza, D. B. Judd, et al ., Tetrahedron Lett., 2004, 45, 2363-2366. 
32. C. G. Francisco, C. C. Gonza'lez, A. J. Herrera, et al ., Tetrahedron Lett., 2006, 47, 9057-9060.

33. W.-j. Chung, G.-H. Jeon, J.-Y. Yoon, and S. Kim, Bull. Korean Chem. Soc., 2002, 23,1187-1188.

34. Y. Guindon, M. Bencheqroun, and A. Bouzide, J. Am. Chem. Soc., 2005, 127, 554-558.

35. R. SanMartin, B. Tavassoli, K. E. Walsh, et al ., Org. Lett., 2000, 2, 4051-4054.

36. L. Grant, Y. Liu, K. E. Walsh, et al ., Org. Lett., 2002, 4, 4623-4625.

37. D. H. R. Barton and M. Ramesh, J. Am. Chem. Soc., 1990, 112, 891-892.

38. S. Yamago, H. Miyazoe, and J.-i. Yoshida, Tetrahedron Lett., 1999, 40, 2343-2346.

39. S. Yamago, H. Miyazoe, R. Goto, et al., J. Am. Chem. Soc., 2001, 123,3697-3705.

40. W. He, H. Togo, Y. Waki, and M. Yokoyama, J. Chem. Soc., Perkin Trans. 1 , 1998, 2425-2433.

41. R. P. Spencer and J. Schwartz, J. Org. Chem., 1997, 62, 4204-4205.

42. R. P. Spencer and J. Schwartz, Tetrahedron, 2000, 56, 2103-2112.

43. S. K. Readman, S. P. Marsden, and A. Hodgson, Synlett, 2000, 1628-1630.

44. H. Gong, R. S. Andrews, J. L. Zuccarello, et al ., Org. Lett., 2009, 11,879-882.

45. H. Gong and M. R. Gagne', J. Am. Chem. Soc., 2008, 130, 12177-12183.

46. R. S. Andrews, J. J. Becker, and M. R. Gagne', Angew. Chem. Int. Ed., 2010, 49,7274-7476.

47. Z. Juha'sz, K. Micskei, E. Ga'1, and L. Somsa'k, Tetrahedron Lett., 2007, 48, 7351-7353.

48. J. D. Parrish and R. D. Little, Org. Lett., 2002, 4, 14391442.

49. P. de Pouilly, A. Che'nede', J.-M. Mallet, and P. Sinay", Bull. Soc. Chim. Fr., 1993, 130, 256-265.

50. P. de Pouilly, A. Che'nede', J.-M. Mallet, and P. Sinay", Tetrahedron Lett., 1992, 33, 8065-8068.

51. D. Maze'as, T. Skrydstrup, and J.-M. Beau, Angew. Chem. Int. Ed. Engl., 1995, 34,909-912.

52. T. Skrydstrup, O. Jarreton, D. Maze'as, et al ., Chem.-Eur. J., 1998, 4, 655-671.

53. N. Miquel, G. Doisneau, and J.-M. Beau, Angew. Chem. Int. Ed., 2000, 39, 4111-4114.

54. S.-C. Hung and C.-H. Wong, Angew. Chem. Int. Ed. Engl., 1996, 35, 2671-2674.

55. J. L. Chiara and E. Sesmilo, Angew. Chem. Int. Ed., 2002 , 41, 3242-3246.

56. T. F. Herpin, W. B. Motherwell, and M. J. Tozer, Tetrahedron: Asymmetry, 1994, 5, 2269-2282.

57. A. Wegert, R. Miethchen, M. Hein, and H. Reinke, Synthesis, 2005, 1850-1858.

58. B. Moreno, C. Quehen, M. Rose-He'lène, et al ., Org. Lett., 2007, 9, 2477-2480.

59. B. Giese and T. Witzel, Angew. Chem. Int. Ed. Engl., 1986, 25, 450-451.

60. B. Giese, M. Hoch, C. Lamberth, and R. R. Schmidt, Tetrahedron Lett., 1988, 29, 1375-1378.

61. C. Pasquarello, S. Picasso, R. Demange, et al ., J. Org. Chem., 2000, 65, 4251-4260.

62. Z. J. Witczak, R. Chhabra, and J. Chojnacki, Tetrahedron Lett., 1997, 38, 2215-2218.
63. O. Jarreton, T. Skrydstrup, J.-F. Espinosa, et al ., Chem.-Eur. J., 1999, 5, 430-441.

64. L. M. Mikkelsen, S. L. Krintel, J. Jime'nez-Barbero, and T. Skrydstrup, J. Org. Chem., 2002, 67, 6297-6308.

65. L. M. Mikkelsen and T. Skrydstrup, J. Org. Chem., 2003 , 68, 2123-2128.

66. L. Andersen, L. M. Mikkelsen, J.-M. Beau, and T. Skrydstrup, Synlett, 1998, 1393-1395.

67. S. Palmier, B. Vauzeilles, and J.-M. Beau, Org. Biomol. Chem., 2003, 1, 1097-1098

68. A. Malapelle, Z. Abdallah, G. Doisneau, and J.-M. Beau, Angew. Chem. Int. Ed., 2006, 45, 6016-6020.

69. A. Malapelle, Z. Abdallah, G. Doisneau, and J.-M. Beau, Heterocycles, 2009, 77, 1417-1424.

70. Z. Abdallah, G. Doisneau, and J.-M. Beau, Angew. Chem. Int. Ed., 2003, 42, 5209-5212.

71. I. R. Vlahov, P. I. Vlahova, and R. J. Linhardt, J. Am. Chem. Soc., 1997, 119, 1480-1481.

72. M. Koketsu, B. Kuberan, and R. J. Linhardt, Org. Lett., 2000, 2, 3361-3363.

73. E. I. Leo'n, A. Mart'in, I. Pere'z-Mart'in, et al ., Eur. J. Org. Chem., 2010, 5248-5262.

74. J. Dupuis, B. Giese, J. Hartung, et al ., J. Am. Chem. Soc., $1985, \mathbf{1 0 7}, 4332-4333$.

75. G.-R. Chen, Z. B. Fei, X.-T. Huang, et al ., Eur. J. Org. Chem., 2001, 2939-2946.

76. Y. Liu and T. Gallagher, Org. Lett., 2004, 6, 2445-2448.

77. H. Woodward, N. Smith, and T. Gallagher, Synlett, 2010, 869-872.

78. T. Polat, Y. Du, and R. J. Linhardt, Synlett , 1998, 11951196.

79. Y. Du and R. J. Linhardt, Carbohydr. Res., 1998, 308, 161-164.

80. A. Malapelle, A. Coslovi, G. Doisneau, and J.-M. Beau, Eur. J. Org. Chem., 2007, 3145-3157.

81. J. Yin, T. Sommermann, and T. Linker, Chem.-Eur. J., 2007, 13, 10152-10167.

82. R. U. Lemieux and R. M. Ratcliffe, Can. J. Chem., 1979, 57, 1244-1251.

83. Z. Benko, B. Fraser-Reid, P. S. Mariano, and A. L. J. Beckwith, J. Org. Chem., 1988, 53, 2066-2072, references cited therein

84. J. Mann and A. C. Weymouth-Wilson, J. Chem. Soc. Perkin Trans. 1 , 1994,3141-3148.

85. M. H. D. Postema, J. L. Piper, L. Liu, et al ., J. Org. Chem., $2003,68,4748-4754$.

86. D. Benito, M. I. Matheu, A. More're, et al ., Carbohydr Res., 2009, 344, 2559-2567.

87. A. Cordero-Vargas, B. Quiclet-Sire, and S. Z. Zard, Tetrahedron Lett., 2004, 45, 7335-7338.

88. J. E. Baldwin, J. Chem. Soc., Chem. Commun., 1976, 734 736.

89. A. L. J. Beckwith and C. H. Schiesser, Tetrahedron, 1985 , 41, 3925-3941.

90. A. L. J. Beckwith, Tetrahedron, 1981, 37, 3073-3100.

91. M. Julia, Acc. Chem. Res., 1971, 4, 386-392.

92. C. H. Schiesser and M. A. Skidmore, Calculations: a useful tool for synthetic chemists, in Radicals in Organic Synthesis, eds. P. Renaud and M. Sibi, Wiley-VCH Verlag GmbH, Weinheim, 2001, vol. 1, 337-359.

93. K. S. Gröninger, K. F. Jäger, and B. Giese, Liebigs Ann. Chem., 1987, 731-732. 
94. A. De Mesmaeker, A. Waldner, P. Hoffmann, et al., Synlett, 1992, 285-290.

95. S. Czernecki, E. Ayadi, and J. Xie, Tetrahedron Lett., 1996, 37, 9193-9194.

96. A. De Mesmaeker, P. Hoffmann, B. Ernst, et al ., Tetrahedron Lett., 1989, 30, 6311-6314.

97. G. Stork, H. S. Suh, and G. Kim, J. Am. Chem. Soc., 1991, 113, 7054-7056.

98. T. Skrydstrup, D. Maze'as, M. Elmouchir, et al ., Chem.-Eur. J., 1997, 3, 1342-1356.

99. Y. C. Xin, J. M. Mallet, and P. Sinay", J. Chem. Soc., Chem. Commun., 1993, 864-865.

100. A. Mallet, J.-M. Mallet, and P. Sinay", Tetrahedron: Asymmetry, 1994, 5, 2593-2608.

101. A. Helmboldt, J.-M. Mallet, M. Petitou, and P. Sinay", Bull. Soc. Chim. Fr., 1997, 134,1057-1067.

102. E. D. Rekä1, G. Rubinstenn, J.-M. Mallet, et al ., Synlett, 1998, 831-833.

103. J. Kovensky, D. Burrieza, V. Colliou, et al ., J. Carbohydr. Chem., 2000, 19, 1-12.

104. G. Rubinstein, J.-M. Mallet, and P. Sinay", Tetrahedron Lett., 1998, 39, 3697-3700.

105. B. Vauzeilles and P. Sinay", Tetrahedron Lett., 2001, 42, 7269-7272.

106. H. Abe, S. Shuto, and A. Matsuda, J. Org. Chem., 2000, 65, 4315-4325.

107. A. Che'nede',E. Perrin, E. D. Rekä1, and P. Sinay", Synlett, 1994, 420-422.

108. D. Maze'as, T. Skrydstrup, O. Doumeix, and J.-M. Beau, Angew. Chem. Int. Ed. Engl., 1994, 33, 1383-1386.

109. A. Mart'in, I. Pe'rez-Mart'in, L. M. Quintanal, and E. Sua'rez, Tetrahedron Lett., 2008, 49, 5179-5181.

110. A. J. Herrera, M. Rondo'n, and E. Sua'rez, J. Org. Chem., 2008, 73, 3384-3391.

111. C. Lesueur, R. Nouguier, M. P. Bertrand, et al ., Tetrahedron, 1994, 50, 5369-5380, references cited therein.

112. N. Moufid, Y. Chapleur, and P. Mayon, J. Chem. Soc., Perkin Trans. 1, 1992,991-998.

113. J. C. Lo'pez, A. M. Go'mez, and B. Fraser-Reid, J. Org. Chem., 1995, 60, 3871-3878.

114. N. Moufid, Y. Chapleur, and P. Mayon, J. Chem. Soc., Perkin Trans. 1, 1992,999-1007.

115. D. R. Kelly and M. R. Picton, J. Chem. Soc., Perkin Trans. 1, 2000, 1559-1569.

116. J. M. Bueno, J. M. Cotero'n, J. L. Chiara, et al ., Tetrahedron Lett., 2000, 41, 4379-4382.

117. H. Nishiyama, T. Kitajima, M. Matsumoto, and K. Itoh, J. Org. Chem., 1984, 49, 2298-2300.

118. G. Stork and M. J. Sofia, J. Am. Chem. Soc., 1986, 108, 6826-6828

119. V. Pedretti, J.-M. Mallet, and P. Sinay", Carbohydr. Res., 1993, 244, 247-257.

120. K. Augustyns, J. Rozenski, A. Van Aerschot, et al ., Tetrahedron, 1994, 50, 1189-1198.

121. R. J. Ferrier and P. M. Petersen, Tetrahedron, 1990, 46, 111.

122. A. M. Go'mez, J. C. Lo'pez, and B. Fraser-Reid, J. Org. Chem., 1995, 60, 3859-3870.

123. D. R. Kelly and M. R. Picton, J. Chem. Soc., Perkin Trans. 1, 2000, 1571-1586.

124. C. Audin, J.-M. Lancelin, and J.-M. Beau, Tetrahedron Lett., 1988, 29, 3691-3694.
125. A. De Mesmaeker, P. Hoffmann, and B. Ernst, Tetrahedron Lett., 1989, 30, 57-60.

126. O. Yamazaki, K. Yamaguchi, M. Yokoyama, and H. Togo, J. Org. Chem., 2000, 65,5440-5442.

127. H. M. R. Hoffmann, U. Herden, M. Breithor, and O. Rhode, Tetrahedron, 1997, 53, 8383-8400.

128. S. W. T. Choe and M. E. Jung, Carbohydr. Res., 2000, 329, 731-744.

129. G. V. M. Sharma and T. Gopinath, Tetrahedron Lett., 2005, 46, 1307-1309.

130. H. Hashimoto, K. Furuichi, and T. Miwa, J. Chem. Soc., Chem. Commun., 1987, 1002-1003.

131. K. J. Henry Jr, and B. Fraser-Reid, J. Org. Chem., 1994, 59, 5128-5129.

132. J. Xu, Y. Liu, C. Dupouy, and J. Chattopadhyaya, J. Org. Chem., 2009, 74, 6534-6554.

133. Z. Xi, J. Rong, and J. Chattopadhyaya, Tetrahedron, 1994, 50, 5255-5272.

134. S. Shuto, M. Kanazaki, S. Ichikawa, et al ., J. Org. Chem., 1998, 63, 746-754.

135. P. Mayon and Y. Chapleur, Tetrahedron Lett., 1994, 35, 3703-3706.

136. Y. Chapleur, ed., Carbohydrate Mimics: Concepts and Methods, Wiley-VCH Verlag $\mathrm{GmbH}$, Weinheim, New York, 1998.

137. B. Fraser-Reid and R. Tsang, Carbocycles from carbohydrates: the "Annulated Sugar" approach, in Strategies and Tactics in Organic Synthesis, ed. T. Lindberg, Academic Press, New York, 1989, vol. 2, pp. 123-162.

138. R. J. Ferrier, Chem. Rev., 1993, 93, 2779-2831.

139. T. V. RajanBabu, Functionalized carbocyclic deriva- tives from carbohydrates: free radical and organometal- lic methods, in Preparative Carbohydrate Chemistry, ed. S. Hanessian, Marcel Dekker, New York, 1997, 545-568.

140. A. Mart'inez-Grau and J. Marco-Contelles, Chem. Soc. Rev., 1998, 27, 155-162.

141. C. S. Wilcox and L. M. Thomasco, J. Org. Chem., 1985, 50, 546-547.

142. M. Matsugi, K. Gotanda, C. Ohira, et al ., J. Org. Chem., 1999, 64, 6928-6930.

143. S. M. Roberts and K. A. Shoberu, J. Chem. Soc., Perkin Trans. 1, 1992,2625-2632.

144. M. Bøjstrup, M. Fanefjord, and I. Lundt, Org. Biomol. Chem., 2007, 5, 3164-3171.

145. G. Fourrière, J. Lalot, N. V. Hijfte, et al ., Tetrahedron Lett., 2009, 50, 7048-7050.

146. T. V. RajanBabu, T. Fukunaga, and G. S. Reddy, J. Am. Chem. Soc., 1989, 111, 1759-1769.

147. P. A. Bartlett, K. L. McLaren, and P. C. Ting, J. Am. Chem. Soc., 1988, 110, 1633-1634.

148. For a recent review of the chemistry of aminocyclitols see: A. Delgado, Eur. J. Org. Chem., 2008, 3893-3906, and references cited therein.

149. S. Hanessian and R. Le'ger, J. Am. Chem. Soc., 1992, 114, 3115-3117.

150. J. Marco-Contelles and M. Rodr' 1guez-Ferna'ndez, $C$. $R$. Acad. Sci. Paris, Chim., 2001, 4, 443-452.

151. J.-C. Malanda and A. Doutheau, J. Carbohydr. Chem., 1993, 12,999-1016.

152. E. J. Enholm and A. Trivellas, J. Am. Chem. Soc., 1989, 111, 6463-6465. 
153. J. J. C. Grove', C. W. Holzapfel, and D. B. G. Williams, Tetrahedron Lett., 1996, 37, 1305-1308.

154. T. Kan, S. Nara, T. Ozawa, et al ., Angew. Chem. Int. Ed., 2000, 39, 355-357.

155. Z. Zhou and S. M. Bennett, Tetrahedron Lett., 1997, 38, 1153-1156.

156. A. Che'nede', P. Pothier, M. Sollogoub, et al ., J. Chem Soc., Chem. Commun., 1995, 1373-1374.

157. D. J. Jenkins and B. V. L. Potter, J. Chem. Soc., Perkin Trans. 1, 1998,41-50.

158. M. Adinolfi, G. Barone, A. Iadonisi, and L. Mangoni, Tetrahedron Lett., 1998, 39, 2021-2024.

159. Y. Ble'riot, E. Untersteller, B. Fritz, and P. Sinay", Chem.-Eur. J., 2002, 8, 240-246.

160. A. Boiron, P. Zillig, D. Faber, and B. Giese, J. Org. Chem., 1998, 63, 5877-5882.

161. I. S. de Gracia, H. Dietrich, S. Bobo, and J. L. Chiara, J. Org. Chem., 1998, 63,5883-5889.

162. S. Bobo, I. S. de Gracia, and J. L. Chiara, Synlett, 1999, $1551-1554$.

163. J. L. Chiara and A. Garc'ia, Synlett , 2005, 2607-2610, and references cited therein.

164. D. H. R. Barton, S. D. Gero, P. Holliday, and B. Quiclet-Sire, Tetrahedron, 1996, 52, 8233-8244.

165. J. De'sire' and J. Prandi, Eur. J. Org. Chem., 2000, 30753084.

166. J. K. Gallos, C. C. Dellios, and E. E. Spata, Eur. J. Org. Chem., 2001, 79-82.

167. J. L. Chiara, S. Bobo, and E. Sesmilo, Synthesis, 2008, 3160-3166.

168. D. Álvarez-Dorta, E. I. Leo'n, A. R. Kennedy, et al., Angew. Chem. Int. Ed., 2008, 47, 8917-8919.

169. F. O. Andersson, B. Classon, and B. Samuelsson, J. Org. Chem., 1990, 55, 4699-4704.

170. W. Schmid and G. M. Whitesides, J. Am. Chem. Soc., 1990, 112, 9670-9671.

171. H. Redlich, W. Sudau, A. K. Szardenings, and R. Vollerthun, Carbohydr. Res., 1992, 226, 57-78.

172. J. Marco-Contelles, C. Pozuelo, and E. de Opazo, Carbohydr. Res., 2001, 332, 341-349.

173. J. Marco-Contelles, C. Pozuelo, M. L. Jimeno, et al., J. Org. Chem., 1992, 57, 2625-2631.

174. S. H. Wagner and I. Lundt, J. Chem. Soc., Perkin Trans. 1 , 2001, 780-788.

175. J. S. Yadav, A. Maiti, A. R. Sankar, and A. C. Kunwar, J. Org. Chem., 2001, 66,8370-8378.

176. R. E. McDevitt and B. Fraser-Reid, J. Org. Chem., 1994, 59, 3250-3252.

177. E. Maudru, G. Singh, and R. H. Wightman, Chem. Commun., 1998, 1505-1506.

178. A. M. Go'mez, M. D. Company, C. Uriel, et al ., Tetrahedron Lett., 2007, 48, 1645-1649.

179. J. L. Chiara and M. Mart'in-Lomas, Tetrahedron Lett., 1994, 35, 2969-2972.

180. J. P. Guidot, T. Le Gall, and C. Mioskowski, Tetrahedron Lett., 1994, 35, 6671-6672.

181. G. Luchetti, K. Ding, A. Kornienko, and M. d'Alarcao, Synthesis, 2008,3148-3154.

182. T. Kan, S. Hosokawa, S. Nara, et al ., J. Org. Chem., 2004, 69, 8956-8958.

183. D. B. G. Williams, J. Caddy, and K. Blann, Carbohydr. Res., 2005, 340, 1301-1309.
184. D. B. G. Williams, J. Caddy, K. Blann, et al ., Synthesis, 2009, 2009-2014.

185. J. Marco-Contelles and E. de Opazo, J. Org. Chem., 2002, 67, 3705-3717.

186. J. Auge' and S. David, Carbohydr. Res., 1977, 59, 255-257.

187. P. Kocienski and C. Pant, Carbohydr. Res., 1982, 110, 330-332.

188. A. Alberti, S. Bertini, M. Comoli, et al., Tetrahedron, 2000, 56, 6291-6297.

189. A. Scha"fer, D. Henkensmeier, L. Kro"ger, and J. Thiem, Tetrahedron: Asymmetry, 2009, 20, 902-909.

190. O. Yamazaki, H. Togo, and M. Yokoyama, J. Chem. Soc., Perkin Trans. 1 , 1999, 2891-2896.

191. H. Abe, M. Terauchi, A. Matsuda, and S. Shuto, J. Org. Chem., 2003, 68, 7439-7447.

192. H. Togo, S. Matsubayashi, O. Yamazaki, and M. Yokoyama, J. Org. Chem., 2000, 65, 2816-2819.

193. S. Yamago and A. Matsumoto, J. Org. Chem., 2008, 73, 7300-7304.

194. C. Chatgilialoglu, Chem.-Eur. J., 2008, 14, 2310-2320.

195. D. Leca, L. Fensterbank, E. Laco`te, and M. Malacria, Chem. Soc. Rev., 2005, 34, 858-865.

196. R. M. Lo'pez, D. S. Hays, and G. C. Fu, J. Am. Chem. Soc., 1997, 119,6949-6950.

197. M. R. Medeiros, L. S. Schacherer, D. A. Spiegel, and J. L. Wood, Org. Lett., 2007, 9, 4427-4429.

198. J.-P. Praly, Tetrahedron Lett., 1983, 24, 3075-3078.

199. B. Giese and J. Dupuis, Tetrahedron Lett., 1984, 25, 1349 1352.

200. D. Kahne, D. Yang, J. J. Lim, et al., J. Am. Chem. Soc., 1988, 110, 8716-8717.

201. D. Crich, J.-T. Hwang, and H. Yuan, J. Org. Chem., 1996, 61, 6189-6198.

202. D. Crich and T. Ritchie, J. Chem. Soc., Perkin Trans. 1 , 1990, 945-954.

203. P. Garner, J. T. Anderson, S. Dey, et al., J. Org. Chem., 1998, 63, 5732-5733.

204. R. Ravishankar, A. Surolia, M. Vijayan, et al ., J. Am. Chem. Soc., 1998, 120, 11297-11303.

205. N. Yamazaki, E. Eichenberger, and D. P. Curran, Tetrahedron Lett., 1994, 35, 6623-6626.

206. D. Crich, S. Sun, and J. Brunckova, J. Org. Chem., 1996, 61, 605-615.

207. A. Mart'in, L. M. Quintanal, and E. Sua'rez, Tetrahedron Lett., 2007, 48, 5507-5511.

208. A. Mart'in, I. Pe'rez-Mart'in,L. M. Quintanal, and E. Sua'rez, J. Org. Chem., 2008, 73, 7710-7720.

209. D. Crich, Radical rearrangements of esters, in Radicals in Organic Synthesis, eds P. Renaud and M. Sibi, Wiley-VCH Verlag GmbH, Weinheim, 2001, vol. 2, pp. 188-206.

210. A. L. J. Beckwith, D. Crich, P. J. Duggan, and Q. Yao, Chem. Rev., 1997, 97, 3273-3312.

211. B. Giese, K. S. Gröninger, T. Witzel, et al ., Angew. Chem. Int. Ed. Engl., 1987, 26,233-234.

212. H.-G. Korth, R. Sustmann, K. S. Gro"ninger, et al ., J. Org. Chem., 1988, 53, 4364-4369.

213. B. Giese, B. Kopping, and C. Chatgilialoglu, Tetrahedron Lett., 1989, 30, 681-684.

214. B. Quiclet-Sire and S. Z. Zard, J. Am. Chem. Soc., 1996, 118, 9190-9191. 
215. D. Crich and Q. Yao, J. Am. Chem. Soc., 1993, 115, 1165 1166.

216. A. Koch, C. Lamberth, F. Wetterich, and B. Giese, J. Org. Chem., 1993, 58, 1083-1089.

217. D. H. R. Barton, J. A. Ferreira, and J. C. Jaszberenyi, Free radical deoxygenation of thiocarbonyl derivatives of alcohol, in Preparative Carbohydrate Chemistry, ed. S. Hanessian, Marcel Dekker, New York, 1997, pp. 151-172.

218. D. H. R. Barton and S. W. McCombie, J. Chem. Soc., Perkin Trans. 1 , 1975, 1574-1585.

219. D. H. R. Barton, P. Blundell, J. Dorchak, et al., Tetrahedron, 1991, 47, 8969-8984.

220. B. Quiclet-Sire and S. Z. Zard, Tetrahedron Lett., 1998, 39, 9435-9438.

221. H. S. Park, H. Y. Lee, and Y. H. Kim, Org. Lett., 2005, 7, 3187-3190.

222. S.-H. Ueng, M. M. Brahmi, E. Derat, et al., J. Am. Chem. Soc., 2008, 130, 10082-10083.

223. D. A. Spiegel, K. B. Wiberg, L. N. Schacherer, et al ., J. Am. Chem. Soc., 2005, 127, 12513-12515.

224. D. H. R. Barton, D. O. Jang, and J. C. Jaszberenyi, J. Org. Chem., 1993, 58, 6838-6842.

225. D. H. Cho and D. O. Jang, Tetrahedron Lett., 2005,46, 1799-1802.

226. I. Zlatev, J.-J. Vasseur, and F. Morvan, Tetrahedron Lett., 2008, 49, 3288-3290.

227. A. Studer, S. Amrein, F. Schleth, et al ., J. Am. Chem. Soc., 2003, 125,5726-5733.

228. W. R. Bowman, S. L. Krintel, and M. B. Schilling, Org. Biomol. Chem., 2004, 2, 585-592.

229. A. Odedra, K. Geyer, T. Gustafsson, et al ., Chem. Commun., 2008,3025-3027.

230. D. O. Jang, J. Kim, D. H. Cho, and C.-M. Chung, Tetrahedron Lett., 2001, 42, 1073-1075.

231. K. Lam and I. E. Marko',Tetrahedron, 2009, 65, 10930 10940.

232. L. Zhang and M. Koreeda, J. Am. Chem. Soc., 2004, 126, 13190-13191.

233. A. Veit and B. Giese, Synlett, 1990, 166-166.

234. D. H. R. Barton, J. C. Jaszberenyi, E. A. Theodorakis, and J. H. Reibenspies, J. Am. Chem. Soc., 1993, 115, 80508059.

235. C. Ollivier and P. Renaud, J. Am. Chem. Soc., 2001, 123, 4717-4727.

236. F. Santoyo-Gonza'lez, F. G. Calvo-Flores, P. Garc'iaMendoza, et al., J. Org. Chem., 1993, 58, 6122-6125.

237. S. Czernecki and D. Randriamandimby, Tetrahedron Lett., 1993, 34, 7915-7916.

238. M. Tingoli, M. Tiecco, L. Testaferri, and A. Temperini, J. Chem. Soc., Chem. Commun., 1994, 1883-1884.

239. Y. V. Mironov, A. A. Sherman, and N. E. Nifantiev, Tetrahedron Lett., 2004, 45, 9107-9110.

240. C. G. Francisco, A. J. Herrera, and E. Sua'rez, J. Org. Chem., 2003, 68, 1012-1017.

241. C. G. Francisco, A. J. Herrera, A. Mart'in, et al ., Tetrahedron Lett., 2007, 48, 6384-6388.

242. A. Mart'in, I. Pe'rez-Mart'in, and E. Sua'rez,Tetrahedron, 2009, 65, 6147-6155.

243. A. Mart'in, I. Pe'rez-Mart' in, and E. Sua'rez, Org. Lett., 2005, 7, 2027-2030
244. R. L. Whistler, C.-C. Wang, and S. Inokawa, J. Org.Chem., 1968, 33, 2495-2497.

245. T. F. Herpin, W. B. Motherwell, B. P. Roberts, et al ., Tetrahedron, 1997, 53, 15085-15100.

246. J. Kovensky, M. McNeil, and P. Sinay", J. Org. Chem., 1999, 64, 6202-6205.

247. C. M. Jessop, A. F. Parsons, A. Routledge, and D. J. Irvine, Tetrahedron Lett., 2004, 45, 5095-5098.

248. E. Elamparuthi and T. Linker, Angew. Chem. Int. Ed., 2009, 48, 1853-1855.

249. G. Descotes, J. Carbohydr. Chem., 1988, 7, 1-20.

250. A. Mart'in, J. A. Salazar, and E. Sua'rez, J. Org. Chem. 1996, 61,3999-4006.

251. R. L. Dorta, A. Mart'in, J. A. Salazar, et al ., Tetrahedron Lett., 1996, 37, 6021-6042.

252. C. Chatgilialoglu, T. Giminis, and G. P. Spada, Chem.-Eur. J., 1999, 5, 2866-2876.

253. C. G. Francisco, A. J. Herrera, and E. Sua'rez, J. Org. Chem., 2002, 67, 7439-7445.

254. C. G. Francisco, R. Freire, A. J. Herrera, et al ., Org. Lett., 2002, 4, 1959-1961.

255. C. G. Francisco, A. J. Herrera, A. R. Kennedy, et al ., Chem.-Eur. J., 2008, 14, 10369-10381.

256. J. Madsen, C. Viuf, and M. Bols, Chem.—Eur. J., 2000, 6, $1140-1146$

257. A. Boto, D. Herna'ndez, R. Herna'ndez, and E. Sua'rez, J. Org. Chem., 2005, 70,1938-1948.

258. S. Moutel and J. Prandi, Tetrahedron Lett., 1994, 35, 8163 8166.

259. A. G. M. Barrett, B. C. B. Bezuidenhoudt, and L. M. Melcher, J. Org. Chem., 1990, 55, 5196-5197.

260. T. Posner, Ber. Dtsch. Chem. Ges., 1905, 38, 646-657.

261. A. Gress, A. Vo"lkel, and H. Schlaad, Macromolecules, 2007, 40, 7928-7933.

262. A. Dondoni, Angew. Chem. Int. Ed., 2008, 47, 8995-8997.

263. K. Igarashi and T. Honma, J. Org. Chem., 1970, 35, 606610.

264. S. Paul and N. Jayaraman, Carbohydr. Res., 2004, 339, 2197-2204.

265. J. Gervay, T. M. Flaherty, and D. Holmes, Tetrahedron, 1997, 53, 16355-16364.

266. S. Knapp and D. S. Myers, J. Org. Chem., 2002, 67, 2995-2999.

267. M. Fiore, A. Marra, and A. Dondoni, J. Org. Chem., 2009, 74, 4422-4425.

268. H. Bader, L. C. Cross, I. Heilbron, and E. R. H. Jones, J. Chem. Soc., 1949, 619-623.

269. M. L. Conte, S. Pacifico, A. Chambery, et al ., J. Org. Chem., 2010, 75, 4644-4647.

270. M. A. Lucas, O. T. K. Nguyen, C. H. Schiesser, and S.-L. Zheng, Tetrahedron, 2000, 56, 3995-4000.

271. R. J. Ferrier and R. H. Furneaux, J. Chem. Soc., Perkin Trans. 1, 1977, 1996-2000.

272. R. J. Ferrier and R. H. Furneaux, Aust. J. Chem., 1980, 33, 1025-1036.

273. L. Somsa'k and R. J. Ferrier, Adv. Carbohydr. Chem. Biochem., 1991, 49, 37-92.

274. R. J. Ferrier and P. C. Tyler, J. Chem. Soc., Perkin Trans. 1 1980, 1528-1534.

275. For a review, see: H. Pellissier, Org. Prep. Proced. Int., 2002, 34, 441-465.

276. D. Medakovic, Carbohydr. Res., 1994, 253, 299-300. 
277. H. N. Yu, J.-i. Furukawa, T. Ikeda, and C.-H. Wong, Org. Lett., 2004, 6, 723-726.

278. T. Chiba and P. Sinay", Carbohydr. Res., 1986, 151, 379389.

279. F. W. Lichtenthaler and P. Jarglis, Angew. Chem. Int. Ed. Engl., 1982, 21, 625-626.

280. K. Czifra'k, P. Szila'gyi, and L. Somsa'k, Tetrahedron: Asymmetry, 2005, 16, 127-141.

281. K. Czifra'k and L. Somsa'k, Tetrahedron Lett., 2002, 43, 8849-8852.

282. C. S. Rye and S. G. Withers, J. Org. Chem., 2002, 67, 4505-4512.

283. P. M. Harrington and M. E. Jung, Tetrahedron Lett., 1994, 35, 5145-5148.

284. Y. Ble'riot, M. I. Simone, M. R. Wormald, et al ., Tetrahedron: Asymmetry, 2006, 17, 2276-2286.

285. E. Sua'rez and M. S. Rodr'iguez, $\beta$-Fragmentation of alkoxyl radicals: synthetic applications, in Radicals in Organic Synthesis, eds. P. Renaud and M. Sibi, WileyVCH Verlag GmbH, Weinheim, 2001, vol. 2, pp. 440-454.

286. P. de Armas, C. G. Francisco, and E. Sua'rez,Angew.Chem. Int. Ed. Engl., 1992, 31,772-774.

287. C. G. Francisco, C. G. Mart'in, and E. Sua'rez, J. Org. Chem., 1998, 63, 8092-8093.

288. J. Inanaga, Y. Sugimoto, Y. Yokoyama, and T. Hanamoto, Tetrahedron Lett., 1992, 33, 8109-8112.

289. A. Boto, R. Herna'ndez, and E. Sua'rez, Tetrahedron Lett., 2001, 42,9167-9170.

290. A. Boto, D. Herna'ndez, and R. Herna'ndez, J. Org. Chem., 2008, 73, 5287-5297.
291. C. C. Gonza'lez, A. R. Kennedy, E. I. Leo'n, et al ., Chem.-Eur. J., 2003, 9, 5800-5809.

292. C. G. Francisco, C. C. Gonza'lez, A. R. Kennedy, et al., Chem.-Eur. J., 2008, 14, 6704-6712.

293. P. de Armas, C. G. Francisco, and E. Sua'rez, J. Am. Chem. Soc., 1993, 115, 8865-8866.

294. P. de Armas, C. G. Francisco, and E. Sua'rez, Tetrahedron Lett., 1993, 34, 7331-7334.

295. C. G. Francisco, C. G. Mart'in, and E. Sua'rez, J. Org. Chem., 1998, 63, 2099-2109.

296. C. G. Francisco, R. Freire, C. C. Gonza'lez, et al ., J. Org. Chem., 2001, 66, 1861-1866.

297. C. R. Alonso-Cruz, A. R. Kennedy, M. S. Rodr'iguez, and E. Sua'rez,J. Org. Chem., 2008, 73, 4116-4122.

298. C. R. Alonso-Cruz, E. I. León, F. J. Ortiz-Lo'pez, et al., Tetrahedron Lett., 2005, 46, 5265-5268.

299. R. Herna'ndez, E. I. Leo'n, P. Moreno, et al ., J. Org. Chem., 2004, 69, 8437-8444.

300. C. G. Francisco, E. I. Leo'n, A. Mart'in, et al ., J. Org. Chem., 2001, 66, 6967-6976.

301. J. Hartung, C. Schur, I. Kempter, and T. Gottwald, Tetrahedron, 2010, 66, 1365-1374.

302. A. Mart'in, I. Pe'rez-Mart'in, and E. Sua'rez, Tetrahedron Lett., 2002, 43, 4781-4784.

303. R. W. Binkley and D. J. Koholic, J. Org. Chem., 1979, 44, 2047-2048.

304. L. Herna'ndez-Garc' 1a, L. Quintero, M. Sa'nchez, and F. Sartillo-Piscil, J. Org. Chem., 2007, 72, 8196-8201. 